NBER WORKING PAPER SERIES

\title{
THE EFFECTS OF THE AFFORDABLE CARE ACT ON HEALTH INSURANCE COVERAGE AND LABOR MARKET OUTCOMES
}

\author{
Mark Duggan \\ Gopi Shah Goda \\ Emilie Jackson \\ Working Paper 23607 \\ http://www.nber.org/papers/w23607 \\ NATIONAL BUREAU OF ECONOMIC RESEARCH \\ 1050 Massachusetts Avenue \\ Cambridge, MA 02138 \\ July 2017
}

We would like to thank Paula Gablenz and Audrey Guo for exceptional research assistance, and Alex Gelber, Kosali Simon, and seminar participants at the University of Wisconsin, UC Berkeley, UC Irvine, UC Davis, University of Iowa, University of Chicago, Michigan State University and the SIEPR-Sloan Working Longer conference for helpful comments. We thank the Alfred P. Sloan Foundation for generous support. The content is solely the responsibility of the authors and not Stanford University or the NBER. The views expressed herein are those of the authors and do not necessarily reflect the views of the National Bureau of Economic Research.

NBER working papers are circulated for discussion and comment purposes. They have not been peer-reviewed or been subject to the review by the NBER Board of Directors that accompanies official NBER publications.

(C) 2017 by Mark Duggan, Gopi Shah Goda, and Emilie Jackson. All rights reserved. Short sections of text, not to exceed two paragraphs, may be quoted without explicit permission provided that full credit, including $(\odot$ notice, is given to the source. 
The Effects of the Affordable Care Act on Health Insurance Coverage and Labor Market Outcomes Mark Duggan, Gopi Shah Goda, and Emilie Jackson

NBER Working Paper No. 23607

July 2017

JEL No. H31,H51,J18,J20,J38

\begin{abstract}
$\underline{\text { ABSTRACT }}$
The Affordable Care Act (ACA) includes several provisions designed to expand insurance coverage that also alter the tie between employment and health insurance. In this paper, we exploit variation across geographic areas in the potential impact of the ACA to estimate its effect on health insurance coverage and labor market outcomes in the first two years after the implementation of its main features. Our measures of potential ACA impact come from preexisting population shares of uninsured individuals within income groups that were targeted by Medicaid expansions and federal subsidies for private health insurance, interacted with each state's Medicaid expansion status. Our findings indicate that the majority of the increase in health insurance coverage since 2013 is due to the ACA and that areas in which the potential Medicaid and exchange enrollments were higher saw substantially larger increases in coverage. While labor market outcomes in the aggregate were not significantly affected, our results indicate that labor force participation reductions in areas with higher potential exchange enrollment were offset by increases in labor force participation in areas with higher potential Medicaid enrollment

Mark Duggan

Stanford University

Department of Economics

579 Serra Mall

Stanford, CA 94305-6072

and NBER

mgduggan@stanford.edu

Gopi Shah Goda

Stanford University

SIEPR

366 Galvez St.

Stanford, CA 94305

and NBER

gopi@stanford.edu

Emilie Jackson

Stanford University

579 Serra Mall

Stanford, CA 94305

emilyj91@stanford.edu
\end{abstract}




\section{INTRODUCTION}

The Affordable Care Act (ACA), passed in 2010, represents the largest reform to the U.S. health care system since the introduction of Medicare and Medicaid in 1965. One of its primary goals was to reduce the number of uninsured, which had hovered around one-sixth of the non-elderly population during the prior decade. Several provisions of the law aimed to achieve this goal, including expansions of the Medicaid program to cover low-income individuals, private health insurance subsidies provided to individuals with family incomes between 100 and $400 \%$ of the federal poverty line (FPL), mandates on employers to offer health insurance coverage to employees, and penalties imposed on individuals without insurance. After many of these provisions were implemented in January of 2014, uninsurance rates among non-elderly adults fell substantially, from 20.1 percent in the fourth quarter of 2013 to 15.1 percent by the fourth quarter of 2014 and 12.6 percent by the fourth quarter of 2015, as shown in Figure 1. ${ }^{1}$ However, these aggregate patterns do not indicate how insurance coverage would have evolved in the absence of the ACA.

Many of these same provisions also serve to weaken the tie between employment and health insurance coverage, and therefore may affect both labor supply and demand. Consistent with this, the Congressional Budget Office (CBO) has estimated that the ACA will reduce the size of the labor force by 1.5 to 2 percent ( 2 to 2.5 million individuals) by 2024 (CBO 2014). While the primary channels for this projected effect are through the incentive effects resulting from the availability of subsidies for private health insurance coverage and the expanded coverage for the Medicaid program that could reduce labor supply, there is also scope for effects on employment through policies that could impact labor demand. Aggregate labor force participation rates do not show any significant changes after the legislation was passed in 2010 or after key provisions were implemented in early 2014 (see Figure 2). But again, these aggregate rates do not indicate how labor force participation would have changed if the ACA had not been implemented.

In this paper, we examine how the ACA affected health insurance coverage and labor market outcomes in the two years after the key provisions of the ACA took effect on January 1,2014. Because the

\footnotetext{
${ }^{1}$ Source: National Center for Health Statistics. Health Insurance Coverage: Early Release of Quarterly Estimates from the National Health Interview Survey, January 2010 - March 2016, Table 3, retrieved on September 12, 2016. Available at: http://www.cdc.gov/nchs/data/nhis/earlyrelease/quarterly_estimates_2010_2016_q11.pdf.
} 
ACA is a national reform and affected all states, it is difficult to disentangle the effects of the law from other changes that would have happened without it. For example, employment growth in the first year after the ACA averaged 241 thousand per month, which was the most rapid pace since the late 1990s and 30 percent greater than the average growth in the preceding three years. It is plausible that health insurance coverage would have risen substantially even in the absence of the ACA. Similarly, as shown in Figure 1, the fraction of non-elderly adults without health insurance was trending down even prior to 2014. Thus, how much of the increase in health insurance coverage was driven by the ACA versus other factors is ultimately an empirical question.

To investigate this issue, we use individual-level data from the American Community Survey (ACS) to exploit geographic variation in the potential impact of the ACA. In January 2014, ACA expanded Medicaid to individuals in families with incomes below $138 \%$ of the federal poverty line (FPL). However, only about half of all states initially proceeded with the Medicaid expansion, and thus the overall effect of this provision on coverage may be much smaller as a result. Additionally, the ACA provided subsidies to purchase private health insurance through state health insurance exchanges to individuals with incomes between $100 \%$ and $400 \%$ of FPL. To the extent that these provisions raised health insurance coverage, one would expect areas with a higher fraction of the population both uninsured and below 400\% FPL to experience larger increases in insurance coverage. However, the magnitude of the effects may depend on whether the state proceeded with the Medicaid expansion. More specifically, an area with a substantial fraction both uninsured and below 138\% FPL may see a relatively small coverage increase if the state did not expand Medicaid. Similarly, individuals with incomes between 100 and 138\% of FPL might be on Medicaid in expanding states and privately insured in states that did not expand.

Our data allow us to estimate the share of each area that was (a) uninsured and below 138 percent of the poverty line and (b) uninsured and between 139 and 399 percent of the federal poverty line in 20102013, just prior to the implementation of the ACA's key provisions. ${ }^{2}$ The large sample size in the ACS

\footnotetext{
${ }^{2}$ Other provisions that expanded health insurance to adults under the age of 26 through their parents' private health insurance plans took effect three years earlier in 2011 and also increased coverage (Antwi, Moriya and Simon 2013).
} 
along with the geographic identifiers allows us to divide the U.S. into more than 1,000 areas known as Public Use Microdata Areas (PUMAs). ${ }^{3}$

Theoretically, one would expect areas with a large share uninsured and below 400\% of FPL prior to ACA implementation to experience larger increases in health insurance coverage beginning in 2014 . The effect for the group below 138\% FPL would likely be sensitive to whether the state had expanded Medicaid. We empirically test these predictions using annual ACS data from the 2010 to 2015 period exploiting variation across PUMAs. Our methodology is similar to that used by previous work to estimate the effect of the introduction of Medicare in 1965 (Finkelstein, 2007; Finkelstein and McKnight, 2008) and of the 2006 Massachusetts Health Reform (Kolstad and Kowalski, 2012; Miller, 2012). However, our sample size and level of geographic detail allow us to use much more granular variation than in this previous work.

Our results indicate that the ACA had a substantial impact on overall health insurance coverage. For areas with average characteristics prior to the ACA, we estimate that health insurance coverage increased by 4.2 percentage points in states that expanded Medicaid, and 2.6 percentage points in states that did not, as a result of this legislation. These changes amplified the difference in coverage between the two groups of states given that 19 percent of non-elderly adults were uninsured just prior to ACA implementation in states that expanded Medicaid versus 23 percent in states that did not. Additionally, the ACA-induced coverage increases are generally larger in 2015 than in 2014.

We also find evidence that regions with lower levels of baseline insurance coverage and/or higher shares of the population eligible for Medicaid coverage or financial assistance to purchase insurance saw larger increases in coverage. In particular, in regions where the share of the population less than 138\% FPL and uninsured is 10 percentage points higher (approximately 2.5 standard deviations), the coverage increase was 4 percentage points higher in expansion states but not significantly higher in non-expansion states. In regions where the share of the population between $139 \%$ and 399\% FPL and uninsured is 10 percentage points higher, the coverage increase was 2.5 percentage points higher in non-expansion states and the increase in expansion states was somewhat lower but not significantly different.

\footnotetext{
${ }^{3}$ While there are more than 2,000 PUMAs, we focus on a consistent set of boundaries across census years which results in fewer PUMAs of larger average size.
} 
Data on the source of coverage allow us to understand the channels through which health insurance is increasing. We find that increases in Medicaid coverage accounted for the majority of coverage increases in expansion states, while privately-purchased health insurance, including policies purchased on the ACA exchanges, accounted for the majority in non-expansion states. We find little evidence that private health insurance from employers changes after the ACA is implemented in either expansion or non-expansion states, suggesting that there was little crowdout of this coverage.

We also investigate the impact of the ACA on non-elderly adults' labor market outcomes. These effects are also empirically ambiguous. On one hand, individuals might reduce their labor supply in response to incentive effects (as subsidies to purchase private insurance decline with income and the provision of Medicaid to those with lower incomes may reduce the incentive to work) or income effects (as health insurance is valuable and individuals may respond to this increase in effective income by working less). The availability of less costly health insurance outside of employment may lead near-elderly workers to retire earlier or shift to part-time employment. On the other hand, some may value the option of obtaining private health insurance and increase their work effort to qualify for the subsidies, which are especially large at incomes just above the poverty line. Additionally, increases in insurance coverage may increase the demand for labor in areas that previously had a large share uninsured. ${ }^{4}$ For example, hospitals might need to hire more nurses if the demand for their services grows.

Our findings indicate that the average labor supply effects of the ACA were close to zero but that this average masks important heterogeneity in its effects. More specifically, we find that in areas with a high share uninsured and eligible for private insurance subsidies, labor force participation fell significantly. In contrast, in areas with a high share uninsured but with incomes too low to qualify for private insurance subsidies, labor force participation increased significantly. These changes suggest that middle-income individuals reduced their labor supply due to the additional tax on earnings while lower income individuals worked more in order to qualify for private insurance. In the aggregate, these countervailing effects approximately balance.

\footnotetext{
${ }^{4}$ Chodorow-Reich et al. (2012) find that expansions in Medicaid funding from the American Recovery and Reinvestment Act led to substantial increases in employment in the health care sector.
} 
Our paper builds on a growing literature on the effects of the ACA on health insurance coverage and labor market outcomes. Previous literature suggests that the ACA substantially increased health insurance coverage (Sommers et al. 2014, 2015; Courtemanche et al. 2017, Frean et al. 2017) but that it had little impact on the labor market (Buchmueller et al, 2015; Kaestner et al, 2015; Leung and Mas, 2016; Gooptu et al. 2016; Moriya et al. 2016; Gustman et al. 2016; Abraham and Royalty 2017). ${ }^{5}$ However, research on the policy's labor market effects has not explored how the ACA-induced increases in coverage vary by area based on income. Our results highlight the importance of using the underlying income distribution of an area to consider the possible heterogeneous response to this policy.

The rest of the paper proceeds as follows. Section II contains background information on the key features of the ACA for our analysis and describes the related literature. In Section III, we describe our empirical strategy. Section IV provides details regarding the data we use in the analysis including average characteristics prior to ACA implementation. We report our results in Section V, robustness exercises in Section VI, and Section VII concludes.

\section{BACKGROUND}

In this section, we describe various features of the Affordable Care Act designed to increase health insurance coverage, the primary channels through which this legislation may influence the labor market, and previous literature relevant to the impacts of similar policies on health insurance coverage and the tie between health insurance and labor market outcomes.

\section{A. The Affordable Care Act}

\footnotetext{
${ }^{5}$ Other studies have examined the effects on employer-sponsored health insurance (Blavin et al, 2015; Abraham et al. 2016) and the effects of the dependent care mandate that took effect in late 2010 (Cantor et al. 2012; Sommers and Kronick 2012; Antwi et al 2013, Bailey and Chorniy, 2015; Heim et al, 2015). In addition to these studies, several descriptive analyses have used a variety of novel data sources to document the ACA's impact on coverage (Long et al. 2014; Smith and Medalia 2014; Carman et al. 2015; Black and Cohen 2015; Courtemanche et al. 2016) and some authors have modeled the impact of the ACA on labor supply (Heim, Hunter, Lurie, and Ramnath 2014; Mulligan 2014, 2015a, 2015b; Fang and Shephard 2015). Also, note that some studies have found evidence of changes in labor demand in occupations and industries most affected by the employer shared responsibility requirement, resulting in an increase in involuntary part-time work (Even and Macpherson 2016; Dillender et al. 2016).
} 
The Affordable Care Act includes dozens of provisions to expand health insurance coverage, slow the growth rate in health care costs, and reform the market for private health insurance. In this section, we focus on the provisions designed to expand health insurance coverage.

\section{The Medicaid Expansion}

Just prior to the passage of the Affordable Care Act, the federal-state Medicaid program provided health insurance to 57 million people. ${ }^{6}$ There was substantial variation across states with respect to which individuals were eligible, what health care services were covered, the generosity of reimbursement to providers, and the role of private managed care organizations (Duggan and Hayford 2013). This program is means-tested and there is virtually no cost-sharing, with Medicaid premiums essentially equal to zero in most states. Medicaid provides valuable protection to many of the nation's most vulnerable residents, with many studies finding that it improves health outcomes (e.g., Currie and Gruber, 1996, Sommers et al. 2012) and enhances economic well-being (Baicker et al. 2014).

The Affordable Care Act substantially expanded eligibility for the Medicaid program. More specifically, all individuals with family incomes less than or equal to 138 percent of the poverty-line (adjusted for family size) would become eligible for the program. In early 2010 prior to ACA's passage, virtually all states already covered children in this income range, and thus the ACA's primary effect was to expand eligibility among non-elderly adults. Projections from CBO initially estimated that Medicaid enrollment would - by 2016 - increase by 16 million as a result of the ACA. This represented half of the increase in projected insurance coverage resulting from the ACA. However, this projection was later reduced to just 11 million after the 2012 Supreme Court decision made it optional for states to move forward with the Medicaid expansion and many states elected not to do so (CBO 2015). ${ }^{7}$

The actual impact of the ACA Medicaid expansion is likely to vary substantially across states for three reasons. First, only 25 states (including the District of Columbia) chose to expand Medicaid by January 2014 following the Supreme Court decision, as shown in Figure $3{ }^{8}$ As a result, while the number

\footnotetext{
${ }^{6}$ These data and state-by-state enrollment data were obtained from https://www.medicaid.gov/medicaid/programinformation/medicaid-and-chip-enrollment-data/report-highlights/index.html in March 2017.

${ }^{7}$ On June 28, 2012, the Supreme Court ruled that the ACA's Medicaid expansion was "unconstitutionally coercive," and that the appropriate remedy was to constrain the Federal government's power in enforcing state compliance.

${ }^{8}$ As of July 2016, 7 additional states have followed suit, bringing the total to 32 states.
} 
of Medicaid recipients nationally increased from 57 million in July-September 2013 to 74.8 million in November 2016, the increase was substantially greater among states that elected to expand their Medicaid programs. ${ }^{9}$ A second reason for a differential effect is that some states already covered a substantial fraction of adults below 133 percent of the poverty line at the time the ACA was passed. All else equal, the likely increase in coverage would be smaller in these states. ${ }^{10}$ A third reason that the effect of the Medicaid expansion is likely to vary across states is that the fraction of individuals in poverty differs substantially across states. Because of this, any expansion of Medicaid coverage would, all else equal, lead to a larger increase in insurance coverage in states with high rates of poverty. ${ }^{11}$

\section{Subsidized Coverage through State or the Federal Health Insurance Exchanges}

Subsidies for private health insurance purchased on the ACA exchanges are calculated by first determining a family's (modified adjusted gross) income ${ }^{12}$ as a percentage of the federal poverty line. This percentage maps to a maximum percentage of income that one is responsible for paying towards the cost of health insurance, ranging from just 2 percent (at low levels of income) to 9.5 percent (from 300 to 400 percent of the poverty line). The subsidy level is the cost of the second lowest cost "silver tier" plan available on the exchange less the maximum premium payment the person is responsible for. Once a family's income exceeds 400 percent of the poverty line, members are no longer eligible for subsidies for purchasing health insurance through the exchanges. If a family earns less than 100 percent of the poverty line, members were expected to be covered by Medicaid and therefore do not receive a subsidy (even in non-expansion states). Therefore, subsidies vary considerably by income. Premiums also vary

\footnotetext{
${ }^{9}$ Consider the contrast between California, which did expand its Medicaid program, and Texas, which did not. In California, Medicaid enrollment increased by 57 percent (to 12.2 million) from September 2013 to November 2016. In contrast, in Texas, enrollment rose just 8.2 percent over the same time period to 4.8 million.

${ }^{10}$ For example, non-disabled childless adults in California were not eligible for Medicaid in 2013 regardless of income level. In contrast, their counterparts in New York were eligible if their incomes were below the poverty line. This may partially explain why California's 57 percent increase in Medicaid enrollment since 2013 is much larger than New York's 13 percent increase (to 6.4 million) despite the fact that both expanded their programs as a result of the ACA. ${ }^{11}$ Consider the difference between New Mexico and Colorado, two states that expanded Medicaid as a result of the ACA. In 2013 just prior to this coverage expansion, 22 percent of New Mexico's residents had family incomes below the poverty line. In contrast, just 13 percent of Colorado residents were below the poverty line in that same year. Because of this difference, one would expect the ACA to have a greater impact on Medicaid enrollment in New Mexico. Consistent with this, the fraction of New Mexico residents with Medicaid coverage increased by substantially more in New Mexico (from 22 to 36 percent) than in Colorado (from 15 to 25 percent) from 2013 to 2016.

${ }^{12}$ Gross income includes salary, investment, and business income. Qualified deductions such as student loan interest and IRA contributions are subtracted to arrive at adjusted gross income (AGI). Tax-exempt interest income is added to AGI to arrive at modified adjusted gross income (MAGI).
} 
considerably across states and counties and this leads to a large divergence in the effective subsidy available to individuals in high- vs. low-cost areas. The value of the subsidy for different levels of income for an individual 60 years of age is shown in Appendix Figure A.1, and the geographic variation in the subsidy level is shown in Appendix Figure A.2.

Just as the growth in Medicaid enrollment since 2013 has varied substantially across states, so too has the increase in coverage through the health insurance exchanges. ${ }^{13}$ The variation in Medicaid enrollment combined with variation in exchange enrollment has led to differential changes in the share uninsured by state, ranging from an estimated 0.7 percentage point reduction in Virginia to 12.9 percent reductions in both Arkansas and Kentucky (see Appendix Table A.1).

\section{B. The Affordable Care Act and the Labor Market}

The Congressional Budget Office (CBO) has estimated that the ACA will reduce the size of the labor force by 1.5 to 2 percent ( 2 to 2.5 million individuals) by 2024 (CBO 2014). The two primary channels for this effect are the incentive effects resulting from the availability of subsidies for private health insurance coverage and the expanded coverage for the Medicaid program.

Because Medicaid provides a source of insurance coverage regardless of employment, and its means-tested nature may result in a high marginal tax on working, Medicaid expansions could affect labor market outcomes by reducing the amount of labor supplied by workers. A limited recent literature has examined the effect of Medicaid expansions or contractions on employment outcomes. In particular, Garthwaite, Gross and Notowidigdo (2014) examine a contraction of Medicaid in Tennessee that led to a marked increase in employment in Tennessee; Dague, DeLeire and Leininger (2014) and Baicker et al. (2014) find more modest effects of Medicaid on employment in Wisconsin and Oregon, respectively. Since these expansions or contractions were often targeted to childless adults, similar to the ACA, their experiences are valuable in informing expectations of the effects of ACA Medicaid expansions on employment. However, the difference in estimates leave considerable ambiguity regarding the expected

\footnotetext{
${ }^{13}$ For example, despite having a similar number of non-elderly individuals, there are 1.09 million residents of Texas enrolled in the state's ACA exchange versus just 0.22 million in New York's. This partly reflects the substantially higher fraction uninsured in Texas in 2013, but this is not the only driver of the difference. For example, while Florida has a smaller population and a smaller share uninsured than Texas in 2013, there are substantially more Florida residents enrolled in the exchange ( 1.44 million versus 0.96 million). Exchange enrollment is available by state as of February 2017 from http://kff.org/health-reform/state-indicator/total-marketplace-enrollment-and-financialassistance/.
} 
effects of the ACA's Medicaid expansions on labor market outcomes. Additionally, Medicaid's effect may be different with the ACA because - in contrast to the pre-ACA setting - a person would remain eligible for private health insurance subsidies even if his/her income rose above the Medicaid-eligible threshold.

The private health insurance exchanges could affect labor market outcomes through several channels. First, prior to the ACA, it is likely that some near-elderly workers were continuing to work until they were eligible for Medicare at age 65 because they obtained health insurance through their employer. Because it is less expensive for individuals to purchase coverage outside of employment, some may elect to retire or shift to part-time work sooner as a result of the ACA. Second, the magnitude of the subsidy declines with income. As a worker's income rises from, for example, 133\% of the Federal Poverty Line (FPL) to 399\% of the FPL, there is an effective tax rate of 12 percent on additional earnings. This may reduce the incentive to work, causing some to scale back their hours or to shift to another job with lower earnings (or to drop out of the labor force if their spouse is working). Third and as shown in Appendix Figures A.1 and A.2, there exists a "cliff" in the subsidy at 400 percent of the federal poverty level, at which point the subsidy drops to zero. Fourth, the availability of subsidized coverage in the exchange may encourage workers to shift to smaller firms (which are less likely to offer coverage) or to start their own businesses. Indeed just prior to the Affordable Care Act, workers in firms with fewer than 10 employees were three times more likely than their counterparts in firms with 1,000 or more employees to be uninsured. This difference was partially driven by the substantially higher health insurance premiums that small firms or the self-employed tended to face relative to their larger counterparts (Gabel et al., 2006).

In addition, it is important to note that while many of the ACAs provisions may be theoretically expected to reduce labor supply, one possible mechanism working in the opposite direction is that those under 100\% FPL in non-expansion states receive subsidized health insurance from the exchanges only if they earn more than the federal poverty line and are not eligible for Medicaid unless they fall in certain coverage groups. Relatedly, individuals may prefer private coverage to Medicaid, and therefore increase their earnings to qualify for private coverage even in expansion states. Finally, expansions in coverage may improve health, which could in turn reduce the disutility of work. These effects may not be instantaneous but might instead grow over time as the duration of exposure to additional insurance coverage increased. 
While many of the channels mentioned above relate to labor supply decisions, the ACA may also drive firm behavior. For example, the ACA's employer mandate applies to firms with 50 or more full-time employees, and may therefore encourage some firms to stay below that threshold or to hire more part-time workers. The ACA's Small Business Tax Credit encourages firms with 25 or fewer employees and with low-wage workers to provide health insurance coverage to their employees. This tax credit may lead to an increase in firm offering and may therefore make jobs at these smaller employers more attractive. Related to this, if smaller firms that previously offered coverage can drop it while sending their workers to the exchange, this could lead to increases in wages and in employment as well. A less appreciated feature of the ACA is that it may give some employers an incentive to "contract out" for low-wage workers because the existing ESI system (with its large tax subsidies for high income workers) may be more attractive for high-wage workers while coverage through the exchanges (which provides larger subsidies to those with lower incomes) is more appealing for low-income workers. To the extent that employers respond to the ACA by changing the number of workers, the composition of full versus part-time work, wages, or the use of contracting out, this could substantially affect labor market outcomes. Finally, increases in insurance coverage may increase the demand for labor in areas that previously had a large share uninsured in health care occupations. ${ }^{14}$

Our analysis focuses on labor market outcomes that could be the result of either changing supply, changing demand, or both. Given the different channels through which the ACA-induced changes in health insurance coverage could influence the labor market, both the sign and the magnitude of these effects are theoretically ambiguous. It is thus ultimately an empirical question which we investigate below.

\section{Prior Research on Coverage Expansions, Health Insurance and Labor Market Outcomes}

An active area of prior research has examined the effect of policies that increase access to health insurance on coverage outcomes and crowd-out, from Medicaid expansions in the 1980s and 1990s (Cutler and Gruber 1996; Aizer and Grogger 2003; Hamersma and Kim 2013) to the 2006 Massachusetts health

\footnotetext{
${ }^{14}$ Note that the implementation of some of these provisions has been delayed and therefore would not affect the results in this paper. An additional provision that could affect labor market outcomes is the "Cadillac tax on high-cost plans", which has been delayed until 2020. This provision may cause firms to provide less generous health insurance to their workers, which could then pass-through to higher wages. The CBO estimated that more than 80 percent of the budgetary savings from this tax resulted from an increase in earnings rather than in direct tax revenue.
} 
reform (Long et al. 2009; Yelowitz and Cannon 2010; Kolstad and Kowalski 2012; Sonier et al. 2013). An advantage of the policies examined in these earlier papers is that they varied across states and therefore lent themselves to quasi-experimental variation using difference-in-difference or instrumental variables strategies to identify the impacts on coverage and other outcomes.

For several decades, health insurance in the U.S. has been tied to employment due to the exclusion of employer-based health insurance premiums from individual income taxes. Because health insurance outside of the employer context has historically been difficult and/or costly to obtain, economic theory predicts that employer-sponsored health insurance could affect workers' likelihood of being employed, their job-to-job mobility, and decisions to retire. These predictions have spurred a large body of literature investigating the link between health insurance and labor market outcomes. Early literature found evidence of health insurance-induced "job lock," or the tendency for workers to stay in jobs they would rather leave due to concerns about losing health insurance (Madrian 1994a). Several studies that followed examined the availability of health insurance in retirement on retirement decisions. ${ }^{15}$ While the exact estimates vary, this literature largely finds a substantial role for post-retirement health insurance availability in explaining retirement behavior (Gruber and Madrian, 2002).

\section{EMPIRICAL METHODS}

Our empirical approach leverages geographic variation in characteristics that were determined prior to the ACA's implementation and that influence the potential impact of different provisions of the law. We utilize variation stemming from differences in the share of an area that is uninsured, the area's income distribution, and its Medicaid expansion status. For each geographic area, we calculate the pre-ACA share of the population uninsured and with incomes less than $138 \%$ of FPL, denoting this by $M^{*}$. The variable

\footnotetext{
${ }^{15}$ Some studies took a reduced form approach, estimating the impact of employer-provided post-retirement health insurance on retirement and found statistically significant effects of post-retirement health insurance coverage on retirement (Madrian, 1994b; Karoly and Rogowski, 1994; Blau and Gilleskie, 2001). However, these studies often suffered from potential bias due to the potential selection of workers with high tastes for leisure into firms that offered post-retirement health insurance coverage. In an effort to address these concerns, Gruber and Madrian (1995) used variation in in continuation-of-coverage regulations and found evidence that retirement behavior responds to health insurance availability. Other studies used variation stemming from policy changes or eligibility rules for identification (Boyle and Lahey, 2010; Fitzpatrick, 2013; Leiserson, 2013; Coe et al., 2013; Nyce et al., 2013; Shoven and Slavov, 2013). Another strand of literature took a structural approach to identify the effect of post-retirement health insurance availability on retirement (Gustman and Steinmeier, 1994; Lumsdaine, Stock and Wise, 1996; Rust and Phelan, 1997; Blau and Gilleskie, 2006; Blau and Gilleskie 2008; French and Jones, 2011).
} 
$M *$ represents the potential increase in Medicaid enrollment assuming all newly eligible for Medicaid enroll in the program and no crowd out of other sources of coverage. We define $E^{*}$ as the increase in exchange enrollment that would result if all who are both uninsured and between 139 and 399\% of FPL acquired coverage with no crowdout of other coverage. Both measures are averaged over the 2010-2013 period prior to the implementation of the ACA. Note that for a region to have a high value for these factors, it must have both a high share of individuals under 400\% FPL and a high share of individuals without insurance.

Formally, our regression equation is as follows:

(1) $I N S_{\text {iast }}=\alpha_{1}$ POST $_{t} \times M_{a}^{*}+\alpha_{2}$ POST $_{t} \times E_{a}^{*}+\beta X_{i t}+\gamma_{t}+\mu_{a}+\emptyset_{a} \mathrm{t}+\varepsilon_{\text {iast }}$

where $I N S_{\text {iast }}$ represents an indicator for whether individual $i$ living in area $a$ and state $s$ has any health insurance, private employer coverage, privately-purchased coverage, or Medicaid coverage in time $t$; $\mathrm{POST}_{t}$ is an indicator equal to 1 in 2014 or later and 0 otherwise, $M_{a}^{*}$ and $E_{a}^{*}$ represent the pre-ACA measures of potential Medicaid and exchange enrollment for area $a$ as described above, $X_{i t}$ includes demographic controls for gender, race, and ethnicity and age fixed effects, $\gamma_{t}$ represents year fixed effects, and $\mu_{a}$ and $\emptyset_{a}$ represent area fixed effects and area-specific time trends for area $a$ (described in more detail below), respectively. Both $M_{a}^{*}$ and $E_{a}^{*}$ are demeaned, giving the coefficients on other variables the interpretation of the effects for locations with an average level of the share uninsured within certain income bins. Note that because we include geographic area-level fixed effects, the main effects of $M_{a}^{*}$ and $E_{a}^{*}$ are not included in the regression, and the main effect of $\mathrm{POST}_{t}$ drops out due to year fixed effects.

Our second empirical specification includes interactions between $M_{a}^{*}, E_{a}^{*}$, and $P O S T_{t}$ with a binary indicator that indicates whether the region is in a state that expanded its Medicaid program prior to the beginning of the analysis year. In particular, we also estimate Equation (2) as follows:

(2) $I N S_{\text {iast }}=\theta_{1}$ POST $_{t} \times M_{a}^{*}+\theta_{2}$ POST $_{t} \times E_{a}^{*}+\rho_{0} P O S T_{t} \times E X P A N S I O N_{s}+\rho_{1}$ POST $_{t} \times$ $\operatorname{EXPANSION}_{s} \times M_{a}^{*}+\rho_{2}$ POST $_{t} \times \operatorname{EXPANSION}_{s} \times E_{a}^{*}+\beta X_{i t}+\gamma_{t}+\mu_{a}+\emptyset_{a} \mathrm{t}+\varepsilon_{\text {iast }}$

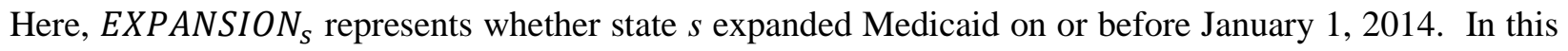
specification, we cluster our standard errors at the state level given that $\operatorname{EXPANSION}_{S}$ varies at the state level and to account for possible serial correlation (Bertrand et al. 2004). 
We hypothesize that the overall level of health insurance increased after the ACA in areas with average $E^{*}$ and $M^{*}$ and differentially more in expansion states, i.e. $\rho_{0}>0$. Including measures of the arealevel income distribution in our specification allows us to explore the channels through which the ACA is affecting health insurance coverage. We hypothesize that regions with a larger $M^{*}$ will have larger increases in Medicaid coverage, but that this effect would be much more important in expansion states. Regions with a larger $E^{*}$ are expected to have larger increases in privately-purchased coverage. Both $M^{*}$ and $E^{*}$ are expected to affect overall health insurance coverage and help to identify the ACA-induced increase in insurance in coverage.

We also hypothesize that the composition of coverage increases is different for expansion and nonexpansion states. In expansion states, Medicaid coverage is expected to increase, while Medicaid coverage would not be expected to change by as much in non-expansion states. Since subsidies to purchase private coverage from the exchanges are available in all states, we expect the ACA to induce higher levels of privately-purchased insurance in both expansion and non-expansion states. The increases in privatelypurchased insurance may even be larger in non-expansion states since individuals there with incomes between 100 and $138 \%$ of the poverty line are eligible for subsidies towards health insurance purchased on the exchanges but not eligible for Medicaid. The impact of the ACA and Medicaid expansions on coverage through employer-sponsored insurance is empirically ambiguous. On one hand, more employees with access to employer coverage may sign up for health insurance through their employer due to the individual mandate. On the other hand, there is the potential for crowd-out away from private coverage towards Medicaid or privately-purchased health insurance given the heavily-subsidized cost.

To estimate the effect of the ACA on labor market outcomes, we perform an analogous set of reduced-form regressions as specified in Equations (1) and (2) using labor market outcomes as the dependent variables instead of insurance coverage. We investigate whether regions with larger ACAinduced increases in health insurance coverage also have larger changes in labor market outcomes. The primary channels through which any estimated effects on labor market outcomes occur can be isolated by examining the different coefficients and their significance.

Our identification strategy isolates the impact of the ACA under the assumption that, absent the ACA, geographic areas with larger shares of individuals uninsured and under $400 \%$ of the poverty line 
would have evolved similarly as those with smaller shares, after controlling for fixed area-level characteristics, area-specific time trends, and person-level demographics. In our second specification, we assume that places with a given share of individuals both uninsured and under 400\% FPL in expansion states would have evolved similarly as those with a similar share in non-expansion states, absent the ACA. Importantly, these assumptions do not rule out different levels of insurance coverage or labor market outcomes across areas for reasons other than the ACA that are fixed over time (and captured by area-level fixed effects). In addition, allowing for trends in insurance coverage and labor market outcomes to vary across areas accounts for, for instance, differential rates of economic recovery following the recession that could be related to the underlying income distribution in an area.

\section{DATA}

For our analysis, we use data from the American Community Survey (ACS). Specifically, we use the annual Public-Use Micro Sample (PUMS) files which contain individual- and household-level responses that have been edited to protect the confidentiality of respondents. ${ }^{16}$ The ACS is an ongoing household survey conducted by the U.S. Census Bureau focusing on a variety of topics including demographic, social, and economic related questions. The ACS includes detailed information relating to employment, demographics, health insurance coverage, and measures of poverty/income. Questionnaires are mailed to approximately 295,000 addresses each month (or 3,540,000 annually). Follow-up phone interviews are conducted for addresses that have not responded and personal visits are conducted by Census field representatives to a sample of addresses that have not responded. The extensive follow up results in a high response rate, typically around 97 percent. ${ }^{17}$

We restrict the sample to observations from 2010 through 2015 for civilians age 26 to 64, resulting in 9,493,231 person-year observations. This sample restriction provides four years of data prior to the ACA and two years after the ACA was implemented. We focus on ages 26 to 64 as these are the ages most likely to be affected by Medicaid expansions and the availability of subsidies given the high rates of insurance

\footnotetext{
16 The ACS was originally developed to provide continuous information on communities across the U.S. between the decennial Census. See http://www.census.gov/programs-surveys/acs/data/pums.html for additional details.

${ }^{17}$ In 2013, there was a drop in the final number of housing units due to the government shutdown, as telephone and in-person follow-up interviews were not conducted during this time.
} 
coverage for the elderly and children prior to the ACA from Medicare and Medicaid, respectively, along with other provisions of the ACA that extended coverage to dependents under age 26 starting in late 2010.

The ACS asks whether an individual has health insurance coverage at the point of interview. ${ }^{18}$ Each individual is provided with a list of seven different types or categories of insurance coverage and can indicate all the types of coverage through which they were insured. The choices include: insurance from a current or former employer; insurance purchased directly from an insurance company; Medicare; Medicaid, Medical Assistance, or any kind of government-assistance plan for those with low incomes or a disability; Tricare or other military healthcare; VA; and Indian Health Service. It is worth noting that the wording of these choices combined with self-reporting can lead to some measurement error in the source of insurance coverage if, for instance, "any kind of government-assistance plan for those with low incomes" is interpreted as subsidies that allow individuals to purchase private insurance on the exchanges.

The ACS creates a variable indicating any insurance coverage as having any of the coverage types other than Indian Health Service. We show insurance coverage in the ACS between 2010 and 2013 for four different age groups (0-25, 26-44, 45-64, and 65+) in Figure 4. Note that since individuals can choose more than one type of coverage, the percentages add up to more than 100 percent. As shown in the figure, uninsurance rates are highest for 26-64 year-olds at baseline, and the highest source of coverage for this group is private employer coverage. The elderly are almost universally covered by Medicare, but many have supplemental coverage from other sources. Children and young adults have relatively high rates of coverage from Medicaid at baseline since the Medicaid eligibility criteria are generally broader for children.

Several labor market outcomes are included in the ACS. We examine whether an individual reports being employed over the last week or out of the labor force (i.e., not employed last week and not looking for employment over the last four weeks). The ACS also includes information about self-employment, usual hours worked per week over the past 12 months, and wage or salary and self-employment income over the past 12 months. We construct an indicator for part-time employment which equals one for individuals employed last week whose hours are less than 30 per week over the past 12 months. Selfemployment is measured by an indicator variable that equals one for individuals employed last week whose chief job activity was self-employment. We examine the effect of the ACA on hours worked conditional

\footnotetext{
${ }^{18}$ This differs from the CPS which asks about insurance coverage in the last calendar year.
} 
on being currently employed. Our baseline labor market outcomes prior to the implementation of the ACA are summarized for different age groups in Table 1. Table 1 also includes baseline demographic characteristics such as gender, race and ethnicity. ${ }^{19}$

Our analysis leverages geographic variation in the income distribution and the share uninsured prior to the ACA. The finest geographic-level identified in the PUMS data are Public Use Microdata Areas, or PUMAs. ${ }^{20}$ PUMAs are defined so as to not cross state borders and are population-based rather than based on physical area. Each PUMA has a population of at least 100 thousand at the time of the decennial census and the largest PUMA population in the 2010 Census is approximately 280 thousand. Large urban areas such as Los Angeles or Chicago typically are divided into many PUMAs based on census tracts while PUMAs in rural areas are typically based on counties.

PUMAs are redefined every ten years following the decennial Census. The ACS used 2,071 PUMAs based on the 2000 Census for years 2010 and 2011, and then switched to 2,351 PUMAs based on the 2010 Census for years 2012 and later. In order to use data spanning this change, we use consistent PUMAs which are an aggregation of 2000 and 2010 PUMAs with boundaries that align across decennial Censuses. ${ }^{21}$ While this harmonization reduces the number of distinct geographic areas by approximately half to 1,078 , it does not drop any observations from the data. In addition, the aggregated PUMAs have a larger average population (including only those aged 26 to 64) of 148,682 and some of the aggregated PUMAs expand to cover the entire state (such as Montana). ${ }^{22}$

Figures 5-7 show the heterogeneity in $M^{*}$ and $E^{*}$ for our sample averaged over the pre-ACA years we examine (2010 - 2013). Figure 5 displays the variation in each measure in histograms, with each ranging from 0 to 100 . The average value of $M^{*}$ across PUMAs is 7.3 percent, with a standard deviation of 4.1 percent, but the share ranges from 0.3 percent to a high value of 29.0 percent. The average value of $E^{*}$ is 8.6 percent, ranging from a low of 0.8 percent to a high of 29.5 percent across PUMAs with a standard deviation of 4.5 percent. Note that these shares can vary either because the share of the population within

\footnotetext{
${ }^{19}$ Races other than Black, White or Asian are assigned as Other. A person reporting only one race is given a value of 1 for that race, and those reporting a mix of two races are credited 0.5 to each race. If a person reports more than two races, they are assigned to Other.

${ }^{20}$ For more information on PUMAs refer to https://www.census.gov/geo/reference/webatlas/pumas.html.

${ }^{21}$ Consistent PUMAs are an aggregation of 2010 and 2000 PUMAs that align, within a $1 \%$ population error tolerance, over our time period. For more information refer to: https://usa.ipums.org/usa/volii/cpuma0010.shtml.

${ }^{22}$ For simplicity, we refer to these consistent PUMA areas as PUMAs in the remainder of the text.
} 
certain income bands varies or because the share of that population that is uninsured varies. A list of PUMAs with the highest and lowest values for $M^{*}$ and $E^{*}$ is provided in Appendix Table A.2.

Figures 6 and 7 show "heat maps" for the entire United States, California, and Los Angeles County, with darker shaded regions representing regions with a larger value of $M^{*}$ and $E^{*}$, respectively. Focusing on Los Angeles County, which has the largest population of any county in the U.S., illustrates the level of geographic detail that PUMA identifiers provide, and the significant variation present within highlypopulated counties.

While the ACS offers many advantages in sample size, response rate and survey measures, one of the main disadvantages is that the month of interview is not available in the public use microdata for privacy concerns. As a result, we cannot estimate how the effect of the ACA varies across the 8 quarters or 24 months of our post period, nor can we make maximum use of the timing differences in Medicaid expansion status for dates after January 2014. However, we explore the extent to which results vary during each of the two years following ACA implementation in the next section.

\section{RESULTS}

\section{A. Health insurance coverage}

We estimate Equations (1) and (2) on outcome variables pertaining to overall health insurance coverage and its source. Table 2 displays these results. All of the specifications include controls for gender, race, ethnicity, single year-of-age fixed effects, year fixed effects, PUMA fixed effects, and PUMA-specific time trends. The outcome variable is listed in the column header, and the regression results are shown for Equation (1) in the odd-numbered columns and for Equation (2) in the even-numbered columns. We include the mean of the dependent variable in the bottom row of the table averaged over the pre-ACA sample years for the overall sample, and separately for expansion and non-expansion states. Because the measures of $M_{a}^{*}$ and $E_{a}^{*}$ that we use are demeaned, the coefficient on $P O S T_{t} \times E X P A N S I O N_{S}$ represents the difference in coverage in expansion relative to non-expansion states after the ACA for PUMAs with average shares of the population under 138\% FPL and uninsured (7.3 percentage points) and between 139\% and 399\% FPL and uninsured (8.6 percentage points). 
The results in the table show evidence that the ACA induced statistically significant increases in insurance coverage in both expansion and non-expansion states. In Column (1), we see that after controlling for PUMA-level fixed effects and PUMA-specific time trends, areas with a higher share of the population between $139 \%$ and $399 \%$ of the FPL and uninsured had higher increases in health insurance coverage: specifically, coverage rates increased by 3.4 percentage points more in regions where $E^{*}$ was 10 percentage points higher. This specification does not show evidence that coverage changes varied significantly with the share under $138 \%$ FPL and uninsured.

When we interact $\mathrm{POST}_{t}$ with our measure of Medicaid expansion status and its interaction with both $E^{*}$ and $M^{*}$ (Column (2)), we see that coverage increases were 2.3 percentage points higher in states that expanded Medicaid relative to states that did not after controlling for demographics, year fixed effects, PUMA fixed effects, and PUMA-specific time trends. In addition, increases in coverage are correlated with pre-ACA population characteristics in the expected direction. In states that did not expand Medicaid, the increase in coverage was higher in regions with a larger share of the population uninsured and between $139 \%$ and $399 \%$ FPL: a 10 percentage point increase in $E^{*}$ led to a 2.5 percentage point higher increase in coverage. In states that did choose to expand Medicaid, the increase in coverage is strongly related to the share under $138 \%$ FPL and uninsured: here, a 10 percentage point increase in $M^{*}$ led to a 3.9 percentage point increase in health insurance coverage. By contrast, there is no evidence that non-expansion states had larger coverage increases in places with a higher $M^{*}$. In expansion states, the relationship between $E^{*}$ and increases in health insurance coverage from the ACA is slightly smaller than that in non-expansion states, though the difference is not statistically significant.

For both $M^{*}$ and $E^{*}$, an increase of 10 percentage points corresponds to approximately 2.5 standard deviations. We depict the relationship between $M^{*}$ and $E^{*}$ and the change in health insurance coverage captured in Column (2) of Table 2 graphically in Figure 8. The top panel shows scatterplots of PUMA-level changes in health insurance coverage, condensed into 100 bins, by $M^{*}$ while also controlling for $E^{*}$, differentially by Medicaid expansion status. The slopes of the red dashed and blue solid lines represent the relationship between $M^{*}$ and the change in health insurance coverage for expansion states and non-expansion states, respectively. The bottom panel is similar but plots the change in coverage against $E^{*}$ on the $x$-axis. 
Under the assumption that our demographic controls and PUMA-level fixed effects and PUMAspecific time trends capture the drivers of health insurance coverage aside from the ACA, we can attribute any larger increase in health insurance coverage occurring for regions with a positive $M^{*}$ and $E^{*}$ as causally driven by the ACA. Using the results from Column (2) to generate these ACA-driven increases at the PUMA level and weighting by PUMA population suggests that the increases in health insurance coverage due to the ACA were 2.6 percentage points in non-expansion states and 4.2 percentage points in expansion states. These effects are substantial relative to the overall increase of 3.8 percentage points in nonexpansion states and 5.3 percentage points in expansion states, and represent 70 and 80 percent of the observed increase during our study period, respectively, with the rest potentially due to improving economic conditions. ${ }^{23}$

In Columns (3) - (8), we examine how the ACA affected source of coverage in places with high versus low potential Medicaid and exchange enrollment. The results are similar to Columns (1) and (2), but come from regressions in which the dependent variable is a binary indicator of whether an individual reports having any Medicaid coverage, privately purchased coverage, and coverage from a private employer. As described earlier, individuals surveyed by the ACS may choose multiple sources of insurance and do not indicate which is primary. Therefore, the outcome variables represent whether an individual has the indicated insurance at all at the time of the survey.

As shown in Column (3), when we do not distinguish between expansion and non-expansion states, it appears that Medicaid coverage is not changing differentially in places with higher $M^{*}$ or $E^{*}$. However, when we interact these variables with expansion status in Column (4), we find strong evidence that Medicaid coverage increases more in places with a higher share of the population uninsured and under $138 \%$ FPL prior to ACA. Specifically, in expansion states, in regions where $M *$ is 10 percentage points higher, Medicaid coverage is 5.2 percentage points higher. ${ }^{24}$

\footnotetext{
${ }^{23}$ The overall increase in non-expansion and expansion states of 3.8 and 5.3 come from the coefficients of $P O S T_{t}$ and $E X P A N S I O N_{s} \times$ POST $_{t}$ in regressions that are similar to Equation (2) but do not include year fixed effects nor $M^{*}$ and $E^{*}$. We also find that - as one would expect given that as shown in Figure 1 the change in coverage was not instantaneous - the estimated effects are substantially larger in 2015 than in 2014.

${ }^{24}$ This represents the sum of 0.0877 and 0.4318 in the table multiplied by 100 .
} 
We would not expect Medicaid coverage to change by as much in non-expansion states as a result of the ACA. Consistent with this, the estimated relationship between $\mathrm{M}^{*}$ and the change in Medicaid coverage is only about one-sixth as large in states that did not expand coverage (0.09 versus 0.52$)$. Some uninsured individuals who were Medicaid-eligible before the ACA in non-expansion states may have signed up due to the individual mandate or because of the additional publicity surrounding the ACA. ${ }^{25}$ The point estimate of -0.1702 for the coefficient on $P O S T_{t} \times E_{a}^{*}$ suggests Medicaid coverage declined among those uninsured and with incomes between $139 \%$ and 399\% FPL. This suggests that, because private health insurance became more affordable for this group, some dropped Medicaid coverage to sign up for a subsidized private plan through their state exchange. ${ }^{26}$

While the coefficients on $\mathrm{POST}_{t} \times M_{a}^{*}$ and $P O S T_{t} \times E_{a}^{*}$ in Column (4) are both statistically significant, they have opposite signs, and in specifications that include the sum of $M^{*}$ and $E^{*}$, their coefficient is economically small and negative (see Appendix Table A.3). This suggests that the ACA induced very little increase in Medicaid coverage in states that did not expand the program. Performing an exercise similar to that above, we find that the ACA increased Medicaid coverage by 2.1 percentage points (40 percent of the total increase in health insurance coverage) in expansion states and by a negligible amount in non-expansion states. ${ }^{27}$

Columns (5) and (6) show that while the increase in privately-purchased health insurance was also substantial overall, the average effect is significantly smaller in magnitude in states that expanded their Medicaid programs. In non-expansion states, the increase is strongly correlated with the share of the population between $139 \%$ and 399\% FPL and uninsured who are most likely to purchase subsidized insurance from the exchanges. Our simulations suggest that the ACA increased privately-purchased insurance by 2.4 percentage points (or 63 percent of the overall increase) in non-expansion states but by just 1.0 percentage points (or 19 percent of the overall increase) in expansion states. The statistically

\footnotetext{
${ }^{25}$ This is referred to as the "woodwork effect". Frean, Gruber, and Sommers (2017) find the woodwork effect accounted for $30 \%$ of the ACA's impact on coverage and similar spillovers have also been documented in earlier expansions (Aizer and Grogger, 2003; Dubay and Kenny, 2003). Other estimates, just prior to the ACA's implementation, also suggest the large potential magnitude of the woodwork effect in the ACA (Sommers and Epstein, 2011; Sonier et. al. 2013).

${ }^{26}$ According to individual-level data from the 2010-2013 ACS, 41 percent of those aged 26 to 64 and enrolled in Medicaid had family incomes above 138 percent of the federal poverty line.

${ }^{27}$ Specifically, we use the results from Column (2) to generate ACA-driven increases in Medicaid coverage at the PUMA level and weight by the population age 26-64 in each PUMA.
} 
significant estimate of -0.0826 in column (6) for the $P O S T_{t} \times M_{a}^{*}$ coefficient is comparable in magnitude but opposite in sign to the corresponding estimate for Medicaid coverage in Column (4). This suggests that - even in states that did not expand Medicaid - greater awareness of this coverage caused some low-income individuals to shift from private to public coverage.

Finally, Columns (7) and (8) show little evidence that health insurance coverage from private employers changed substantially in either direction as a result of the ACA, suggesting that there was little crowd-out occurring. Figures similar to Figure 8 but for Medicaid coverage, privately-purchased coverage and coverage from private employers are included in the appendix.

We examine the heterogeneity in the effects of the ACA on health insurance coverage by minority status, presence of a dependent child, education, sex, age, and marital status in Table 3. In these specifications, we retain the definitions of $M^{*}$ and $E^{*}$ used above, so that these two variables represent the averages for the overall adult population rather than for the sub-populations considered here. Estimates for the EXPANSION $_{S} \times$ POST $_{t}$ coefficients suggest a relatively large average gain in health insurance coverage in states that expanded Medicaid for childless adults, for adults with only a high school degree or less, and for unmarried adults. This is consistent with the prediction that the Medicaid expansion would differentially affect coverage for these groups. And consistent with the results in the previous table, the estimates for the $\mathrm{POST}_{t} \times E_{a}^{*}$ and $E X P A N S I O N_{s} \times P O S T_{t} \times M_{a}^{*}$ coefficients are positive and, in 20 out of 24 cases, statistically significant. In contrast, only 1 of 24 estimates for the $\operatorname{POST}_{t} \times M_{a}^{*}$ and the EXPANSION $N_{s} \times$ POST $_{t} \times E_{a}^{*}$ coefficients are significant.

Taken together, these results reveal that the ACA induced significantly larger increases in coverage in low-income areas in expansion states than in states that did not expand. Additionally, coverage in areas with a large share uninsured and with incomes between $139 \%$ and 399\% FPL rose significantly in both groups of states. Even after controlling for the share uninsured, increases in coverage were much greater in states that expanded their Medicaid programs.

In Appendix Table A.4, we estimate a companion set of specifications in which we sum $E^{*}$ and $M^{*}$ (rather than including each separately). For 10 of the 12 sub-groups that we consider, the increase in coverage is significantly greater in areas with high values of $E^{*}+M^{*}$ in states that did not expand their Medicaid programs. Furthermore, this relationship is significantly stronger for all 12 sub-groups in states 
that did expand their Medicaid programs. And finally, for all twelve sub-groups, the increases in coverage are significantly greater in states that expanded even after controlling for $E^{*}+M^{*}$.

\section{B. Labor market outcomes}

We provide evidence on the effect of the ACA on labor market outcomes in Tables 4 and 5, which display the results of estimating Equations (1) and (2) on the labor market outcomes summarized in Table 1. Table 4 sheds light on how the ACA affected labor market outcomes on the extensive margin (e.g. labor force participation), and Table 5 focuses on labor market outcomes on the intensive margin (e.g. hours of work). As in earlier tables, the column heading denotes the dependent variable. All of the results reported are from regressions that include basic demographic controls, year fixed effects, PUMA fixed effects and PUMA-specific time trends. Pre-ACA means of the dependent variables are reported in the final three rows below the regression results.

If the ACA-induced changes in health insurance coverage were influencing labor market outcomes, one would expect to detect a significant coefficient on $\mathrm{POST}_{t} \times M_{a}^{*}, \mathrm{POST}_{t} \times E_{a}^{*}$ or their interactions with the state's Medicaid expansion decision. As the first and second columns show, the change in the share of adults aged 26 to 64 out of the labor force is significantly related with both $M^{*}$ and $E^{*}$ but in opposing directions. Specifically, the results indicate that there is an increase in labor force participation in areas where the share uninsured and under 138\% FPL is larger and a reduction in labor force participation in areas where the share uninsured and between 139\% and 399\% FPL is larger. The latter effect may appear surprising given that dropping out of the labor force and earning no income would make one ineligible for subsidies through the ACA, which are not available to those with income below 100\% FPL. However, since subsidies are based on total household income, one member could drop out of the labor force while another continued to work, thus increasing the family's total subsidy.

As discussed earlier, the increase in labor force participation among those in areas with a greater proportion of individuals uninsured and under 138\% FPL could occur if, for instance, people prefer health insurance policies offered on the exchanges to Medicaid coverage (in expansion states) or people are induced to work more in order to become eligible for exchange subsidies (in non-expansion states). The results in Column (2) provide no evidence that this effect differs in expansion and non-expansion states, 
suggesting that both of these mechanisms may be at play. As mentioned earlier, the effects of Medicaid expansions as part of the ACA may be different than in isolation because a person can obtain subsidized private health insurance coverage even if their earnings rise above the Medicaid eligibility threshold. An additional possible margin is that the expansions in health insurance coverage in relatively poor areas may increase labor demand and thus total employment in the health care sector. ${ }^{28}$

The subsequent columns in Table 4 provide additional information on the source of the changes in labor force participation. Columns (3) and (4) display the results of estimating Equations (1) and (2) on employment and Columns (5) and (6) provide evidence on the ACA's effects on unemployment. The results indicate that the increased labor force participation in areas where $M^{*}$ is high reflects an increase in employment, and are suggestive that the reduction in labor force participation in areas where $E^{*}$ is high is roughly equally split between a reduction in employment and a reduction in unemployment, though we do not have sufficient power to decompose the source definitively. Unemployment could fall if, for example, workers became less likely to search for a job and more likely to drop out of the labor force because of the availability of subsidized health insurance. ${ }^{29}$

Table 5 presents results on the effects of the ACA on part-time employment, self-employment and hours worked (conditional on working). We find little evidence to suggest that these outcomes changed differentially in places with higher potential Medicaid or exchange enrollment. The only estimate in the table that is statistically significant is the estimated coefficient of $\operatorname{POST}_{t} \times \operatorname{EXPANSION}_{s} \times E_{a}^{*}$ in Column (6), providing weak evidence that subsidy-induced changes in hours are different in expansion and nonexpansion states. However, the total relationship between reported hours conditional on working and areas with higher potential exchange enrollment in expansion states is still economically negligible and statistically insignificant.

In Table 6, we report the results of specifications that aggregate $M^{*}$ and $E^{*}$ into $E^{*}+M^{*}$ rather than distinguishing these two potential channels using our extensive margin measures of labor market outcomes. The statistically insignificant point estimate of 0.0054 in Column (2) suggests that labor force

\footnotetext{
${ }^{28}$ Consistent with this, Chodorow-Reich et al (2012) find that increases in Medicaid funding from the American Recovery and Reinvestment Act increased employment in the health care sector.

${ }^{29}$ Autor and Duggan (2003) find that an increase in the generosity of the SSDI program reduced unemployment because unemployed workers became more likely to drop out of the labor force rather than search for a new job.
} 
participation did not change differentially in areas with a large share both uninsured and with family incomes below 400\% FPL. Multiplying this point estimate by the average value for $E^{*}+M^{*}$ would suggest a change in labor force participation of just 0.003 percentage points. These results highlight that failing to distinguish between areas with different pre-ACA income distributions would mask the heterogeneous effects that we estimate on labor force participation.

The next four columns summarize specifications for employment and unemployment. The results reported there suggest that areas with a high share uninsured and below 400\% FPL experienced significant increases in employment and reductions in unemployment. These two effects roughly balance out so that there is no corresponding change in labor force participation. Additionally, states that expanded their Medicaid programs experienced larger average reductions in unemployment. In addition to the labor supply margins highlighted above, the policy-induced increase in insurance coverage may have increased labor demand and thus the total number employed.

We estimate Equation (2) for each of the subsamples defined earlier in Table 3 with labor force non-participation as the outcome variable and display the results in Table 7. The results reveal that - for none of the 12 sub-populations we consider - did labor force participation change differentially in states that expanded their Medicaid programs. We do, however, find a stronger relationship between labor force participation changes and area-level uninsurance rates for minorities, childless adults, men, and married individuals. Minorities, childless adults, and men were more likely to be uninsured pre-ACA and those who are married may be more responsive to labor supply incentives. For each group, labor force participation rose significantly in areas with a large share both poor and uninsured while it fell significantly in areas with a large share with middle incomes and uninsured.

Theoretically, one might expect a larger average labor supply response by older workers given that the average disutility of work likely rises with age and because more of these workers may be on the margin for retirement. We therefore also examine how the estimated effects of the ACA-induced increases in insurance coverage vary by age group. While the results in Columns (9) and (10) of Table 7 are not statistically significant, the point estimates are similar to those that are estimated in the full sample, suggesting that we lose precision when cutting the sample by age and that effects are not very different between 26-44 and 45-64 year olds. 
In Appendix Table A.5, we estimate a companion set of specifications in which we sum $\mathrm{E}^{*}$ and $M^{*}$ (rather than including each separately). This table shows 36 coefficient estimates, with three for each of the twelve sub-groups. An examination of this table reveals that just 2 of the 36 coefficient estimates are significant at the 5 percent level, suggesting very little average effect. In contrast, 34 of the 36 estimates in the corresponding table for health insurance coverage were statistically significant.

Taken together, our findings demonstrate that the aggregate labor market effects are relatively small in both expansion and non-expansion states. However, this aggregate impact masks countervailing effects through two channels: reductions in labor force participation coming from the availability of subsidies to purchase insurance through new health insurance exchanges, and increases in labor force participation stemming from a combination of incentives to enter the labor force and become eligible for subsidized coverage through the health insurance exchanges and preferences for exchange policies over public insurance options. We note that our empirical strategy does not allow us to distinguish between income effects and incentive effects in that some of the effects we estimate could be due to larger government transfers resulting in a higher demand for leisure. The increase in insurance coverage and the associated rise in health care spending may also influence labor market outcomes through a rise in labor demand.

\section{Pre-trends, year-by-year results, and robustness}

Our identification rests on the assumption that, absent the ACA, geographic areas with larger shares of uninsured individuals under 400\% FPL would have evolved similarly as those with smaller shares, after controlling for person-level demographics, year effects, area-level fixed effects, and area-specific time trends. We further assume that places with a given share of individuals both uninsured and under $400 \%$ FPL in expansion states would have evolved similarly as those with a similar share in non-expansion states, absent the ACA. Both assumptions may be violated if we see areas with high levels of potential Medicaid or exchange enrollment trending differently before ACA implementation.

We investigate trends in the relationship between $M^{*}, E^{*}$ and health insurance by estimating versions of Equation (2) where we replace $\mathrm{POST}_{t}$ with a full set of year dummy variables to trace out the relationship between health insurance coverage and potential Medicaid and exchange enrollment before and after the ACA took effect. Because our data do not permit analysis on a quarterly or monthly basis, the 
estimates represent the effects on average throughout the year. Because we include PUMA-specific time trends, two coefficients on year drop out of the equation.

The results of running fully-interacted specifications with health insurance coverage as the outcome are provided in Figure 9. The effects mirror those shown in Table 2 but also show that the relationship between potential Medicaid and exchange enrollment and health insurance coverage was generally stable and statistically indistinguishable from zero in the pre-ACA period, while increasing markedly in the postACA period. The main exception is that health insurance coverage is not related to $M *$ in non-expansion states post-ACA, which is consistent with our prior findings and intuitive. We include similar figures for the different sources of coverage, namely Medicaid, privately-purchased insurance and coverage from private employers, in the appendix.

Finally, we also examine the robustness of our results to different specifications and definitions of geographic areas. As mentioned previously, our analysis uses aggregated PUMAs in order to include years prior to the change in PUMA definition, which allows a more systematic analysis of pre-trends that could otherwise confound our results. However, using these aggregated PUMAs results in approximately half the number of geographic areas and coarser variation than would be present otherwise. We examine the robustness of our results to using the finer set of PUMAs, limiting the sample years to 2012-2015. ${ }^{30}$ These results are consistent with our results using the full sample period and the aggregated PUMAs and provide additional evidence that the ACA led to increases in health insurance coverage with little evidence that labor market outcomes changed due to the ACA's provisions. Finally, we also examine the sensitivity of including states that expanded their Medicaid programs during 2014 as expansion states in our analysis and find that our results are qualitatively and quantitatively similar. Both of these sets of results are available upon request.

\section{CONCLUSION}

The Affordable Care Act represents the most significant change to the U.S. health care system and implemented a variety of policies that sought to reduce the number uninsured while simultaneously slowing the growth rate of health care spending. Our paper shows that a large share ( 75 percent) of the drop in

\footnotetext{
${ }^{30}$ Due to the limited number of years, we omit PUMA-specific time trends from these specifications.
} 
uninsurance that occurred after the key components of the ACA were implemented was due to these provisions and occurred differentially in regions where a greater share of the population was uninsured and eligible for Medicaid or for private insurance subsidies.

Due to the strong link between health insurance coverage and employment, the CBO predicted a sizable reduction in the labor force as a result of the ACA. Many proponents of the legislation predicted positive employment effects from improved health and subsidies for small businesses (CEA, 2009). If the ACA had led to a reduction (or increase) in employment, hours, or labor force participation relative to what it would have been in the absence of the ACA, we would have expected to find evidence of larger changes in labor market outcomes in regions that were differentially affected by the legislation or among subpopulations with higher labor supply elasticities.

Data from the first two years of the law's implementation suggests that, in the aggregate, any labor supply effects of the ACA have been modest. This is consistent with the time series evidence in Figure 2, which shows no evidence of a change in the level or trend of labor force participation after ACA implementation. However, this aggregate effect masks countervailing effects in regions with higher potential Medicaid enrollment, where labor force participation increased, and regions with higher potential exchange enrollment, where labor force participation decreased. More work is clearly needed to estimate the economic effects of this legislation as additional years of data become available. 


\section{References}

Abraham, Jean, Anne B. Royalty, and Coleman Drake (2016). "Employer-Sponsored Insurance Offers: Largely Stable in 2014 Following ACA Implementation.” Health Affairs, 35(11): 2133-2137.

Abraham, Jean, and Anne B. Royalty (2017). "How Has the Affordable Care Act Affected Work and Wages.” LDI Issue Brief, 21(3).

Aizer, Anna, and Jeffrey Grogger (2003). "Parental Medicaid Expansions and Health Insurance Coverage.” National Bureau of Economic Research Working Paper 9907.

Antwi, Yaa Akosa, Asako S. Moriya and Kosali Simon (2013), "Effects of Federal Policy to Insure Young Adults: Evidence from the 2010 Affordable Care Act's Dependent-Coverage Mandate," American Economic Journal: Economic Policy, 5(4), pp. 1-28.

Autor, David H., and Mark G. Duggan (2003). "The Rise in Disability Rolls and the Decline in Unemployment.” The Quarterly Journal of Economics, 118(1): 157-206.

Baicker, Katherine, Amy Finkelstein, Jae Song, and Sarah Taubman, (2014). "The Impact of Medicaid on Labor Market Activity and Program Participation: Evidence from the Oregon Health Insurance Experiment," American Economic Review: Papers and Proceedings, 104(5), pp. 322-328.

Bailey, James, and Anna Chorniy (2015). "Employer Provided Health Insurance and Job Mobility: Did the Affordable Care Act Reduce Job Lock?” Contemporary Economic Policy, 34(1): 173-183.

Bertrand, Marianne, Esther Duflo, and Sendhil Mullainathan (2004). "How much should we trust differences-in-differences estimates?." The Quarterly Journal of Economics 119(1): 249-275.

Black, Lindsey I., and Robin A. Cohen (2015). "Insurance Status by State Medicaid Expansion Status: Early Release of Estimates From the National Health Interview Survey, 2013-September 2014." National Center for Health Statistics.

Blau, David M. and Donna B. Gilleskie (2008). "The Role of Retiree Health Insurance in the Employment Behavior of Older Men.” International Economic Review, 49(2), 475-514.

Blau, David M. and Donna B. Gilleskie (2006). "Health Insurance and Retirement of Married Couples." Journal of Applied Econometrics, 21(7), 935-953.

Blau, David M. and Donna B. Gilleskie (2001). "Retiree Health Insurance and the Labor Force Behavior of Older Men in the 1990s." Review of Economics and Statistics, 83(1), 64-80.

Blavin Fredric, Adele Shartzer, Sharon K. Long, and John Holahan (2015). "An Early Look at Changes in Employer-Sponsored Insurance under the Affordable Care Act.” Health Affairs, 34(1): 170-177.

Boyle, Melissa A. \& Lahey, Joanna N. (2010). "Health insurance and the labor supply decisions of older workers: Evidence from a U.S. Department of Veterans Affairs expansion," Journal of Public Economics, vol. 94(7-8), pages 467-478, August.

Buchmueller, Thomas, Helen C. Levy and Sayeh Nikpay (2015). "The Effect of Health Reform on Retirement." Working paper prepared for the $17^{\text {th }}$ Annual Joint Meeting of the Retirement Research Consortium. 
Cantor, Joel C., Alan C. Monheit, Derek DeLia, and Kristen Lloyd (2012). "Early Impact of the Affordable Care Act on Health Insurance Coverage of Young Adults." Health Services Research, 47(5): 1773-1790.

Carman, Katherine G., Christine Eibner, and Susan M. Paddock (2015). "Trends In Health Insurance Enrollment, 2013-15." Health Affairs, 34(6): 1044-1048.

CEA (2009). "The Economic Case for Health Reform.” Available at https://obamawhitehouse.archives.gov/administration/eop/cea/TheEconomicCaseforHealthCareR eform/

Chodorow-Reich, Gabriel, Laura Feiveson, Zachary Liscow, and William Gui Woolston (2012). "Does State Fiscal Relief During Recessions Increase Employment? Evidence from the American Recovery and Reinvestment Act." American Economic Journal: Economic Policy, 4(3): 118-145.

Coe, Norma B., Mashfiqur R. Kahn, and Matthew S. Rutledge (2013). "Sticky Ages: Why Is Age 65 Still A Retirement Peak?" Working Paper 2013-2. Chestnut Hill, MA: Center for Retirement Research at Boston College.

Congressional Budget Office (2014). "Labor Market Effects of the Affordable Care Act: Updated Estimates."

Congressional Budget Office (2015). "Appendix B: Updated Estimates of the Insurance Coverage Provisions of the Affordable Care Act," from The Budget and Economic Outlook: 2015 to 2025.

Courtemanche, Charles, James Marton, and Aaron Yelowitz (2016). "Who Gained Insurance Coverage in 2014, the First Year of Full ACA Implementation?” Health Economics, 25(6): 778-784.

Courtemanche, Charles, James Marton, Benjamin Ukert, Aaron Yelowitz, and Daniela Zapata. (2017). "Impacts of the Affordable Care Act on Health Insurance Coverage in Medicaid Expansion and Non-Expansion States." Journal of Policy Analysis and Management, 36(1): 178-210.

Currie, Janet and Jonathan Gruber (1996). "Health Insurance Eligibility, Utilization of Medical Care, and Child Health," Quarterly Journal of Economics, 111(2): 431-466.

Cutler, David M., and Jonathan Gruber (1996). “Does Public Insurance Crowd Out Private Insurance?” The Quarterly Journal of Economics, 111(2): 391-430.

Dague, Laura Thomas Deleire, and Lindsey Leininger (2014). "The Effect of Public Insurance Coverage for Childless Adults on Labor Supply,” NBER Working Paper 20111.

Dillender, Marcus, Carolyn Heinrich, and Susan Houseman (2016). "Effects of the Affordable Care Act on Part-Time Employment: Early Evidence.” http://ssrn.com/abstract=2796131

Dubay, Lisa and Genevieve Kenny (2003). Expanding Public Health Insurance to Parents: Effects on Children's Coverage under Medicaid. Health Services Research, 38(5): 1283-1302.

Duggan, Mark and Tamara Hayford (2013). "Has the Shift to Managed Care Reduced Medicaid Spending: Evidence from State and Local-Level Mandates." Journal of Policy Analysis and Management. 32:3, 505-535. 
Even, William E., and David A. Macpherson (2016). "The Affordable Care Act and the Growth of Involuntary Part-Time Employment.” http://ssrn.com/abstract=2653995

Fang, Hanming and Andrew Shephard (2015). "Joint Household Labor Supply and Health Care Reform." Manuscript.

Finkelstein, Amy (2007). "The Aggregate Effects of Health Insurance: Evidence from the Introduction of Medicare," Quarterly Journal of Economics, 122(1), pp. 1-37.

Finkelstein, Amy and Robin McKnight (2008). "What Did Medicare Do? The Initial Impact of Medicare on Mortality and Out of Pocket Medical Spending," Journal of Public Economics, 92(7), pp. 1644-1669.

Fitzpatrick, Maria (2013). "Retiree Health Insurance for Public School Employees: Does it Affect Retirement and Mobility?” NBER Working Paper 19524.

Frean, Molly, Jonathan Gruber, and Benjamin D. Sommers (2017). "Premium Subsidies, the Mandate, and Medicaid Expansion: Coverage Effects of the Affordable Care Act." Forthcoming, Journal of Health Economics.

French, Eric and John Bailey Jones (2011). "The Effects of Health Insurance and Self Insurance on Retirement Behavior.” Econometrica, 79(3), 693-732.

Gabel, Jon, Roland McDevitt, Laura Gandolfo, Jeremy Pickreign, Samantha Hawkins and Cheryl Fahlman (2006). "Generosity and Adjusted Premiums in Job-Based Insurance: Hawaii is Up, Wyoming is Down." Health Affairs, 25(3): 832-843.

Garthwaite, Craig Tal Gross and Matthew Notowidigdo (2014). "Public Health Insurance, Labor Supply, and Employment Lock," Quarterly Journal of Economics, 129(2): 653-696, May.

Gooptu, Angshuman, Asako S. Moriya, Kosali I. Simon, and Benjamin D. Sommers. 2016. "Medicaid Expansion Did Not Result In Significant Employment Changes Or Job Reductions In 2014." Health Affairs, 35(1): 111-118.

Gruber, Jonathan and Brigitte C. Madrian (1995). "Health Insurance Availability and the Retirement Decision," American Economic Review 85(4): 938-948.

Gruber, Jonathan and Brigitte C. Madrian (2002). "Health Insurance, Labor Supply, and Job Mobility: A Critical Review of the Literature." In McLaughlin, Catherine (ed.) Health Policy and the Uninsured. Washington, D.C.: Urban Institute Press, 2004.

Gustman, Alan L. and Thomas L. Steinmeier (1994). "Employer Provided Health Insurance and Retirement Behavior," Industrial and Labor Relations Review, 48(1), 124-140.

Gustman, Alan L., Thomas L. Steinmeier, and Nahid Tabatabai (2016). "The Affordable Care Act as Retiree Health Insurance: Implications for Retirement and Social Security Claiming." National Bureau of Economic Research Working Paper 22815.

Hamersma, Sarah and Matthew Kim (2013). "Participation and Crowd-Out: Assessing the Effects of Parental Medicaid Expansions." Journal of Health Economics, 32(1): 160-171. 
Heim, Bradley, Ithai Lurie, and Kosali Simon (2015). "The Impact of the Affordable Care Act Young Adult Provision on Labor Market Outcomes: Evidence from Tax Data." In Brown, Jeffrey R. (ed.) Tax Policy and the Economy, 29, 133-157. University of Chicago Press.

Heim, Bradley, Gillian Hunter, Ithai Lurie, and Shanthi Ramnath (2014). "Wages and Cliffs: Marginal Earnings Incentives in the Affordable Care Act.” Manuscript.

Kaestner, Robert, Bowen Garrett, Anuj Gangopadhyaya, and Caitlyn Fleming (2015). "Effects of ACA Medicaid Expansions on Health Insurance Coverage and Labor Supply." National Bureau of Economic Research Working Paper 21836.

Kafka, Stephanie (2015). "U.S. Uninsured Rate at 11.4\% in Second Quarter.” Gallup-Healthways WellBeing Index.

Karoly, Lynn A. and Jeannette Rogowski (1994). "The Effect of Access to Post- Retirement Health Insurance on the Decision to Retire Early." Industrial and Labor Relations Review, 48(1), 103123.

Kolstad, Jonathan T., and Amanda E. Kowalski (2012). "The impact of health care reform on hospital and preventive care: Evidence from Massachusetts." Journal of Public Economics, 96(11-12): 909929.

Leiserson, Greg (2013). "Retiree Health Insurance and Job Separations: Evidence from Pennsylvania State Employees." Manuscript. Massachusetts Institute of Technology.

Leung, Pauline, and Alexandre Mas (2016). "Employment Effects of the ACA Medicaid Expansions." National Bureau of Economic Research Working Paper 22540.

Long, Sharon K, Karen Stockley, and Alshadye Yemane (2009). "Another Look at the Impacts of Health Reform in Massachusetts: Evidence Using New Data and a Stronger Model." The American Economic Review, 99(2): 508-511.

Long, Sharon K, Michael Karpman, Adele Shartzer, Douglas Wissoker, Genevieve M. Kenney, Stephen Zucherman, Nathanial Anderson, and Katherine Hempstead (2014). "Taking Stock: Health Insurance Coverage under the ACA as of September 2014.” Washington, DC: Urban Institute.

Lumsdaine, Robin L., James H. Stock, and David A. Wise. 1996. "Retirement Incentives: The Interaction between Employer-Provided Pensions, Social Security, and Retiree Health Insurance." In Michael D. Hurd and Naohiro Yashiro (Eds.), The Economic Effects of Aging in the United States and Japan (pp. 261-293). Chicago: University of Chicago Press.

Madrian, Brigitte C. (1994a). "Employment-Based Health Insurance and Job Mobility: Is There Evidence of Job Lock?," Quarterly Journal of Economics 109(1), pp. 27-54.

Madrian, Brigitte C. (1994b). "The Effect of Health Insurance on Retirement," Brookings Papers on Economic Activity, 1994(1), pp. 181-232.

Miller, Sarah (2012). "The Effect of Insurance on Emergency Room Visits: An Analysis of the 2006 Massachusetts Health Reform," Journal of Public Economics, 96 (11), pp. 893-908. 
Moriya, Asako S., Thomas M. Selden, and Kosali I. Simon (2016). "Little Change Seen In Part-Time Employment As A Result Of The Affordable Care Act.” Health Affairs, 35(1): 119-123.

Mulligan, Casey B. (2014). "The Affordable Care Act and the New Economics of Part-Time Work." Mercatus Working Paper.

Mulligan, Casey B. (2015a). "The New Employment and Income Taxes.” Journal of Policy Analysis and Management, 34(2): 466-473.

Mulligan, Casey B. (2015b). “The New Full-Time Employment Taxes.” Tax Policy and the Economy, 29(1): 89-132.

Nyce, Steven, Sylvester Schieber, John B. Shoven, Sita Slavov, and David A. Wise (2013). "Does Retiree Health Insurance Encourage Early Retirement?” Journal of Public Economics, 104, pp. 40-51.

Rust, John and Christopher Phelan (1997). "How Social Security and Medicare Affect Retirement Behavior in a World of Incomplete Markets," Econometrica, 65(4): 781-831.

Shoven, John and Sita Nataraj Slavov (2013). "The Role of Retiree Health Insurance in the Early Retirement of Public Sector Employees." Prepared for Presentation at the NBER Conference on State and Local Health Plans for Active and Retired Public Employees, August.

Sommers, Benjamin D., Katherine Baicker and Arnold M. Epstein (2012). "Mortality and Access to Care among Adults after State Medicaid Expansions," New England Journal of Medicine, 367: 10251034.

Sommers, Benjamin D., and Arnold M. Epstein (2012). "Why States Are So Miffed about Medicaid Economics, Politics, and the 'Woodwork Effect'." New England Journal of Medicine, 365(2): 100-102.

Sommers, Benjamin D., Munira Z. Gunja, Kenneth Finegold, and Thomas Musco (2015). "Changes in Self-reported Insurance Coverage, Access to Care, and Health Under the Affordable Care Act." Journal of the American Medical Association, 314(4): 366-374.

Sommers, Benjamin D., and Richard Kronick (2012). "The Affordable Care Act and Insurance Coverage for Young Adults.” The Journal of the American Medical Association, 307(9): 913-914.

Sommers, Benjamin D., Thomas Musco, Kenneth Finegold, Munira Z. Gunja, Amy Burke, and Audrey M. McDowell (2014). "Health Reform and Changes in Health Insurance Coverage in 2014." New England Journal of Medicine, 371(9): 867-874.

Sonier, J., M. H. Boudreaux, and L. A. Blewett (2013). "Medicaid Welcome-Mat Effect Of Affordable Care Act Implementation Could Be Substantial.” Health Affairs, 32(7): 1319-1325.

Yelowitz, Aaron, and Michael F. Cannon (2010). "The Massachusetts Health Plan - Much Pain, Little Gain.” Cato Institute: Policy Affairs, 657. 
Figure 1

Percentage of Persons 18-64 Uninsured, January 2010 - March 2016

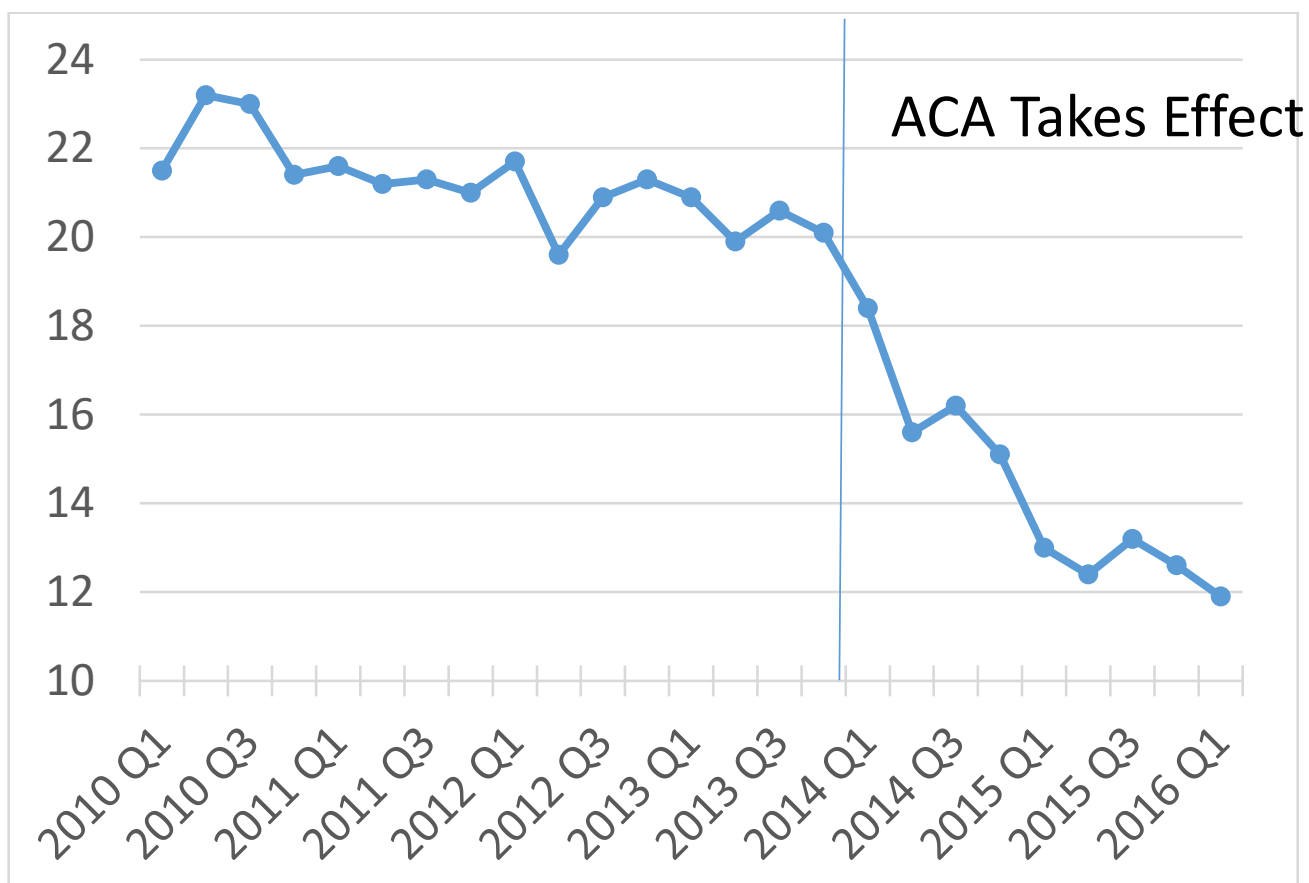

Source: NCHS. National Health Interview Survey Early Release of Quarterly Estimates, retrieved September 12, 2016.

Figure 2

Labor Force Participation Rate, Seasonally Adjusted, Ages 16 and over

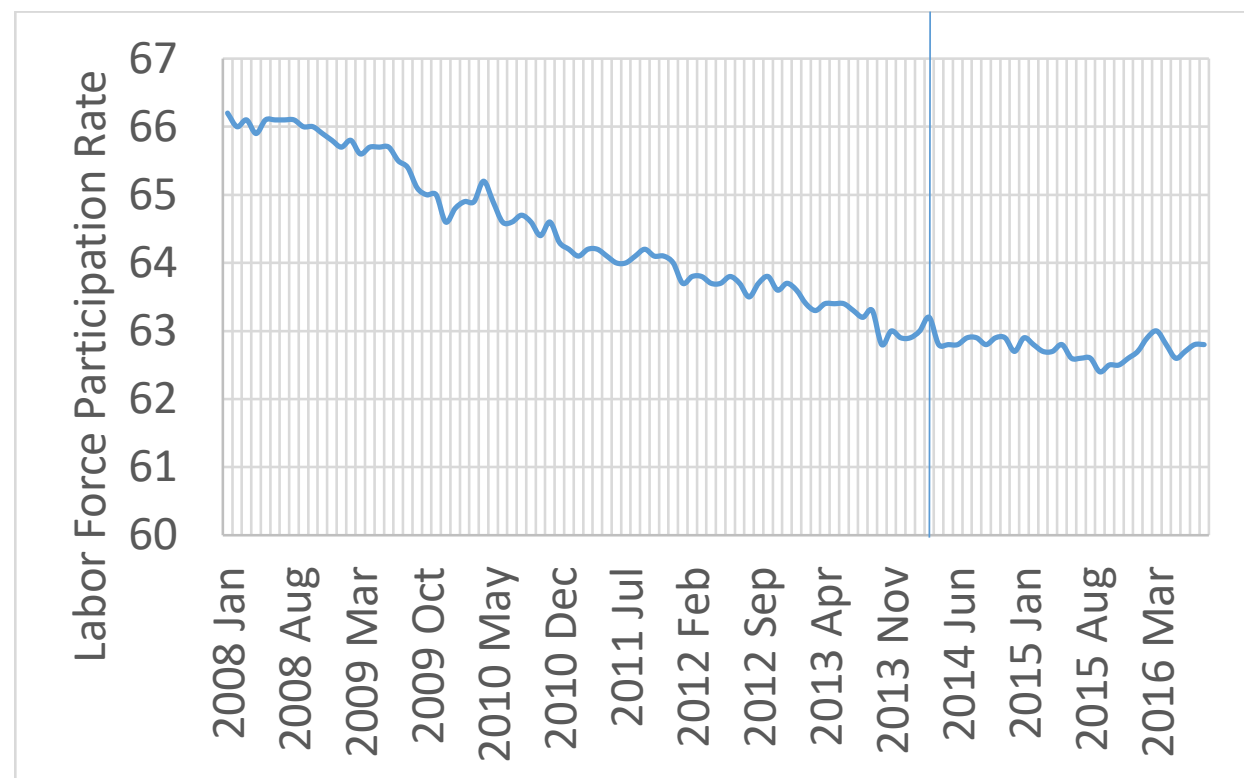

Source: Bureau of Labor Statistics, Series LNS11300000, retrieved September 12, 2016. 


\section{Figure 3}

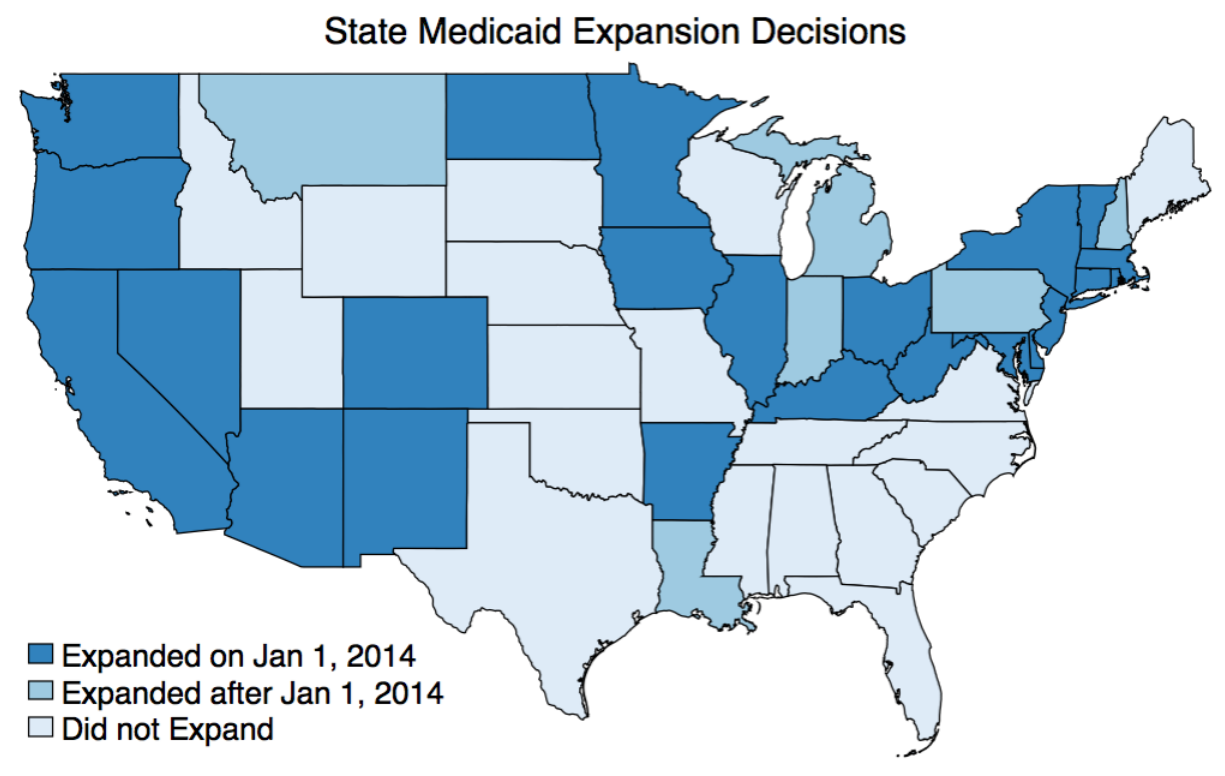

Notes: Data on each state's decision to expand or not expand their Medicaid program was retrieved from Kaiser Family Foundation, Status of State Action on the Medicaid Expansion Decision, on August 31, 2016.

Figure 4

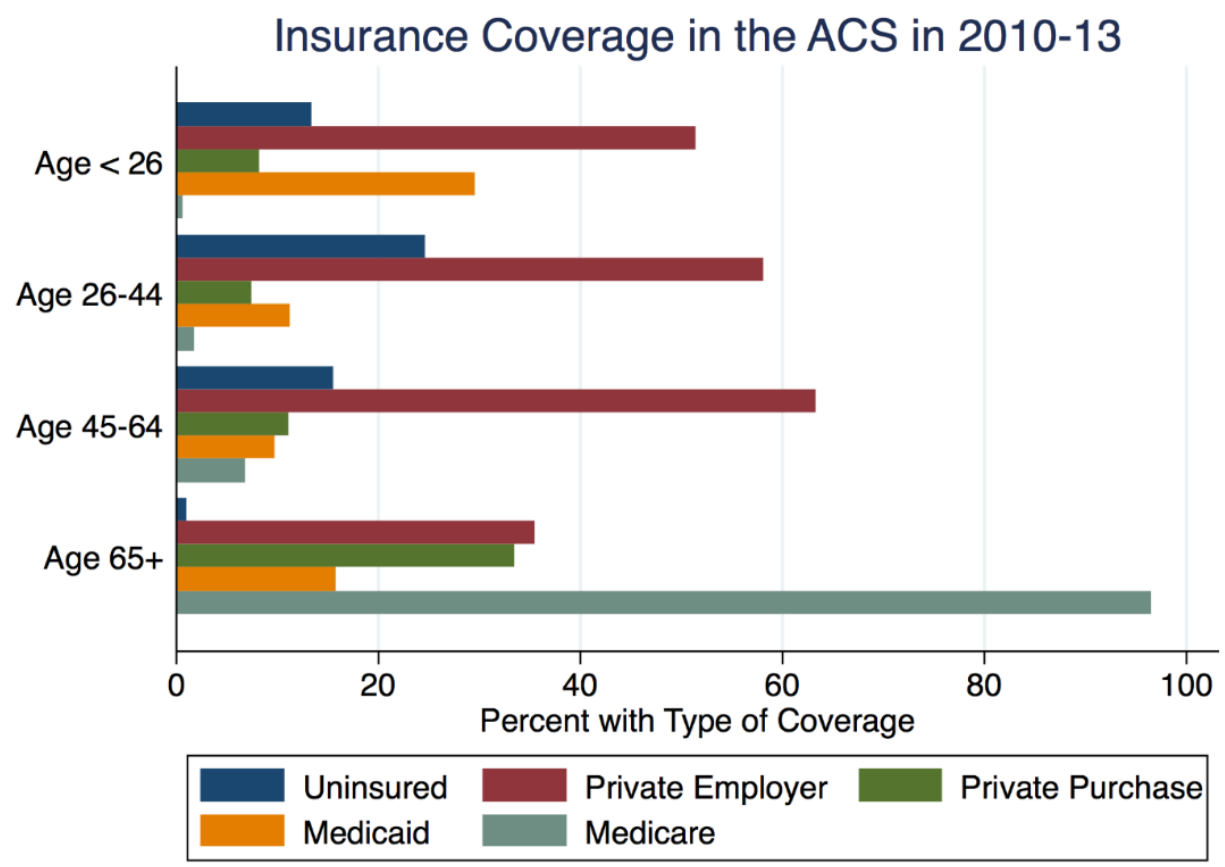




\section{Figure 5}

\section{Heterogeneity across PUMAs in $M^{*}$ and $E^{*}$}

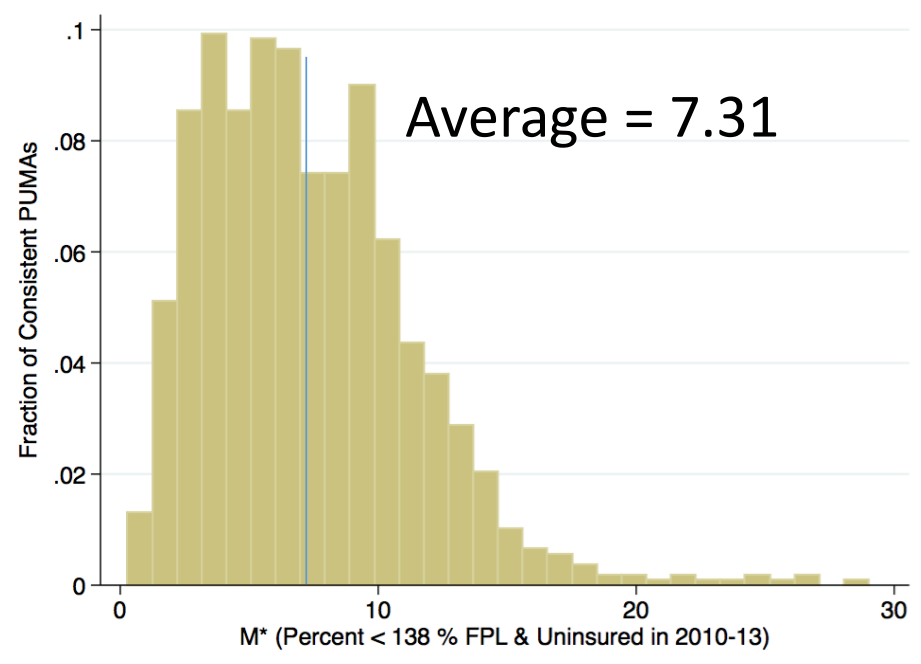

(a) Share $<138 \%$ FPL and Uninsured in 2010-13

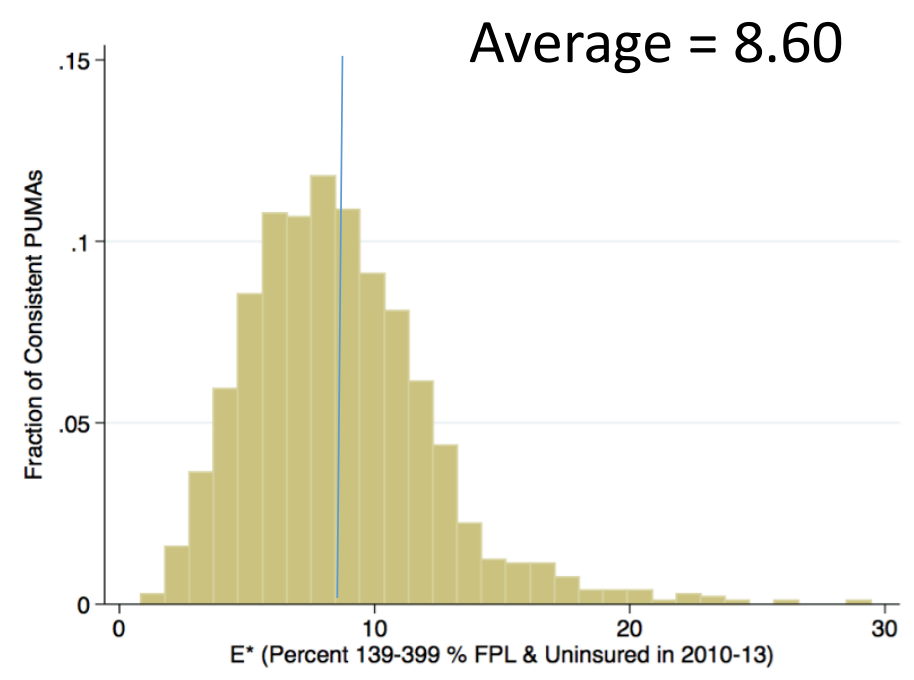

(b) Share 139-399\% FPL and Uninsured in 2010-13

Notes: $M^{*}$ refers to the share of individuals in a PUMA that are uninsured and within 0-138\% FPL in 2010-13. $E^{*}$ refers to the share of individuals in a PUMA that are uninsured and within 139-399\% FPL in 2010-13. 
Figure 6

$M^{*}$ in PUMAs across United States, California and Los Angeles County

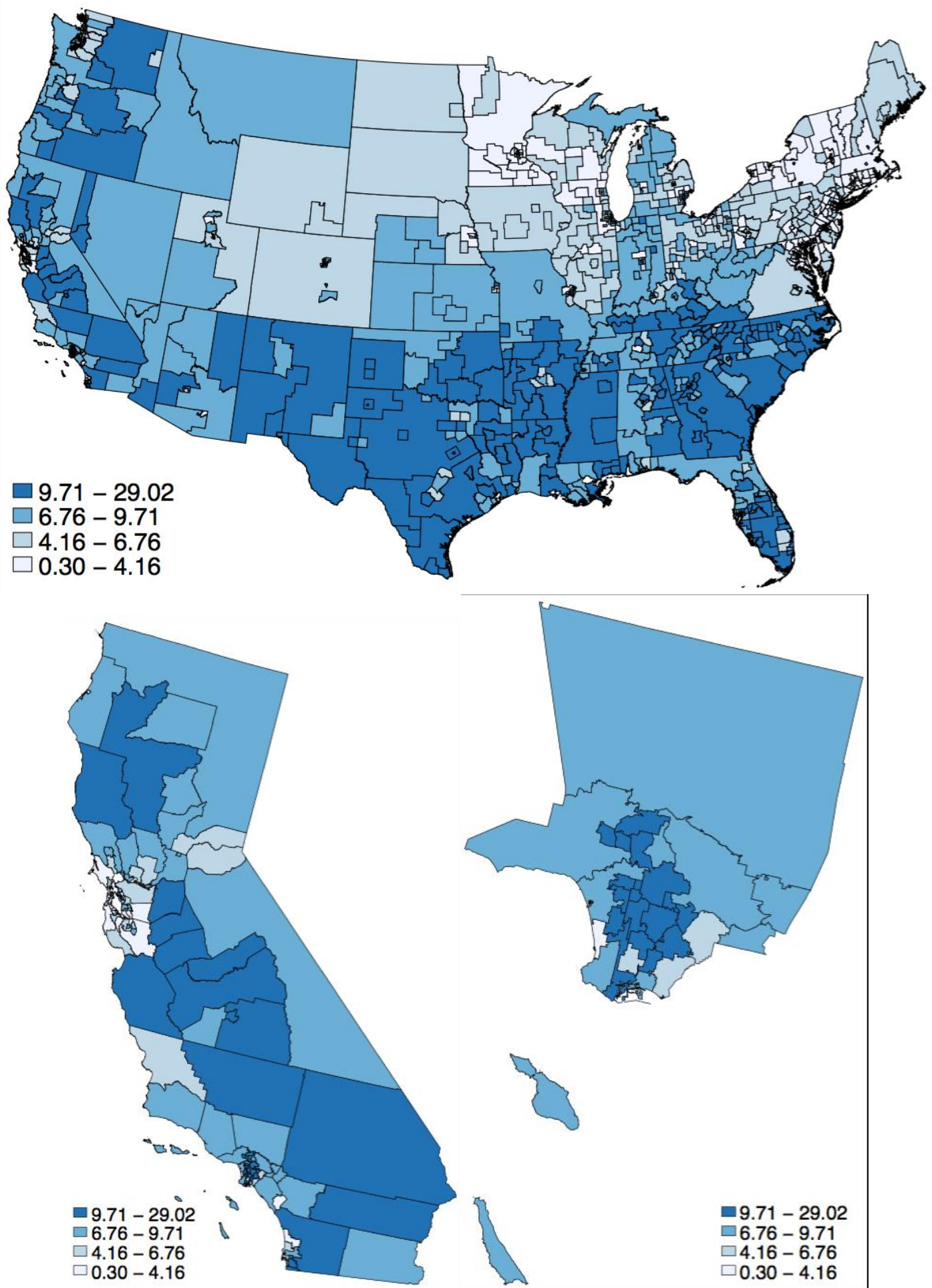

Notes: $M^{*}$ refers to the share of individuals in a PUMA that are uninsured and within 0-138\% FPL in 2010-13. 
Figure 7

$E^{*}$ in PUMAs across United States, California and Los Angeles County
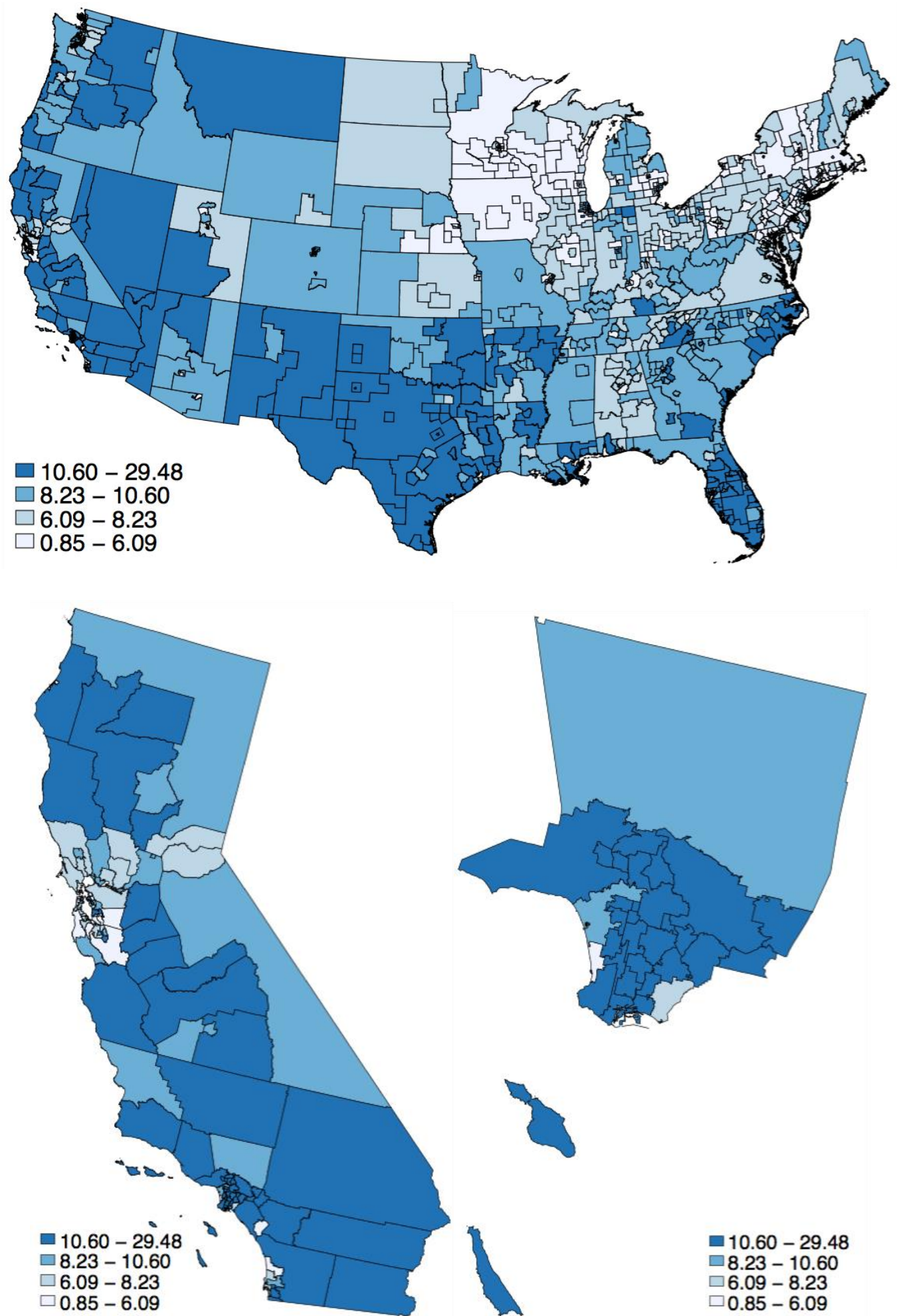

Notes: $E^{*}$ refers to the share of individuals in a PUMA that are uninsured and within 139-399\% FPL in 2010-13. 


\section{Figure 8}

\section{Change in Health Insurance Coverage by $M^{*}, E^{*}$, and Medicaid Expansion Status}

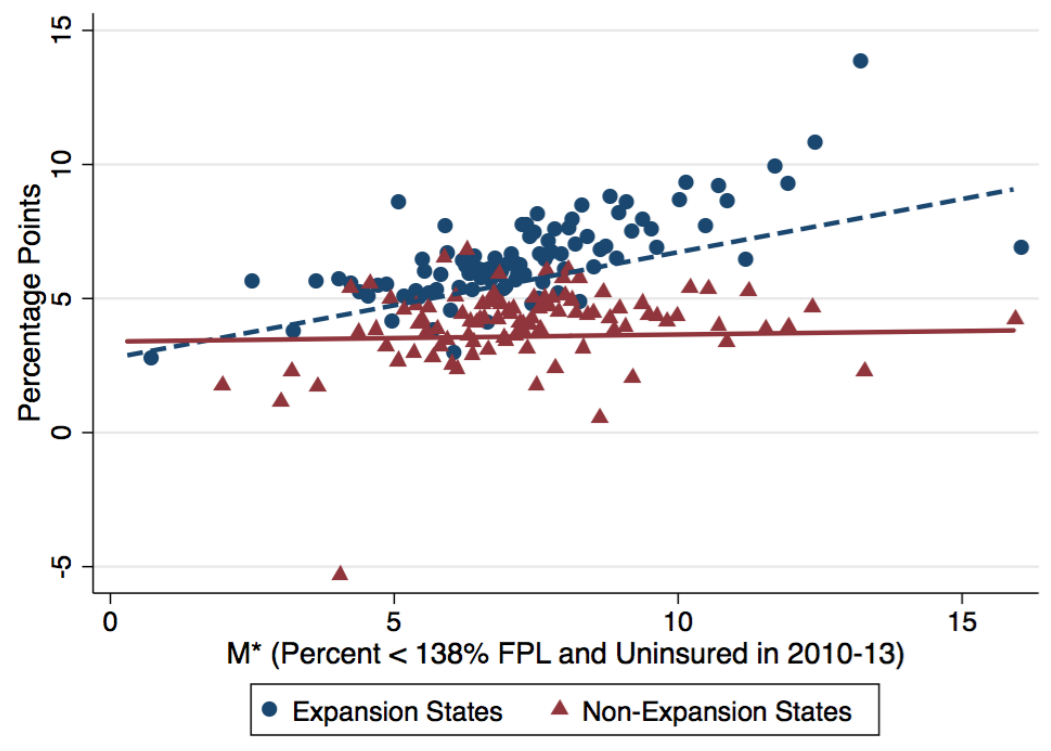

(a) $M *$

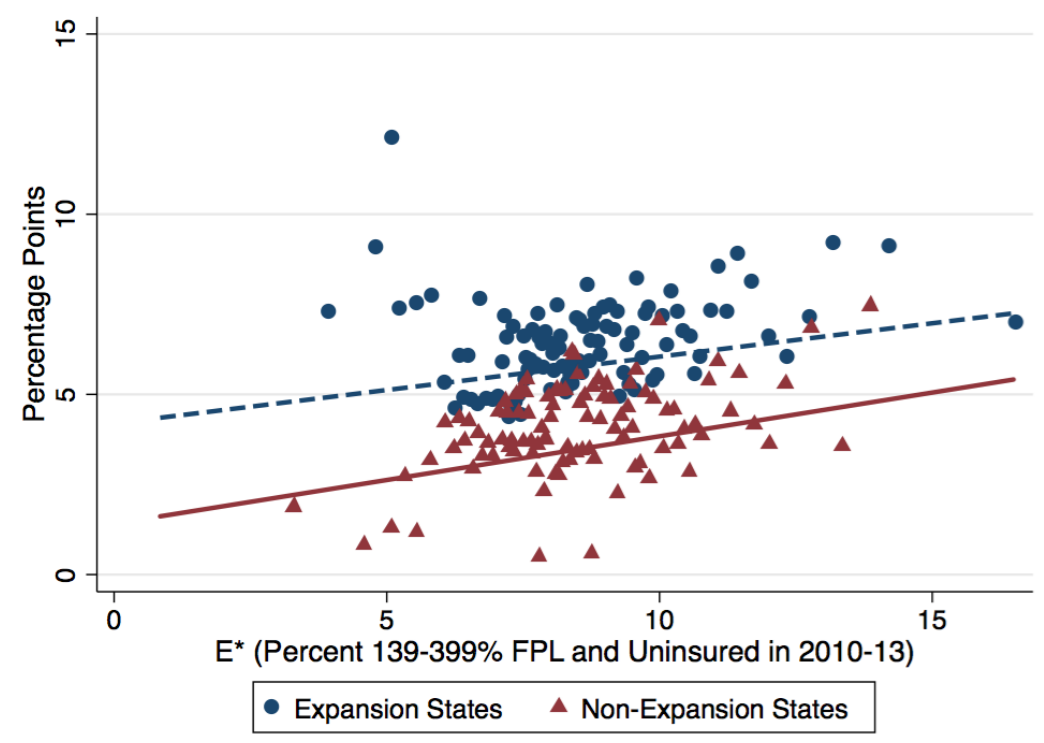

(b) $E^{*}$

Notes: $M^{*}$ refers to the share of individuals in a PUMA that are uninsured and 0-138\% FPL in 2010-13 and $E^{*}$ refers to the share of in a PUMA that are uninsured and 139-399\% FPL in 2010-13. 


\section{Figure 9}

\section{Relationship between $M^{*}, E^{*}$ and Health Insurance Coverage by Year and Medicaid Expansion Status}

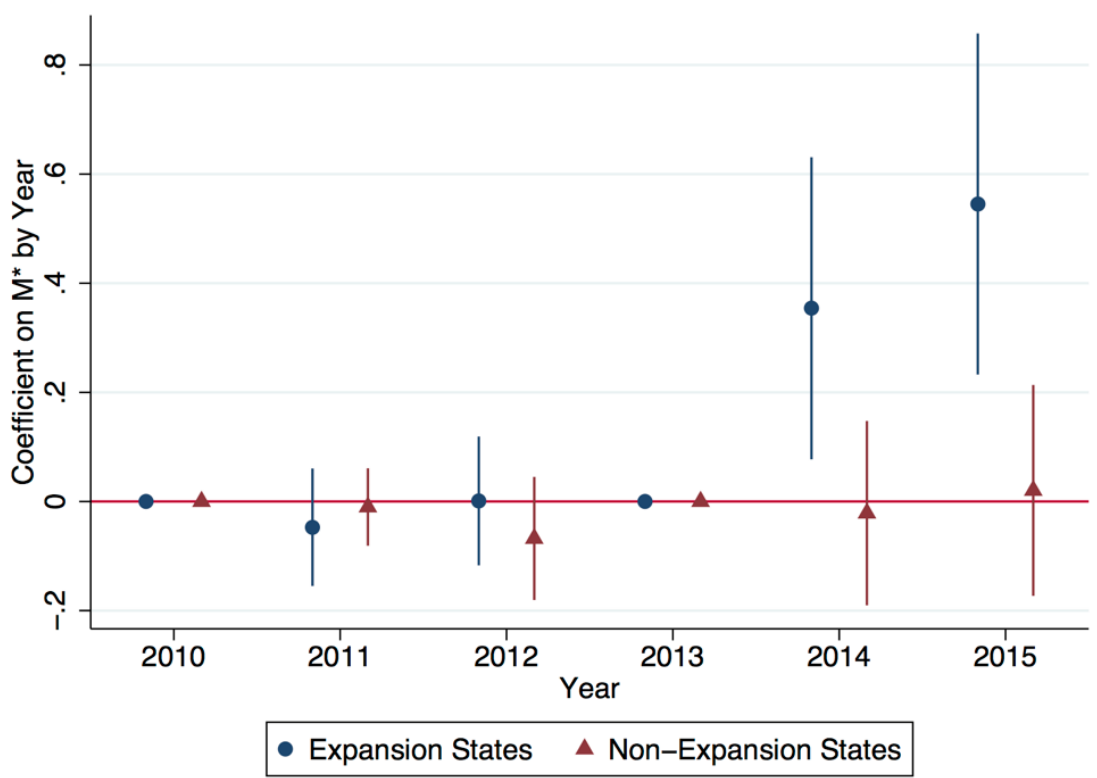

(a) $M^{*}$

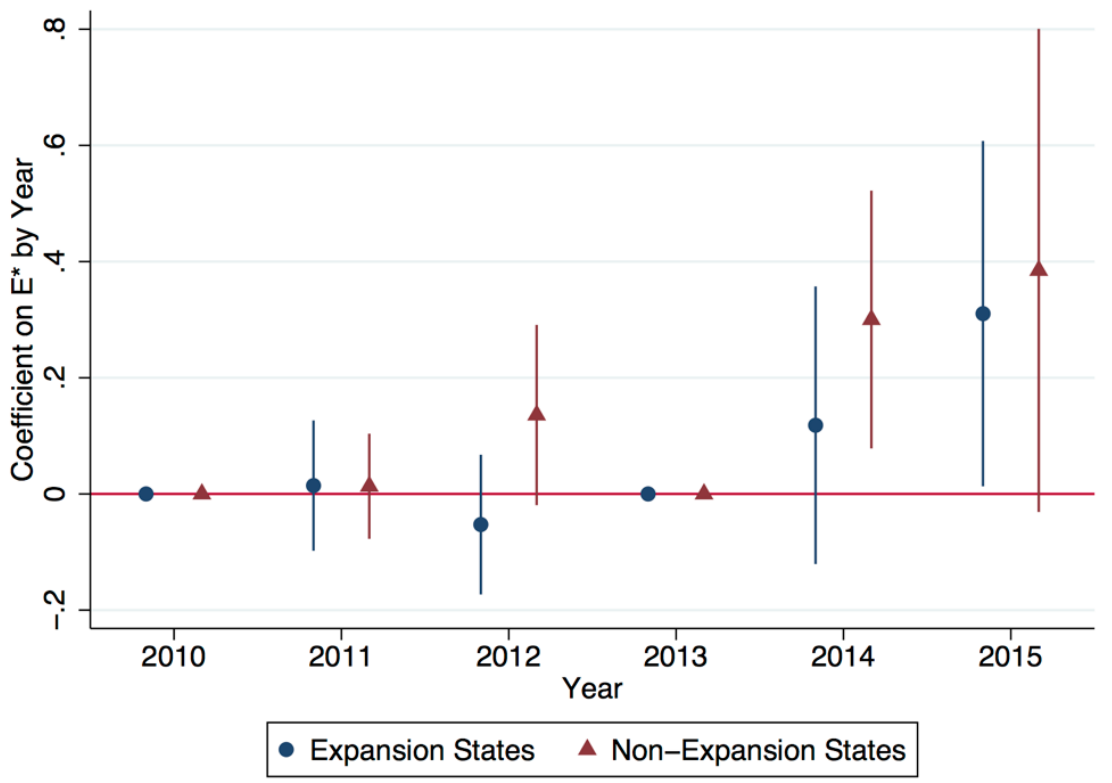

(b) $E^{*}$

Notes: $M^{*}$ refers to the share of individuals in a PUMA that are uninsured and 0-138\% FPL in 2010-13 and $E^{*}$ refers to the share of in a PUMA that are uninsured and 139-399\% FPL in 2010-13. 
Table 1:

Baseline Demographics and Labor Market Outcomes

\begin{tabular}{lcccc}
\hline & \multicolumn{4}{c}{ Ages } \\
\cline { 2 - 5 } & $26-34$ & $35-44$ & $45-54$ & $55-64$ \\
\hline \# of Observations (Unweighted) & $1,280,749$ & $1,497,595$ & $1,818,968$ & $1,729,822$ \\
Female & $50 \%$ & $50 \%$ & $51 \%$ & $52 \%$ \\
White & $72 \%$ & $73 \%$ & $77 \%$ & $81 \%$ \\
Black & $13 \%$ & $13 \%$ & $12 \%$ & $11 \%$ \\
Asian & $7 \%$ & $7 \%$ & $5 \%$ & $4 \%$ \\
Other & $8 \%$ & $7 \%$ & $5 \%$ & $4 \%$ \\
Hispanic & $20 \%$ & $19 \%$ & $13 \%$ & $9 \%$ \\
\% of FPL & $287 \%$ & $309 \%$ & $336 \%$ & $344 \%$ \\
NILF & $18 \%$ & $18 \%$ & $20 \%$ & $36 \%$ \\
Employed & $74 \%$ & $76 \%$ & $74 \%$ & $60 \%$ \\
Self-Employed & $4 \%$ & $7 \%$ & $9 \%$ & $8 \%$ \\
Part-Time & $8 \%$ & $7 \%$ & $7 \%$ & $7 \%$ \\
Hours & 40 & 41 & 41 & 40 \\
Single Coverage & $68 \%$ & $72 \%$ & $74 \%$ & $74 \%$ \\
Double Coverage & $4 \%$ & $6 \%$ & $7 \%$ & $11 \%$ \\
\# of Health Insurance Plans & 0.78 & 0.85 & 0.92 & 1.02 \\
\hline
\end{tabular}

Notes: Baseline summary statistics for years 2010-2013. ACS survey weights used. 
Table 2:

Effect of Potential Medicaid/Exchange Enrollment and Medicaid Expansion on Overall Health Insurance Coverage

\begin{tabular}{|c|c|c|c|c|c|c|c|c|}
\hline VARIABLES & $\begin{array}{c}(1) \\
\text { Health } \\
\text { Insurance } \\
\text { Coverage }\end{array}$ & $\begin{array}{c}(2) \\
\text { Health } \\
\text { Insurance } \\
\text { Coverage }\end{array}$ & $\begin{array}{c}(3) \\
\text { Medicaid } \\
\text { Coverage }\end{array}$ & $\begin{array}{c}(4) \\
\text { Medicaid } \\
\text { Coverage }\end{array}$ & $\begin{array}{c}\text { (5) } \\
\text { Private } \\
\text { Purchase }\end{array}$ & $\begin{array}{c}\text { (6) } \\
\text { Private } \\
\text { Purchase } \\
\end{array}$ & $\begin{array}{c}(7) \\
\text { Private } \\
\text { Employer }\end{array}$ & $\begin{array}{c}\text { (8) } \\
\text { Private } \\
\text { Employer }\end{array}$ \\
\hline Post $\mathrm{x} \mathrm{M}^{*}$ & $\begin{array}{c}0.0361 \\
(0.0926)\end{array}$ & $\begin{array}{c}0.0244 \\
(0.0718)\end{array}$ & $\begin{array}{c}0.0536 \\
(0.1013)\end{array}$ & $\begin{array}{c}0.0877 * * \\
(0.0426)\end{array}$ & $\begin{array}{l}-0.0107 \\
(0.0264)\end{array}$ & $\begin{array}{c}-0.0826 * \\
(0.0442)\end{array}$ & $\begin{array}{c}0.0280 \\
(0.0476)\end{array}$ & $\begin{array}{c}0.0611 \\
(0.0911)\end{array}$ \\
\hline Post x E* & $\begin{array}{c}0.3389 * * * \\
(0.1100)\end{array}$ & $\begin{array}{c}0.2463 * * \\
(0.0956)\end{array}$ & $\begin{array}{c}0.0061 \\
(0.1617)\end{array}$ & $\begin{array}{c}-0.1702 * * * \\
(0.0568)\end{array}$ & $\begin{array}{c}0.1949 * * \\
(0.0738)\end{array}$ & $\begin{array}{c}0.3260 * * \\
(0.1333)\end{array}$ & $\begin{array}{c}0.1070 * * \\
(0.0532)\end{array}$ & $\begin{array}{c}0.0707 \\
(0.0873)\end{array}$ \\
\hline Expansion $\mathrm{x}$ Post & & $\begin{array}{c}2.2653 * * * \\
(0.2879)\end{array}$ & & $\begin{array}{c}3.3507 * * * \\
(0.2918)\end{array}$ & & $\begin{array}{c}-0.4964 * * \\
(0.2192)\end{array}$ & & $\begin{array}{l}-0.2180 \\
(0.1913)\end{array}$ \\
\hline Expansion x Post x $M^{*}$ & & $\begin{array}{c}0.3709 * * \\
(0.1395)\end{array}$ & & $\begin{array}{c}0.4318^{* * * *} \\
(0.1518)\end{array}$ & & $\begin{array}{c}0.0775 \\
(0.0547)\end{array}$ & & $\begin{array}{l}-0.1043 \\
(0.1021)\end{array}$ \\
\hline Expansion $\mathrm{x}$ Post $\mathrm{x} \mathrm{E}^{*}$ & & $\begin{array}{l}-0.0589 \\
(0.1403)\end{array}$ & & $\begin{array}{c}0.0040 \\
(0.1436)\end{array}$ & & $\begin{array}{l}-0.2045 \\
(0.1391)\end{array}$ & & $\begin{array}{c}0.0953 \\
(0.1058)\end{array}$ \\
\hline Observations & $9,493,231$ & $9,493,231$ & $9,493,231$ & $9,493,231$ & $9,493,231$ & $9,493,231$ & $9,493,231$ & $9,493,231$ \\
\hline R-squared & 1.0000 & 1.0000 & 0.9993 & 0.9993 & 0.9991 & 0.9991 & 0.9999 & 0.9999 \\
\hline Pre-ACA Dependent Var Mean & 79.88 & 79.88 & 10.53 & 10.53 & 9.31 & 9.31 & 60.75 & 60.75 \\
\hline Non-Expansion States & 77.98 & 77.98 & 9.20 & 9.20 & 9.32 & 9.32 & 59.54 & 59.54 \\
\hline Expansion States & 81.74 & 81.74 & 11.83 & 11.83 & 9.31 & 9.31 & 61.94 & 61.94 \\
\hline
\end{tabular}

Notes: $\mathrm{M}^{*}$ refers to the share of individuals in a PUMA that are uninsured and within 0-138\% FPL in $2010-13$ and E* refers to the share of individuals in a PUMA that are uninsured and within 139-399\% FPL in 2010-13. All shares $\mathrm{M}^{*}$ and $\mathrm{E}^{*}$ are standardized to have a mean of 0 . Sample includes civilians ages $26-64$ in the years 2010-2015. Robust standard errors are in parentheses and are clustered by state $(* * * \mathrm{p}<0.01, * * \mathrm{p}<0.05, * \mathrm{p}<0.1)$. Controls include demographic controls (female, black, white, asian, other, hispanic), year FEs, age FEs, PUMA FEs, and PUMA-specific time trends. 


\section{Table 3: Heterogeneity in Effect of Potential Medicaid/Exchange Enrollment and Medicaid Expansion on Health Insurance Coverage by Observable Characteristics}

\begin{tabular}{|c|c|c|c|c|c|c|}
\hline VARIABLES & $\begin{array}{c}\text { (1) } \\
\text { Non-minority }\end{array}$ & $\begin{array}{c}\text { (2) } \\
\text { Minority }\end{array}$ & $\begin{array}{c}\text { (3) } \\
\text { Childless } \\
\text { Adult }\end{array}$ & $\begin{array}{c}(4) \\
\text { Has Child } \\
\text { Under } 18\end{array}$ & $\begin{array}{c}\text { (5) } \\
\text { HSG or less }\end{array}$ & $\begin{array}{c}\text { (6) } \\
\text { Some College } \\
\text { or More }\end{array}$ \\
\hline Post x M* & $\begin{array}{c}0.0533 \\
(0.0961)\end{array}$ & $\begin{array}{l}-0.0634 \\
(0.1034)\end{array}$ & $\begin{array}{c}0.0270 \\
(0.0862)\end{array}$ & $\begin{array}{c}0.0002 \\
(0.1217)\end{array}$ & $\begin{array}{c}-0.0455 \\
(0.1080)\end{array}$ & $\begin{array}{c}0.0626 \\
(0.0579)\end{array}$ \\
\hline Post $x E^{*}$ & $\begin{array}{c}0.1143 \\
(0.0880)\end{array}$ & $\begin{array}{c}0.2896 \\
(0.1763)\end{array}$ & $\begin{array}{c}0.2093 \\
(0.1338)\end{array}$ & $\begin{array}{c}0.3451^{* * *} \\
(0.1206)\end{array}$ & $\begin{array}{c}0.2911 * * \\
(0.1287)\end{array}$ & $\begin{array}{c}0.1990 * * \\
(0.0912)\end{array}$ \\
\hline Expansion x Post & $\begin{array}{c}2.1164 * * * \\
(0.2952)\end{array}$ & $\begin{array}{c}2.1588 * * * \\
(0.6043)\end{array}$ & $\begin{array}{c}2.5621 * * * \\
(0.3314)\end{array}$ & $\begin{array}{c}1.6543 * * * \\
(0.4012)\end{array}$ & $\begin{array}{c}3.3077 * * * \\
(0.5775)\end{array}$ & $\begin{array}{c}1.4321 * * * \\
(0.2280)\end{array}$ \\
\hline Expansion $x$ Post $x M^{*}$ & $\begin{array}{c}0.4443 * * \\
(0.1932)\end{array}$ & $\begin{array}{c}0.4127 * * \\
(0.1604)\end{array}$ & $\begin{array}{c}0.2985^{*} \\
(0.1537)\end{array}$ & $\begin{array}{c}0.5100 * * * \\
(0.1875)\end{array}$ & $\begin{array}{c}0.4288^{*} \\
(0.2266)\end{array}$ & $\begin{array}{c}0.2684 * * * \\
(0.0958)\end{array}$ \\
\hline Expansion X Post $\mathrm{x}$ E* & $\begin{array}{c}-0.0682 \\
(0.1716)\end{array}$ & $\begin{array}{l}-0.1551 \\
(0.1943)\end{array}$ & $\begin{array}{c}0.0886 \\
(0.1745)\end{array}$ & $\begin{array}{c}-0.3671 * * \\
(0.1816)\end{array}$ & $\begin{array}{c}-0.1472 \\
(0.2077)\end{array}$ & $\begin{array}{l}-0.0060 \\
(0.1145)\end{array}$ \\
\hline $\begin{array}{l}\text { Observations } \\
\text { R-squared } \\
\text { Pre-ACA DV Mean } \\
\quad \text { Non-Exp States } \\
\quad \text { Expansion States } \\
\end{array}$ & $\begin{array}{c}6,537,661 \\
1.0000 \\
85.56 \\
83.85 \\
87.35 \\
\end{array}$ & $\begin{array}{c}2,955,570 \\
1.0000 \\
69.39 \\
65.85 \\
72.39 \\
\end{array}$ & $\begin{array}{c}6,266,853 \\
1.0000 \\
78.07 \\
76.43 \\
79.68 \\
\end{array}$ & $\begin{array}{c}3,226,378 \\
1.0000 \\
83.19 \\
80.82 \\
85.50 \\
\end{array}$ & $\begin{array}{c}3,602,122 \\
1.0000 \\
68.73 \\
66.79 \\
70.80 \\
\end{array}$ & $\begin{array}{c}5,891,109 \\
1.0000 \\
87.03 \\
85.69 \\
88.26 \\
\end{array}$ \\
\hline VARIABLES & Male & $\begin{array}{c}(8) \\
\text { Female } \\
\end{array}$ & $\begin{array}{c}(9) \\
\text { Young } \\
(26-44) \\
\end{array}$ & $\begin{array}{c}(10) \\
\text { Near Elderly } \\
(45-64) \\
\end{array}$ & $\begin{array}{c}(11) \\
\text { Married }\end{array}$ & $\begin{array}{c}\text { (12) } \\
\text { Not Married } \\
\end{array}$ \\
\hline Post x M* & $\begin{array}{c}0.0118 \\
(0.0841)\end{array}$ & $\begin{array}{c}0.0358 \\
(0.0911)\end{array}$ & $\begin{array}{c}0.0393 \\
(0.0883)\end{array}$ & $\begin{array}{c}0.0118 \\
(0.0756)\end{array}$ & $\begin{array}{c}-0.0099 \\
(0.0636)\end{array}$ & $\begin{array}{c}0.0103 \\
(0.1056)\end{array}$ \\
\hline Post $x E^{*}$ & $\begin{array}{c}0.2743 * * * \\
(0.0921)\end{array}$ & $\begin{array}{l}0.2194^{*} \\
(0.1262)\end{array}$ & $\begin{array}{c}0.1800^{*} \\
(0.0973)\end{array}$ & $\begin{array}{c}0.3042 * * \\
(0.1158)\end{array}$ & $\begin{array}{c}0.3732 * * * \\
(0.0978)\end{array}$ & $\begin{array}{c}0.1015 \\
(0.1229)\end{array}$ \\
\hline Expansion x Post & $\begin{array}{c}2.4995 * * * \\
(0.3116)\end{array}$ & $\begin{array}{c}2.0416 * * * \\
(0.3289)\end{array}$ & $\begin{array}{c}2.4688^{* * *} * \\
(0.3922)\end{array}$ & $\begin{array}{c}2.0734^{* * *} \\
(0.2483)\end{array}$ & $\begin{array}{c}1.6641 * * * \\
(0.2761)\end{array}$ & $\begin{array}{c}2.8224 * * * \\
(0.5191)\end{array}$ \\
\hline Expansion $\mathrm{x}$ Post $\mathrm{x} \mathrm{M}^{*}$ & $\begin{array}{c}0.2745^{*} \\
(0.1391)\end{array}$ & $\begin{array}{c}0.4696 * * * \\
(0.1719)\end{array}$ & $\begin{array}{c}0.3695 * * \\
(0.1629)\end{array}$ & $\begin{array}{c}0.3645 * * \\
(0.1405)\end{array}$ & $\begin{array}{c}0.3501 * * * \\
(0.1110)\end{array}$ & $\begin{array}{l}0.3649 * \\
(0.2097)\end{array}$ \\
\hline Expansion X Post $\mathrm{x}$ E* & $\begin{array}{c}0.0368 \\
(0.1381)\end{array}$ & $\begin{array}{l}-0.1567 \\
(0.1739)\end{array}$ & $\begin{array}{l}-0.0650 \\
(0.1512)\end{array}$ & $\begin{array}{l}-0.0466 \\
(0.1636)\end{array}$ & $\begin{array}{l}-0.1410 \\
(0.1344)\end{array}$ & $\begin{array}{c}0.0459 \\
(0.2016)\end{array}$ \\
\hline Observations & $4,629,672$ & $4,863,559$ & $4,167,626$ & $5,325,605$ & $5,875,157$ & $3,618,074$ \\
\hline R-squared & 1.0000 & 1.0000 & 1.0000 & 1.0000 & 1.0000 & 1.0000 \\
\hline Pre-ACA DV Mean & 77.53 & 82.16 & 75.25 & 84.26 & 86.02 & 71.17 \\
\hline Non-Exp States & 75.75 & 80.13 & 72.79 & 82.82 & 84.75 & 68.16 \\
\hline Expansion States & 79.25 & 84.16 & 77.61 & 85.68 & 87.29 & 74.02 \\
\hline
\end{tabular}

Notes: Dependent variable is health insurance coverage and each column corresponds to a separate subsample. "Nonminority" indicates white non-Hispanic. "Has Child Under 18" refers to individuals with at least one child living in the same household who is under 18. "HSG or less" indicates that a high-school degree (including GED) or less is the highest educational attainment. "Male" refers to gender. "Young" are ages 26-44. "Married" refers to marital status. $M^{*}$ refers to the share of individuals in a PUMA that are uninsured and within 0-138\% FPL in 2010-13 and $E^{*}$ refers to the share of individuals in a PUMA that are uninsured and within 139-399\% FPL in 2010-13. All shares $M^{*}$ and $E^{*}$ are standardized to have a mean of 0 . Robust standard errors are in parentheses and are clustered by state $(* * *$ $\mathrm{p}<0.01, * * \mathrm{p}<0.05, * \mathrm{p}<0.1)$. Controls include demographic controls (female, black, white, asian, other, hispanic), year FEs, age FEs, PUMA FEs, and PUMA-specific time trends. 
Table 4: Effect of Potential Medicaid/Exchange Enrollment and Medicaid Expansion on Labor Market Outcomes: Extensive Margin

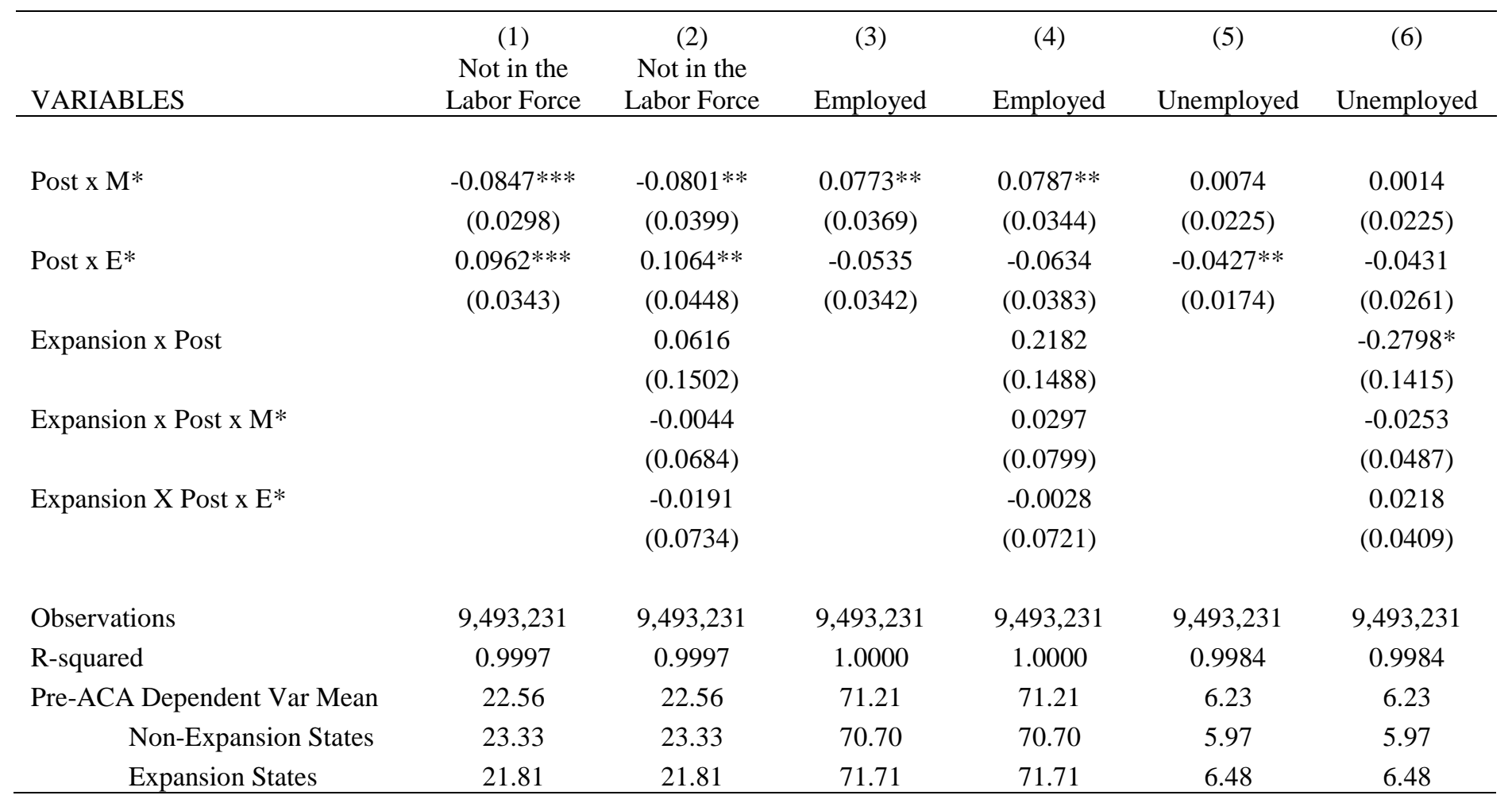

Notes: $M^{*}$ refers to the share of individuals in a PUMA that are uninsured and within $0-138 \%$ FPL in $2010-13$ and $E^{*}$ refers to the share of individuals in a PUMA that are uninsured and within 139-399\% FPL in 2010-13. All shares $M^{*}$ and $E^{*}$ are demeaned to have a mean of 0. Sample includes civilians ages 26-64 in the years 2010-2015. Robust standard errors are in parentheses and are clustered by state $(* * * \mathrm{p}<0.01, * * \mathrm{p}<0.05, * \mathrm{p}<0.1)$. Controls include demographic controls (female, black, white, asian, other, hispanic), year FEs, age FEs, PUMA FEs, and PUMA-specific time trends. 
Table 5: Effect of Potential Medicaid/Exchange Enrollment and Medicaid Expansion on Labor Market Outcomes: Intensive Margin

\begin{tabular}{|c|c|c|c|c|c|c|}
\hline VARIABLES & $\begin{array}{c}\text { (1) } \\
\text { Part-Time }\end{array}$ & $\begin{array}{c}\text { (2) } \\
\text { Part-Time }\end{array}$ & $\begin{array}{c}(3) \\
\text { Self- } \\
\text { Employed } \\
\end{array}$ & $\begin{array}{c}(4) \\
\text { Self- } \\
\text { Employed } \\
\end{array}$ & Hours & $\begin{array}{c}(6) \\
\text { Hours } \\
\end{array}$ \\
\hline Post x $\mathrm{M}^{*}$ & $\begin{array}{c}0.0363 \\
(0.0238)\end{array}$ & $\begin{array}{c}0.0321 \\
(0.0351)\end{array}$ & $\begin{array}{c}0.0078 \\
(0.0221)\end{array}$ & $\begin{array}{l}-0.0023 \\
(0.0289)\end{array}$ & $\begin{array}{c}0.0013 \\
(0.0117)\end{array}$ & $\begin{array}{c}0.0143 \\
(0.0171)\end{array}$ \\
\hline Post $\mathrm{x} \mathrm{E}^{*}$ & $\begin{array}{l}-0.0375 \\
(0.0261)\end{array}$ & $\begin{array}{l}-0.0085 \\
(0.0384)\end{array}$ & $\begin{array}{l}-0.0122 \\
(0.0302)\end{array}$ & $\begin{array}{c}0.0052 \\
(0.0421)\end{array}$ & $\begin{array}{l}-0.0030 \\
(0.0110)\end{array}$ & $\begin{array}{l}-0.0332 \\
(0.0223)\end{array}$ \\
\hline Expansion $\mathrm{x}$ Post & & $\begin{array}{l}-0.0984 \\
(0.0926)\end{array}$ & & $\begin{array}{l}-0.0399 \\
(0.0765)\end{array}$ & & $\begin{array}{c}0.0575 \\
(0.0462)\end{array}$ \\
\hline Expansion x Post x M* & & $\begin{array}{l}-0.0094 \\
(0.0496)\end{array}$ & & $\begin{array}{c}0.0154 \\
(0.0442)\end{array}$ & & $\begin{array}{l}-0.0168 \\
(0.0217)\end{array}$ \\
\hline $\begin{array}{l}\text { R-squared } \\
\text { Pre-ACA Dependent Var Mean }\end{array}$ & $\begin{array}{c}0.9988 \\
7.19\end{array}$ & $\begin{array}{c}0.9988 \\
7.19\end{array}$ & $\begin{array}{c}0.9988 \\
7.26\end{array}$ & $\begin{array}{c}0.9988 \\
7.26\end{array}$ & $\begin{array}{l}1.0000 \\
40.65\end{array}$ & $\begin{array}{l}1.0000 \\
40.65\end{array}$ \\
\hline Non-Expansion States & 6.73 & 6.73 & 7.08 & 7.08 & 40.97 & 40.97 \\
\hline Expansion States & 7.64 & 7.64 & 7.44 & 7.44 & 40.34 & 40.34 \\
\hline
\end{tabular}

Notes: $M^{*}$ refers to the share of individuals in a PUMA that are uninsured and within 0-138\% FPL in 2010-13 and $E^{*}$ refers to the share of individuals in a PUMA that are uninsured and within 139-399\% FPL in 2010-13. All shares $M^{*}$ and $E^{*}$ are demeaned to have a mean of 0 . Sample includes civilians ages $26-64$ in the years 2010-2015. Robust standard errors are in parentheses and are clustered by state $(* * * \mathrm{p}<0.01, * * \mathrm{p}<0.05, * \mathrm{p}<0.1)$. Controls include demographic controls (female, black, white, asian, other, hispanic), year FEs, age FEs, PUMA FEs, and PUMA-specific time trends. 
Table 6: Effect of Potential Medicaid/Exchange Enrollment and Medicaid Expansion on Labor Market Outcomes: Pooled Income Groups

\begin{tabular}{|c|c|c|c|c|c|c|}
\hline VARIABLES & $\begin{array}{c}(1) \\
\text { Not in the } \\
\text { Labor Force }\end{array}$ & $\begin{array}{c}(2) \\
\text { Not in the } \\
\text { Labor Force }\end{array}$ & $\begin{array}{c}(3) \\
\text { Employed } \\
\end{array}$ & $\begin{array}{c}\text { (4) } \\
\text { Employed } \\
\end{array}$ & $\begin{array}{c}\text { (5) } \\
\text { Unemployed } \\
\end{array}$ & $\begin{array}{c}\text { (6) } \\
\text { Unemployed }\end{array}$ \\
\hline Post $x\left(E^{*}+M^{*}\right)$ & $\begin{array}{c}0.0001 \\
(0.0068)\end{array}$ & $\begin{array}{c}0.0054 \\
(0.0090)\end{array}$ & $\begin{array}{l}0.0160 * \\
(0.0094)\end{array}$ & $\begin{array}{c}0.0136 \\
(0.0082)\end{array}$ & $\begin{array}{c}-0.0161 * \\
(0.0082)\end{array}$ & $\begin{array}{c}-0.0190 * * \\
(0.0085)\end{array}$ \\
\hline Expansion $x$ Post $x\left(E^{*}+M^{*}\right)$ & & $\begin{array}{l}-0.0057 \\
(0.0128)\end{array}$ & & $\begin{array}{c}0.0093 \\
(0.0149)\end{array}$ & & $\begin{array}{l}-0.0036 \\
(0.0133)\end{array}$ \\
\hline Observations & $9,493,231$ & $9,493,231$ & $9,493,231$ & $9,493,231$ & $9,493,231$ & $9,493,231$ \\
\hline Expansion States & 21.81 & 21.81 & 71.71 & 71.71 & 6.48 & 6.48 \\
\hline
\end{tabular}

Notes: $\left(\mathrm{E}^{*}+\mathrm{M}^{*}\right)$ refers to the share of individuals in a PUMA that are uninsured and $0-399 \%$ FPL in $2010-13$. All shares are standardized to have a mean of 0 . Sample includes civilians ages 26-64 in the years 2010-2015. Robust standard errors are in parentheses and are clustered by state $(* * * \mathrm{p}<0.01, * * \mathrm{p}<0.05, * \mathrm{p}<0.1)$. Controls include demographic controls (female, black, white, asian, other, hispanic), year FEs, age FEs, PUMA FEs, and PUMA-specific time trends. 


\section{Table 7: Effect of Potential Medicaid/Exchange Enrollment and}

Medicaid Expansion on Not in the Labor Force by Observable Characteristics

\begin{tabular}{|c|c|c|c|c|c|c|}
\hline VARIABLES & $\begin{array}{c}(1) \\
\text { Non-minority }\end{array}$ & $\begin{array}{c}\text { (2) } \\
\text { Minority }\end{array}$ & $\begin{array}{c}\text { (3) } \\
\text { Childless } \\
\text { Adult }\end{array}$ & $\begin{array}{c}(4) \\
\text { Has Child } \\
\text { Under } 18\end{array}$ & $\begin{array}{c}\text { (5) } \\
\text { HSG or less }\end{array}$ & $\begin{array}{c}\text { (6) } \\
\text { Some College } \\
\text { or More }\end{array}$ \\
\hline Post x M* & $\begin{array}{l}-0.0290 \\
(0.0481)\end{array}$ & $\begin{array}{c}-0.1268 * * \\
(0.0630)\end{array}$ & $\begin{array}{c}-0.1312 * * * \\
(0.0470)\end{array}$ & $\begin{array}{c}0.0254 \\
(0.0553)\end{array}$ & $\begin{array}{l}-0.0648 \\
(0.0629)\end{array}$ & $\begin{array}{c}-0.1184 * * \\
(0.0529)\end{array}$ \\
\hline Post $x E^{*}$ & $\begin{array}{c}0.0308 \\
(0.0414)\end{array}$ & $\begin{array}{c}0.1924 * * \\
(0.0797)\end{array}$ & $\begin{array}{c}0.1355^{* * *} \\
(0.0462)\end{array}$ & $\begin{array}{c}0.0253 \\
(0.0715)\end{array}$ & $\begin{array}{c}0.1174 \\
(0.0819)\end{array}$ & $\begin{array}{c}0.1337 * * \\
(0.0635)\end{array}$ \\
\hline Expansion x Post & $\begin{array}{c}0.0657 \\
(0.2041)\end{array}$ & $\begin{array}{c}0.0926 \\
(0.2104)\end{array}$ & $\begin{array}{c}0.1379 \\
(0.1851)\end{array}$ & $\begin{array}{c}-0.0999 \\
(0.1918)\end{array}$ & $\begin{array}{c}0.1825 \\
(0.2382)\end{array}$ & $\begin{array}{c}0.0182 \\
(0.1649)\end{array}$ \\
\hline Expansion x Post x M* & $\begin{array}{l}-0.0590 \\
(0.0981)\end{array}$ & $\begin{array}{c}0.0450 \\
(0.0787)\end{array}$ & $\begin{array}{c}0.0105 \\
(0.0864)\end{array}$ & $\begin{array}{c}-0.0396 \\
(0.0940)\end{array}$ & $\begin{array}{l}-0.0516 \\
(0.0854)\end{array}$ & $\begin{array}{c}0.0461 \\
(0.0921)\end{array}$ \\
\hline Expansion X Post $\mathrm{x} \mathrm{E}^{*}$ & $\begin{array}{c}0.0523 \\
(0.1058)\end{array}$ & $\begin{array}{c}-0.0943 \\
(0.0946)\end{array}$ & $\begin{array}{c}-0.0264 \\
(0.0863)\end{array}$ & $\begin{array}{c}0.0223 \\
(0.1112)\end{array}$ & $\begin{array}{c}0.0331 \\
(0.1011)\end{array}$ & $\begin{array}{c}-0.0989 \\
(0.0950)\end{array}$ \\
\hline $\begin{array}{l}\text { Observations } \\
\text { R-squared } \\
\text { Pre-ACA DV Mean } \\
\quad \text { Non-Exp States } \\
\quad \text { Expansion States } \\
\end{array}$ & $\begin{array}{c}6,537,661 \\
0.9996 \\
21.58 \\
22.34 \\
20.78 \\
\end{array}$ & $\begin{array}{c}2,955,570 \\
0.9998 \\
24.38 \\
25.39 \\
23.52 \\
\end{array}$ & $\begin{array}{c}6,266,853 \\
0.9997 \\
25.39 \\
26.61 \\
24.21 \\
\end{array}$ & $\begin{array}{c}3,226,378 \\
0.9996 \\
17.38 \\
17.32 \\
17.43 \\
\end{array}$ & $\begin{array}{c}3,602,122 \\
0.9998 \\
30.60 \\
31.34 \\
29.82 \\
\end{array}$ & $\begin{array}{c}5,891,109 \\
0.9996 \\
17.41 \\
17.82 \\
17.03 \\
\end{array}$ \\
\hline VARIABLES & Male & $\begin{array}{c}(8) \\
\text { Female } \\
\end{array}$ & $\begin{array}{c}(9) \\
\text { Young } \\
(26-44) \\
\end{array}$ & $\begin{array}{c}(10) \\
\text { Near Elderly } \\
(45-64) \\
\end{array}$ & $\begin{array}{c}(11) \\
\text { Married } \\
\end{array}$ & $\begin{array}{c}(12) \\
\text { Not Married }\end{array}$ \\
\hline Post x M* & $\begin{array}{c}-0.1684 * * * \\
(0.0565)\end{array}$ & $\begin{array}{c}0.0014 \\
(0.0875)\end{array}$ & $\begin{array}{l}-0.0910 \\
(0.0797)\end{array}$ & $\begin{array}{l}-0.0669 \\
(0.0456)\end{array}$ & $\begin{array}{c}-0.0954 * * \\
(0.0450)\end{array}$ & $\begin{array}{c}-0.0369 \\
(0.0648)\end{array}$ \\
\hline Post $x E^{*}$ & $\begin{array}{c}0.2211 * * * \\
(0.0607)\end{array}$ & $\begin{array}{l}-0.0043 \\
(0.0908)\end{array}$ & $\begin{array}{c}0.1336 \\
(0.1038)\end{array}$ & $\begin{array}{c}0.0781 \\
(0.0551)\end{array}$ & $\begin{array}{c}0.1426 * * * \\
(0.0512)\end{array}$ & $\begin{array}{c}0.0342 \\
(0.0648)\end{array}$ \\
\hline Expansion x Post & $\begin{array}{l}-0.1475 \\
(0.2045)\end{array}$ & $\begin{array}{c}0.2723 \\
(0.1918)\end{array}$ & $\begin{array}{c}0.0320 \\
(0.2006)\end{array}$ & $\begin{array}{c}0.0801 \\
(0.2076)\end{array}$ & $\begin{array}{l}-0.0047 \\
(0.1553)\end{array}$ & $\begin{array}{c}0.1475 \\
(0.2262)\end{array}$ \\
\hline Expansion x Post $x M^{*}$ & $\begin{array}{c}0.0844 \\
(0.0842)\end{array}$ & $\begin{array}{l}-0.0875 \\
(0.1059)\end{array}$ & $\begin{array}{c}0.0837 \\
(0.1041)\end{array}$ & $\begin{array}{c}-0.0942 \\
(0.1181)\end{array}$ & $\begin{array}{c}0.0152 \\
(0.0862)\end{array}$ & $\begin{array}{c}-0.0353 \\
(0.0921)\end{array}$ \\
\hline Expansion X Post $\mathrm{x}$ E* & $\begin{array}{c}-0.1468 * \\
(0.0871)\end{array}$ & $\begin{array}{c}0.1052 \\
(0.1131)\end{array}$ & $\begin{array}{c}-0.1264 \\
(0.1326)\end{array}$ & $\begin{array}{c}0.0945 \\
(0.1133)\end{array}$ & $\begin{array}{c}-0.0680 \\
(0.0808)\end{array}$ & $\begin{array}{c}0.0551 \\
(0.1035)\end{array}$ \\
\hline Observations & $4,629,672$ & $4,863,559$ & $4,167,626$ & $5,325,605$ & $5,875,157$ & $3,618,074$ \\
\hline R-squared & 0.9996 & 0.9998 & 0.9997 & 0.9997 & 0.9996 & 0.9998 \\
\hline Pre-ACA DV Mean & 17.14 & 27.82 & 17.74 & 27.11 & 21.23 & 24.45 \\
\hline Non-Exp States & 17.94 & 28.53 & 18.12 & 28.19 & 21.77 & 25.60 \\
\hline Expansion States & 16.35 & 27.12 & 17.37 & 26.05 & 20.70 & 23.35 \\
\hline
\end{tabular}

Notes: Dependent variable is not in the labor force and each column corresponds to a separate subsample. "Nonminority" indicates white non-Hispanic. "Has Child Under 18" refers to individuals with at least one child living in the same household who is under 18. "HSG or less" indicates that a high-school degree (including GED) or less is the highest educational attainment. "Male" refers to gender. "Young" are ages 26-44. "Married" refers to marital status. $M^{*}$ refers to the share of individuals in a PUMA that are uninsured and within 0-138\% FPL in 2010-13 and $E^{*}$ refers to the share of individuals in a PUMA that are uninsured and within 139-399\% FPL in 2010-13. All shares $M^{*}$ and $E^{*}$ are standardized to have a mean of 0 . Robust standard errors are in parentheses and are clustered by state $(* * *$ $\mathrm{p}<0.01, * * \mathrm{p}<0.05, * \mathrm{p}<0.1$ ). Controls include demographic controls (female, black, white, asian, other, hispanic), year FEs, age FEs, PUMA FEs, and PUMA-specific time trends. 


\section{Appendix A: Additional Tables and Figures}

Figure A.1

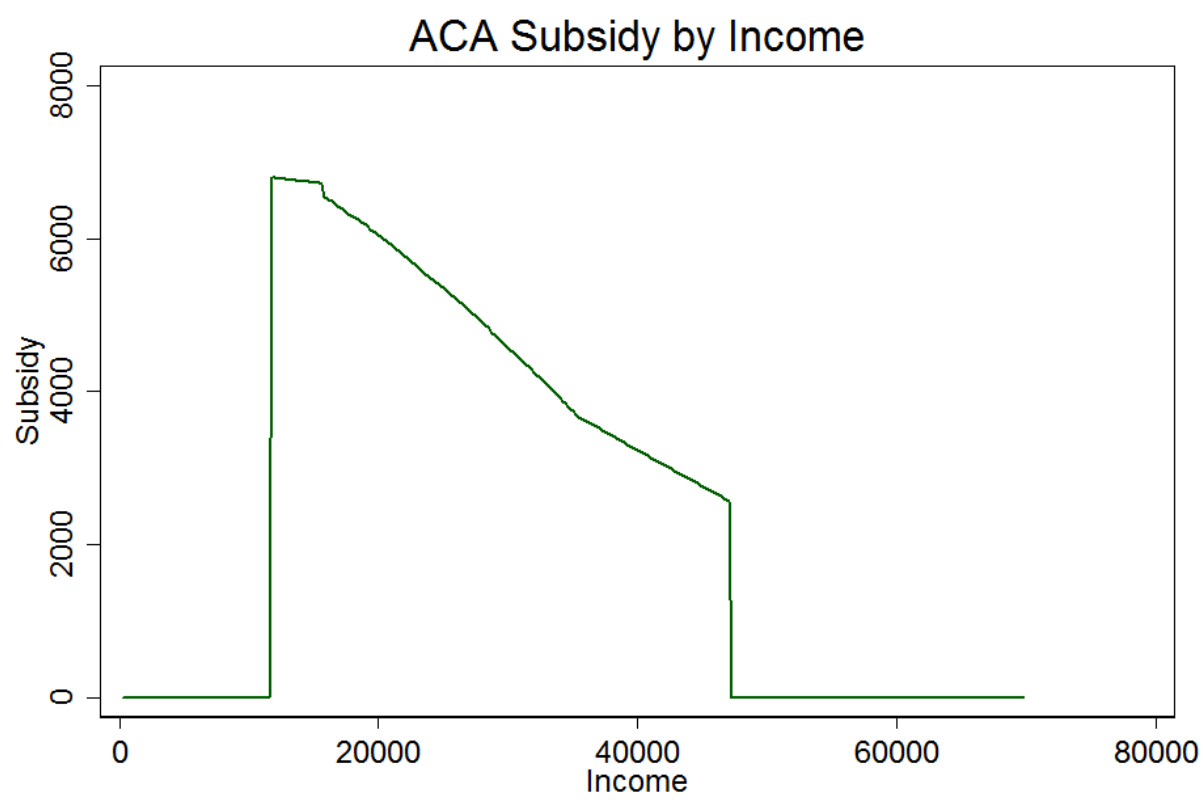

Note: Subsidy calculated for single 60-year-old in 2015.

Figure A.2

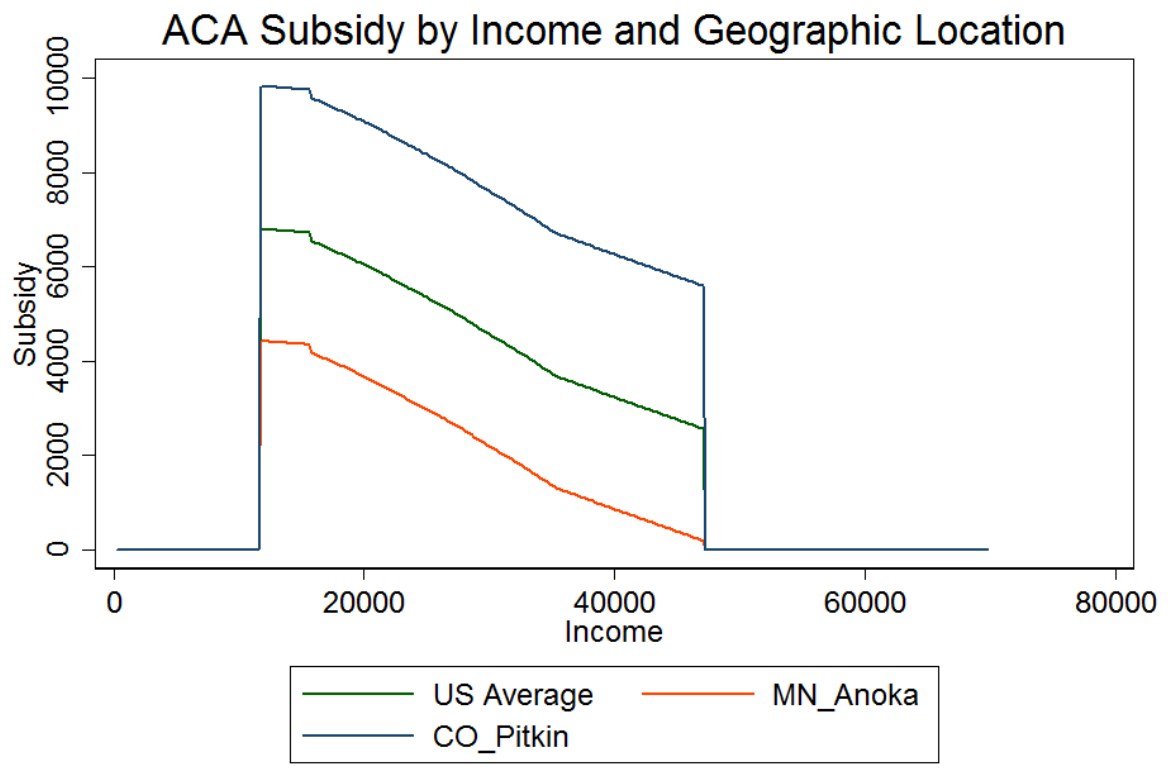

Note: Subsidy calculated for single 60-year-old in 2015 for all scenarios. 


\section{Figure A.3}

Change in Medicaid Coverage by $M^{*}, E^{*}$, and Medicaid Expansion Status
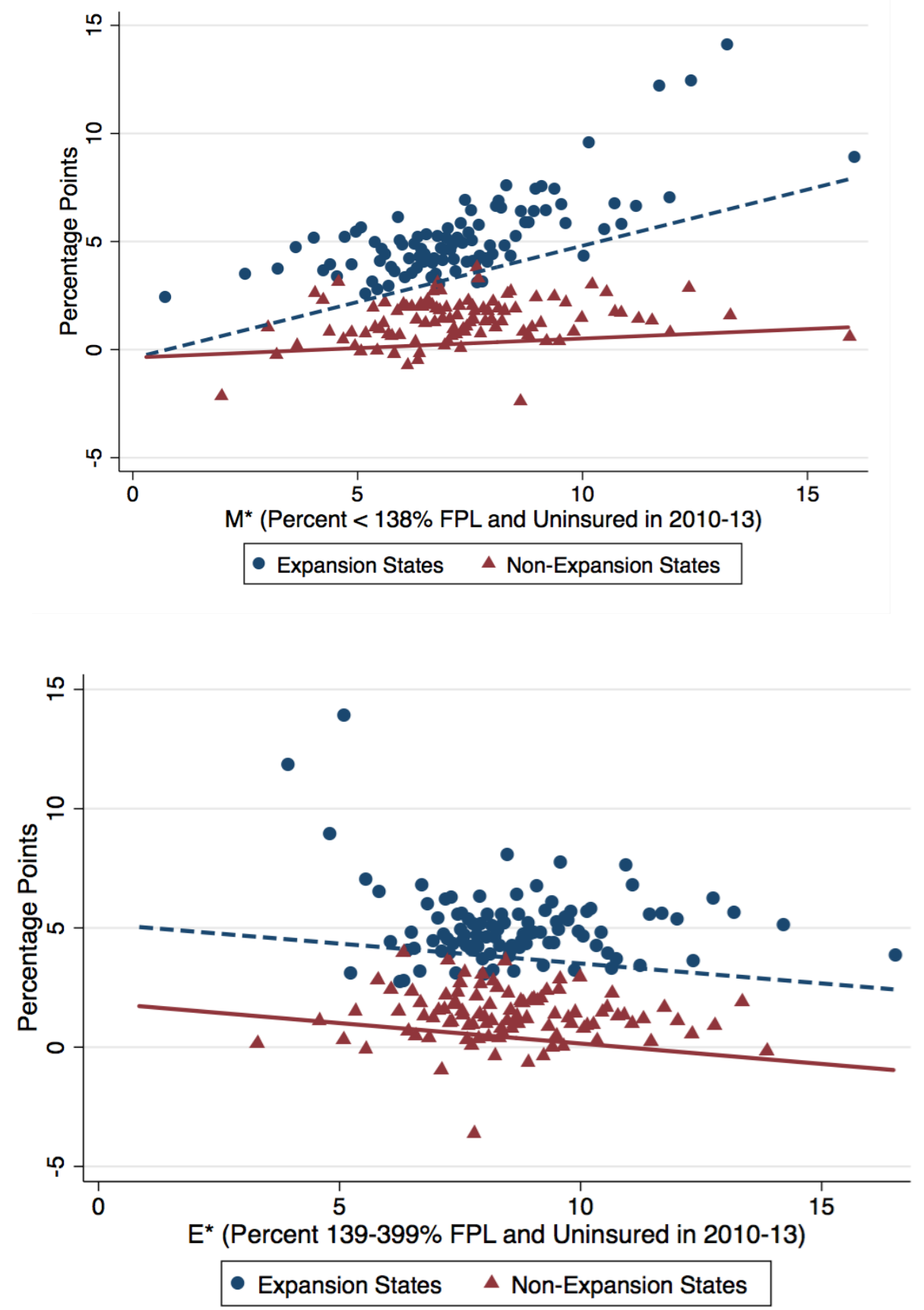


\section{Figure A.4}

Change in Privately-Purchased Coverage by $M^{*}, E^{*}$, and Medicaid Expansion Status
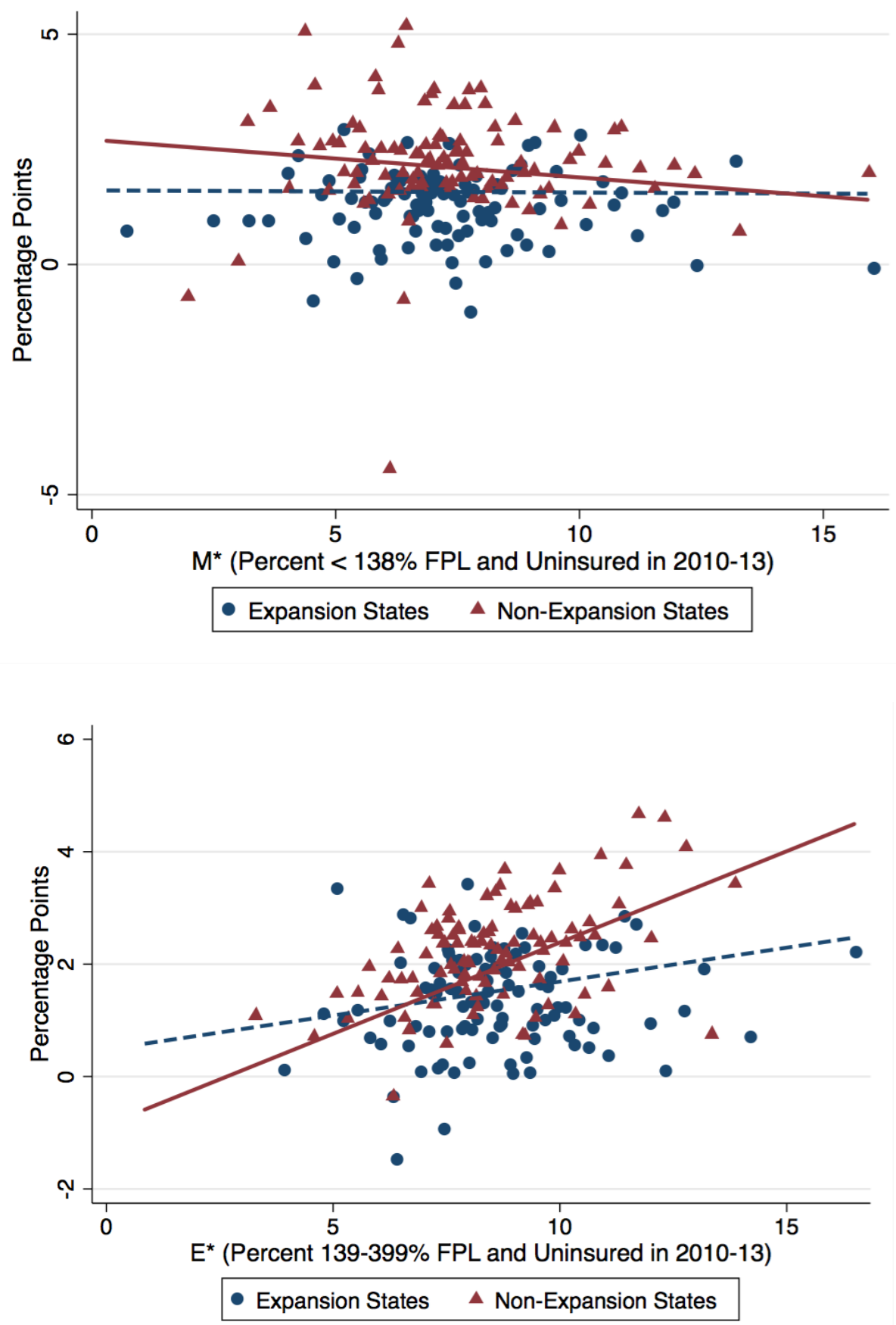


\section{Figure A.5}

Change in Private Employer Coverage by $M^{*}, E^{*}$, and Medicaid Expansion Status
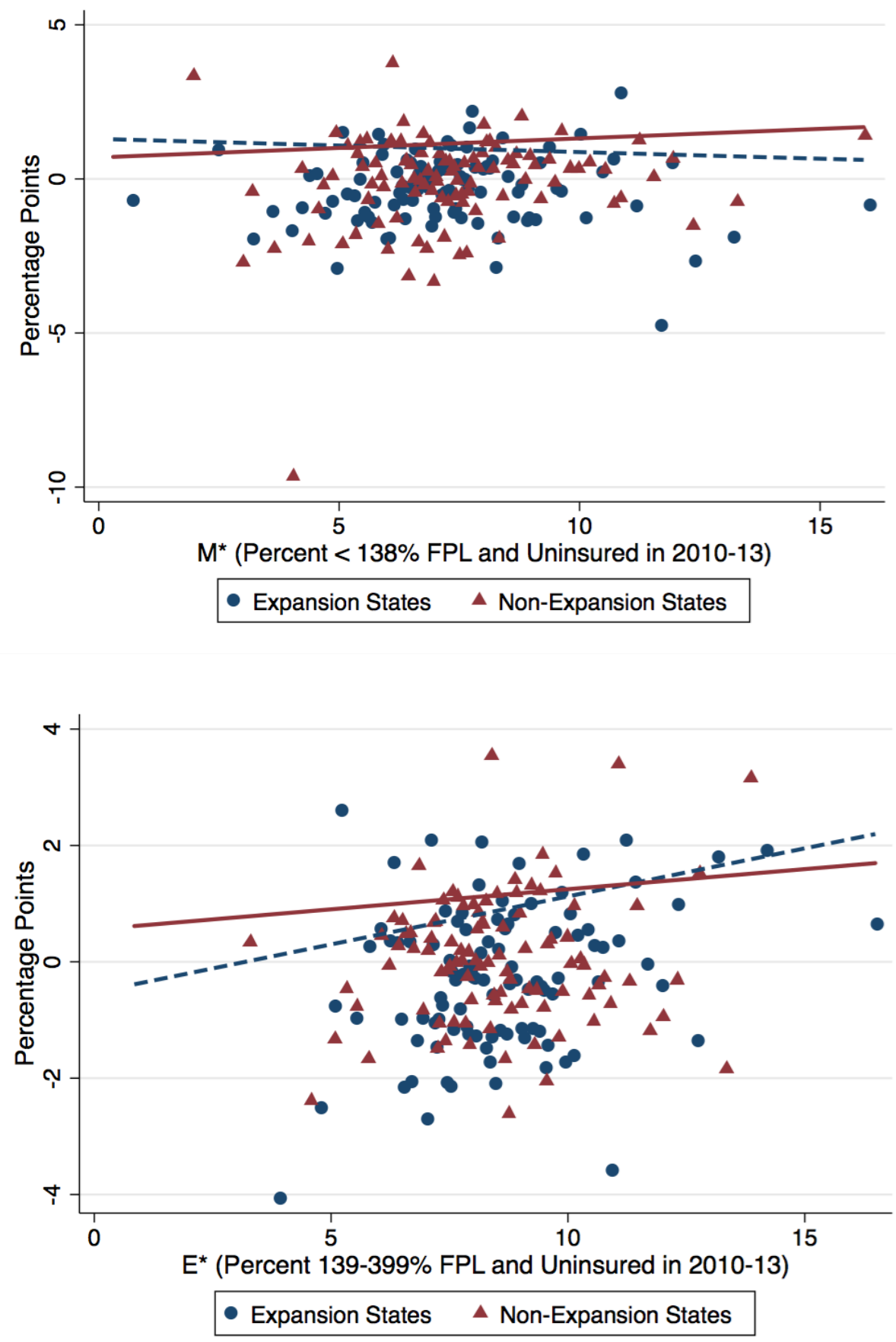


\section{Figure A.6}

Relationship between $M^{*}, E^{*}$ and Medicaid Coverage by Year and Medicaid Expansion Status

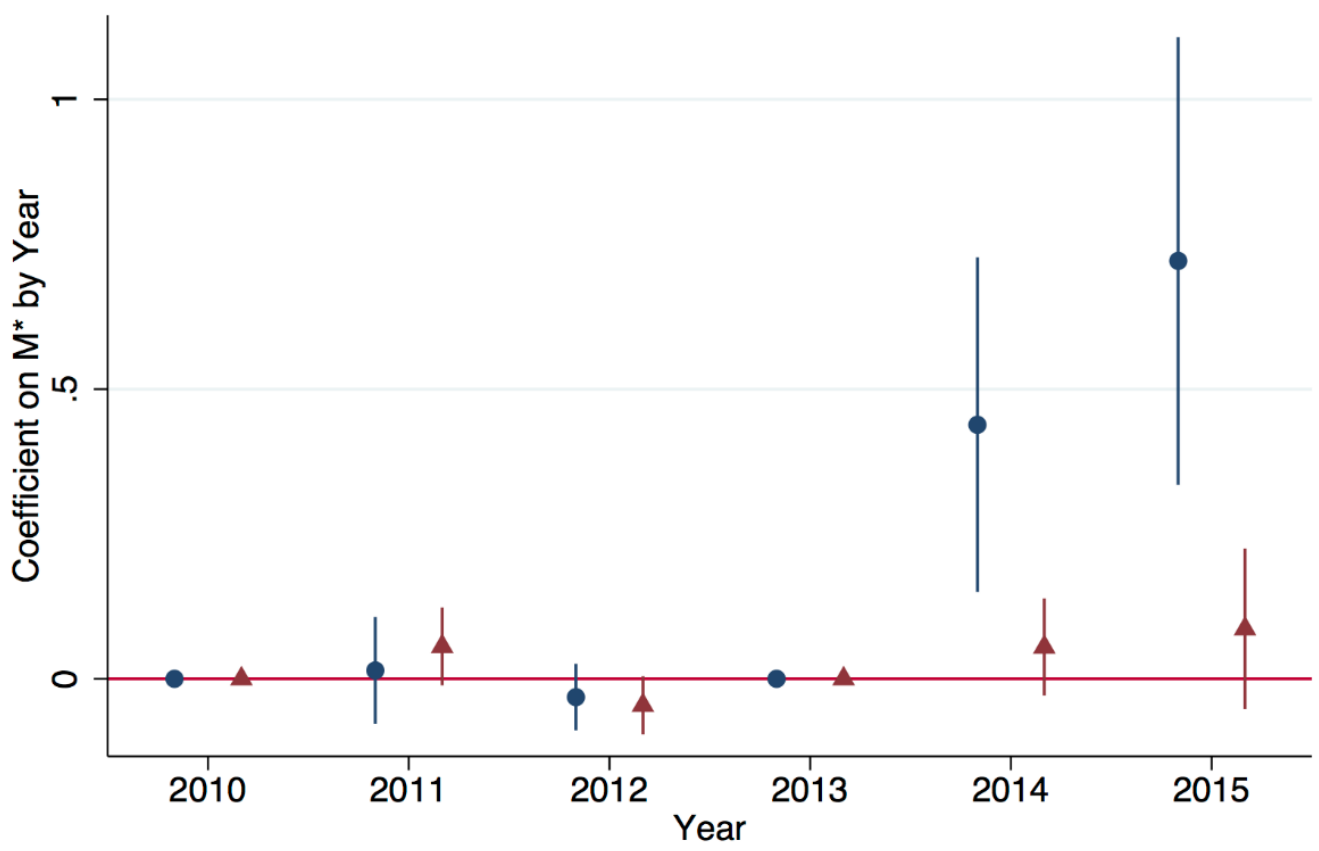

- Expansion States $\Delta$ Non-Expansion States

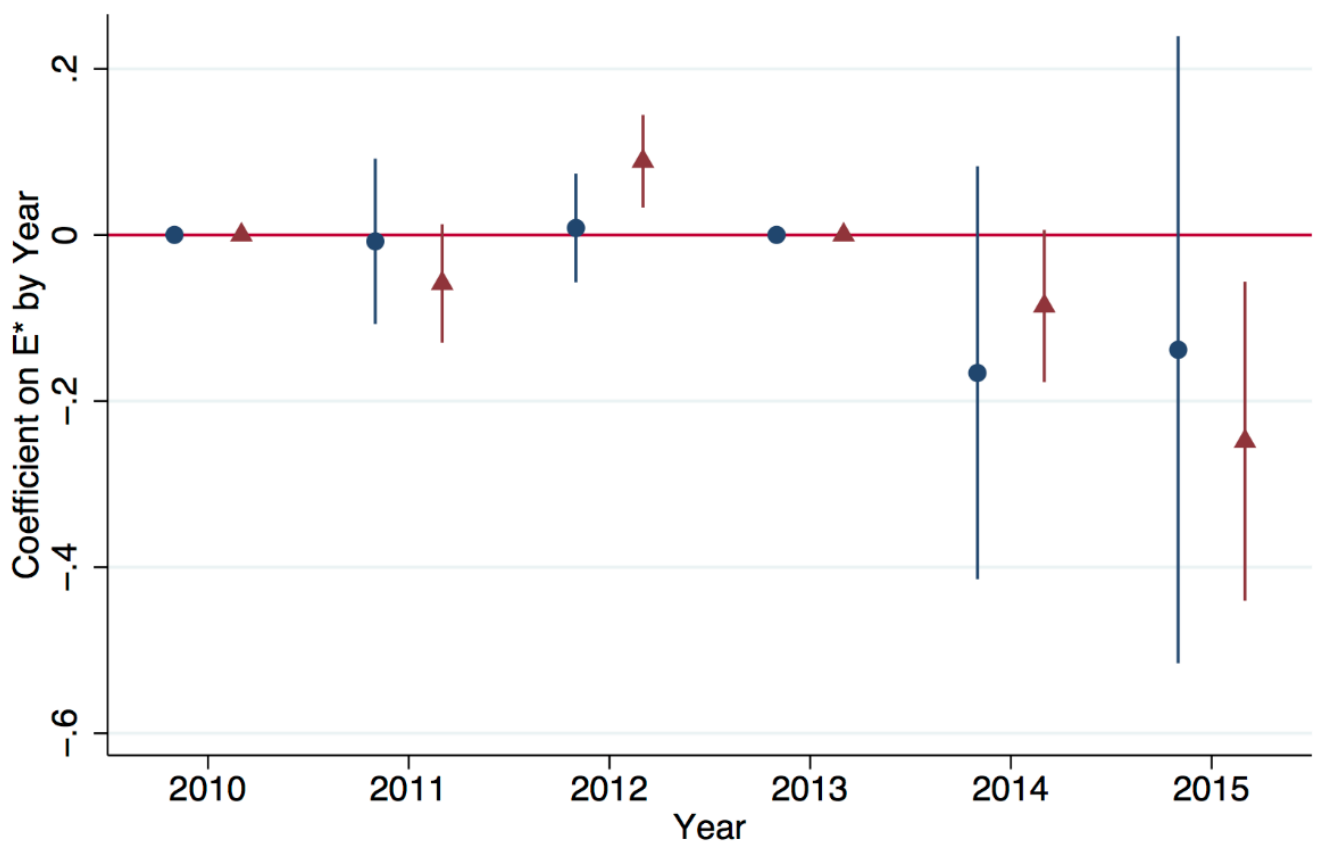

- Expansion States $\Delta$ Non-Expansion States 


\section{Figure A.7}

Relationship between $M^{*}, E^{*}$ and Privately-Purchased Coverage by Year and Medicaid Expansion Status

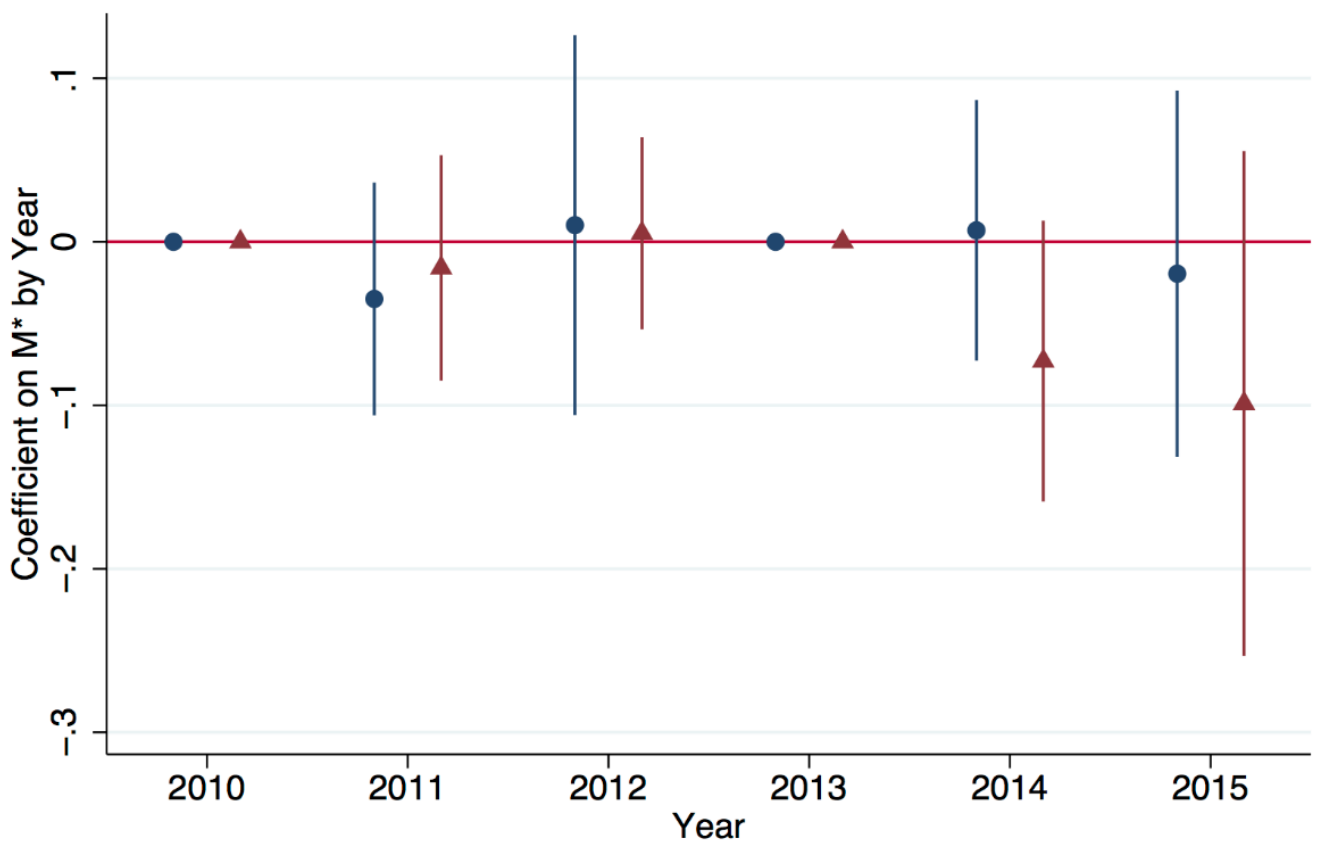

- Expansion States $\Delta$ Non-Expansion States

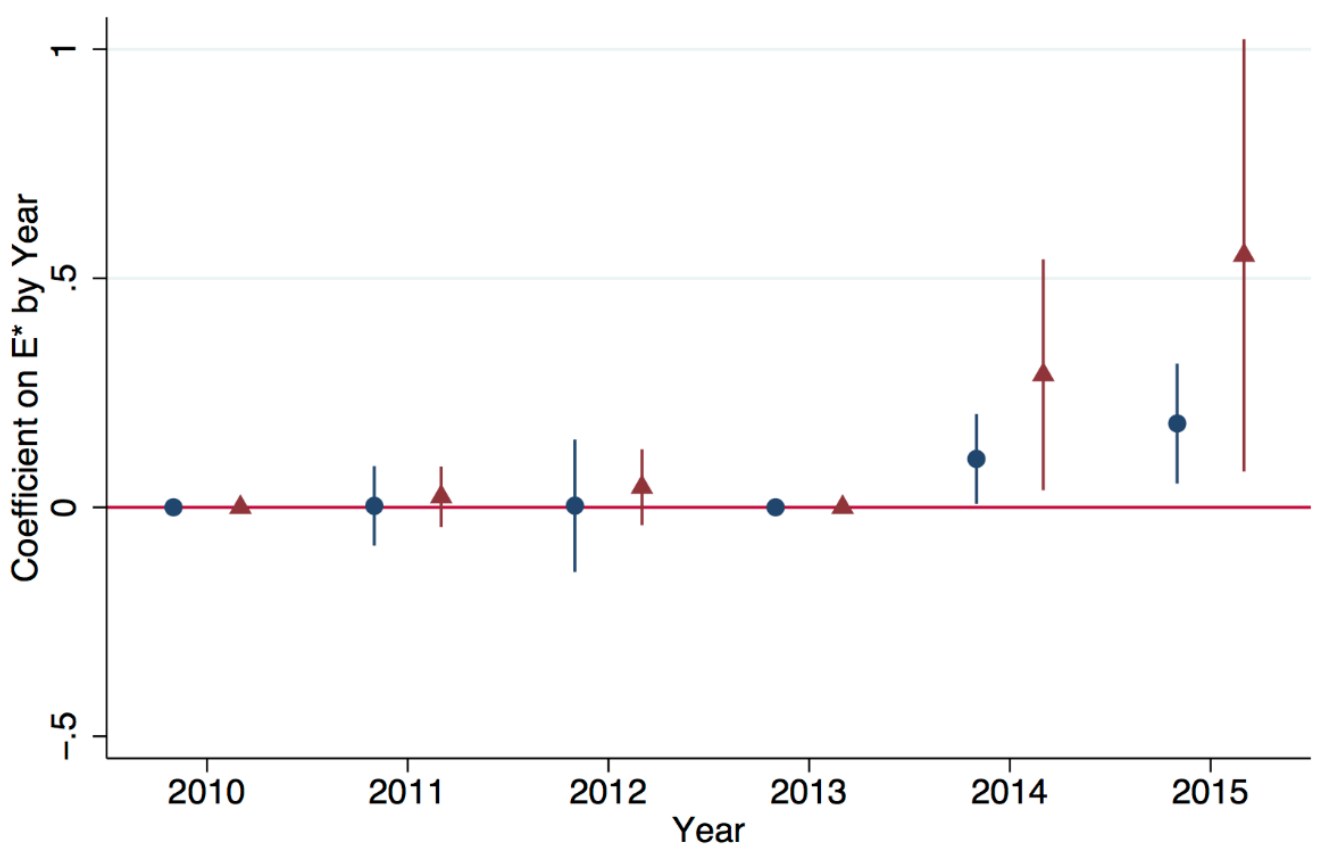

- Expansion States $\Delta$ Non-Expansion States 


\section{Figure A.8}

Relationship between $M^{*}, E^{*}$ and Private Employer Coverage by Year and Medicaid Expansion Status
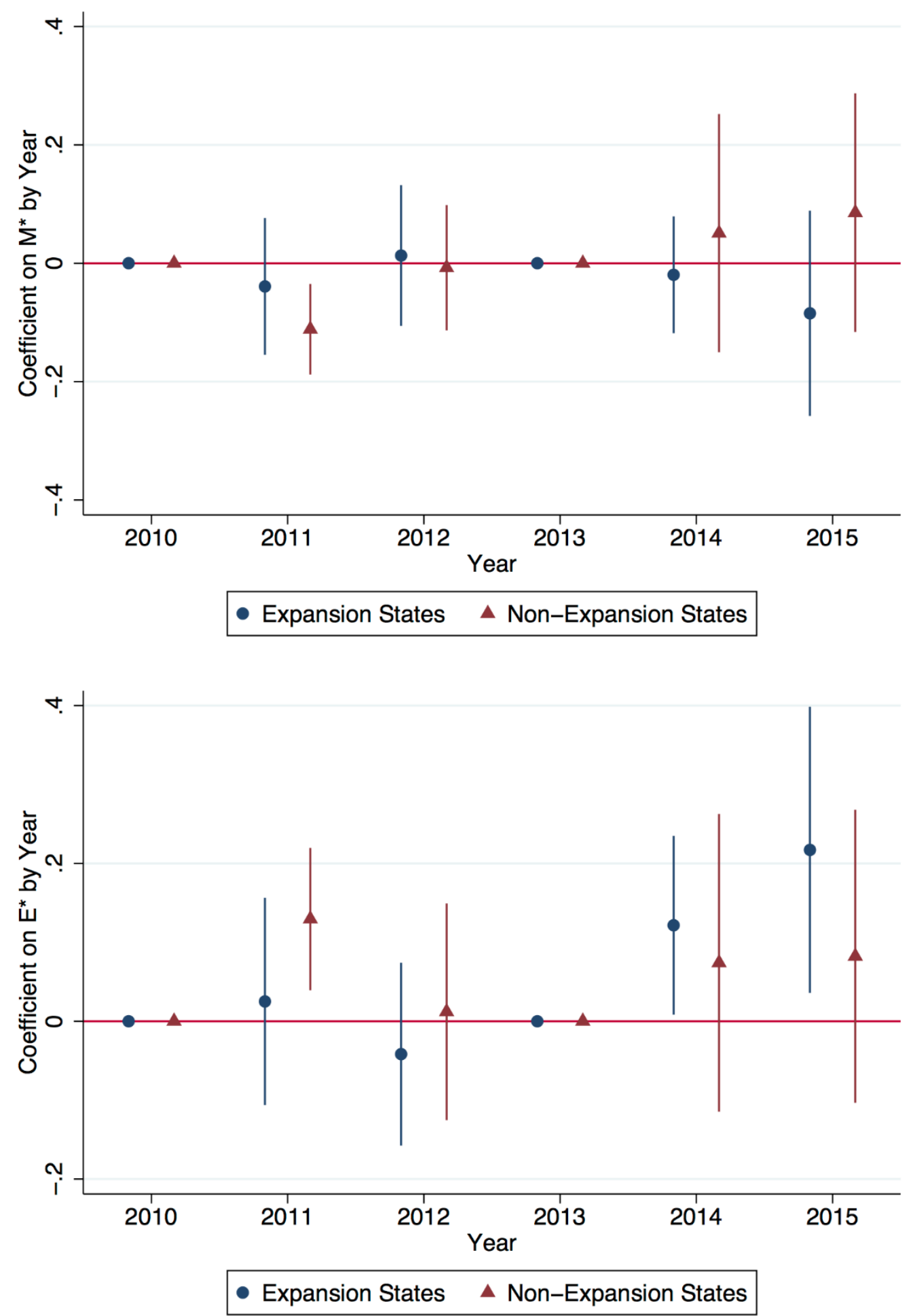
Table A.1

Uninsured Rates for 2013 and 2015, by State

\begin{tabular}{|c|c|c|c|c|c|}
\hline State & $\begin{array}{c}2015 \\
\text { sample } \\
\text { sizes }\end{array}$ & $\begin{array}{c}\% \text { of } \\
\text { residents } \\
\text { without } \\
\text { health } \\
\text { insurance, } \\
2013\end{array}$ & $\begin{array}{c}\% \text { of } \\
\text { residents } \\
\text { without } \\
\text { health } \\
\text { insurance, } \\
2015\end{array}$ & $\begin{array}{c}\text { Percentage- } \\
\text { point change } \\
\text { in uninsured, } \\
2013 \text { to } 2015\end{array}$ & $\begin{array}{c}\text { Medicaid } \\
\text { expansion } \\
\text { and/or state/ } \\
\text { partnership } \\
\text { exchange by } \\
\text { Sep 1, 2015? }\end{array}$ \\
\hline Alabama & 3,063 & 17.7 & 13.0 & -4.7 & Neither \\
\hline Alaska & 520 & 18.9 & 10.3 & -8.6 & One \\
\hline Arizona & 4,324 & 20.4 & 13.7 & -6.7 & One \\
\hline Arkansas & 2,034 & 22.5 & 9.6 & -12.9 & Both \\
\hline California & 17,203 & 21.6 & 11.8 & -9.8 & Both \\
\hline Colorado & 3.456 & 17.0 & 10.3 & -6.7 & Both \\
\hline Connecticut & 1,971 & 12.3 & 6.4 & -5.9 & Both \\
\hline Delaware & 502 & 10.5 & 7.4 & -3.1 & Both \\
\hline Florida & 10,362 & 22.1 & 15.7 & -6.4 & Neither \\
\hline Georgia & 5,210 & 21.4 & 15.9 & $-5 \cdot 5$ & Neither \\
\hline Hawaii & 494 & 7.1 & 4.2 & -2.9 & Both \\
\hline Idaho & 1,248 & 19.9 & 15.2 & -4.7 & One \\
\hline Illinois & 5.557 & 15.5 & 8.7 & -6.8 & Both \\
\hline Indiana & 3,967 & $15 \cdot 3$ & 10.8 & -4.5 & One \\
\hline Iowa & 1,988 & 9.7 & 6.3 & -3.4 & Both \\
\hline Kansas & 1,813 & 12.5 & 11.0 & -1.5 & Neither \\
\hline Kentucky & 2,743 & 20.4 & 7.5 & -12.9 & Both \\
\hline Louisiana & 2,589 & 21.7 & 15.7 & -6.0 & Neither \\
\hline Maine & 1,097 & 16.1 & 8.8 & -7.3 & Neither \\
\hline Maryland & 3,088 & 12.9 & 7.5 & $-5 \cdot 4$ & Both \\
\hline Massachusetts & 3,687 & 4.9 & 3.5 & -1.4 & Both \\
\hline Michigan & 4,978 & 12.5 & 7.6 & -4.9 & Both \\
\hline Minnesota & 3,241 & 9.5 & 5.8 & -3.7 & Both \\
\hline Mississippi & 1,667 & 22.4 & 14.7 & -7.7 & One \\
\hline Missouri & 3.423 & 15.2 & 11.6 & -3.6 & Neither \\
\hline Montana & 1,031 & 20.7 & 13.3 & -7.4 & Neither \\
\hline Nebraska & 1,383 & 14.5 & 10.6 & -3.9 & Neither \\
\hline Nevada & 1,489 & 20.0 & 14.5 & -5.5 & Both \\
\hline $\begin{array}{l}\text { New } \\
\text { Hampshire }\end{array}$ & 849 & 13.8 & 8.8 & -5.0 & Both \\
\hline New Jersey & 4,638 & 14.9 & 9.7 & -5.2 & One \\
\hline New Mexico & 1,423 & 20.2 & 12.8 & -7.4 & Both \\
\hline New York & 10,258 & 12.6 & 8.6 & -4.0 & Both \\
\hline North Carolina & 5.880 & 20.4 & 14.4 & -6.0 & Neither \\
\hline North Dakota & 510 & 15.0 & 6.9 & -8.1 & One \\
\hline Ohio & 6,331 & 13.9 & 7.6 & -6.3 & One \\
\hline Oldahoma & 2,679 & 21.4 & 16.5 & -4.9 & Neither \\
\hline Oregon & 2,984 & 19.4 & 7.3 & -12.1 & Both \\
\hline Pennsylvania & 8,178 & 11.0 & 7.4 & -3.6 & Both \\
\hline Rhode Island & 560 & 13.3 & 5.6 & -7.7 & Both \\
\hline South Carolina & 2,840 & 18.7 & 12.3 & -6.4 & Neither \\
\hline South Dakota & 533 & 14.0 & 10.6 & -3.4 & Neither \\
\hline Tennessee & 4,250 & 16.8 & 13.0 & -3.8 & Neither \\
\hline Texas & 13,190 & 27.0 & 22.3 & -4.7 & Neither \\
\hline Utah & 2,067 & 15.6 & 12.4 & -3.2 & One \\
\hline Vermont & 601 & 8.9 & 4.7 & -4.2 & Both \\
\hline Virginia & 5,039 & 13.3 & 12.6 & -0.7 & Neither \\
\hline Washington & 4.504 & 16.8 & 7.4 & -9.4 & Both \\
\hline West Virginia & 1,224 & 17.6 & 7.7 & -9.9 & Both \\
\hline Wisconsin & 3,628 & 11.7 & 5.9 & -5.8 & Neither \\
\hline Wyoming & 591 & 16.6 & 14.0 & -2.6 & Neither \\
\hline
\end{tabular}

Gallup-Healthways Well-Being Index

GALLUP

Source: Kafka (2015) 


\section{Table A.2}

\section{PUMAs with Lowest and Highest Values of $M^{*}$ and $E^{*}$}

Lowest Values of $M^{*}$

Middlesex (Southeast) \& Norfolk (Northeast) Counties--Newton City \& Brookline Town

Norfolk County (Northeast)--Quincy City \& Milton Town

Northwest Vermont--Chittenden, Franklin \& Grand Isle Counties--Burlington City

Honolulu County--Moanalua to Pearl City

Waukesha County (West)

\section{Lowest Values of $E^{*}$}

Middlesex (Southeast) \& Norfolk (Northeast) Counties--Newton City \& Brookline Town District of Columbia (West)

Honolulu County--Moanalua to Pearl City

Montgomery County (South)--Bethesda, Potomac \& North Bethesda

Howard County (West)--Columbia (West) \& Ellicott City (Northwest)

\section{Highest Values of $M^{*}$}

Hidalgo County--Alamo, Donna, McAllen, Mission, Pharr, San Juan, Hidalgo, Weslaco, Mercedes, Edinburg City

Los Angeles County (Central and South Central)--LA City (Southeast/East Vernon, South

Central/Westmont, South Central/Watts)

Cameron County--Brownsville, Harlingen, San Benito Cities

Los Angeles County (Central)--LA City (Central/Koreatown)

South Texas Development Council--Webb County (North \& East)--Laredo City

\section{Highest Values of $E^{*}$}

Los Angeles County (Central)--LA City (Central/Koreatown)

Los Angeles County (Central)--East Los Angeles

Los Angeles County--LA City (Central/Univ. of Southern California \& Exposition Park)

Prince George's County (Northwest)--College Park City \& Langley Park

Los Angeles County (South and Central)--Bell Gardens, Bell, Maywood, Cudahy, Commerce, Huntington Park, Florence-Graham, Walnut Park, South Gate, Lynwood City 
Table A.3: Heterogeneity in Effect of Potential Medicaid/Exchange Enrollment and Medicaid Expansion on Health Insurance Coverage by Observable Characteristics: Pooled Income Groups

\begin{tabular}{|c|c|c|c|c|c|c|c|c|}
\hline VARIABLES & $\begin{array}{c}(1) \\
\text { Health } \\
\text { Insurance } \\
\text { Coverage }\end{array}$ & $\begin{array}{c}(2) \\
\text { Health } \\
\text { Insurance } \\
\text { Coverage }\end{array}$ & $\begin{array}{c}(3) \\
\text { Medicaid } \\
\text { Coverage }\end{array}$ & $\begin{array}{c}(4) \\
\text { Medicaid } \\
\text { Coverage }\end{array}$ & $\begin{array}{c}\text { (5) } \\
\text { Private } \\
\text { Purchase } \\
\end{array}$ & $\begin{array}{c}\text { (6) } \\
\text { Private } \\
\text { Purchase } \\
\end{array}$ & $\begin{array}{c}\text { (7) } \\
\text { Private } \\
\text { Employer }\end{array}$ & $\begin{array}{c}\text { (8) } \\
\text { Private } \\
\text { Employer }\end{array}$ \\
\hline Post $x\left(E^{*}+M^{*}\right)$ & $\begin{array}{c}0.1781 * * * \\
(0.0433)\end{array}$ & $\begin{array}{c}0.1261 * * * \\
(0.0407)\end{array}$ & $\begin{array}{c}0.0314 \\
(0.0492)\end{array}$ & $\begin{array}{c}-0.0305 * * \\
(0.0121)\end{array}$ & $\begin{array}{c}0.0857 * * * \\
(0.0276)\end{array}$ & $\begin{array}{c}0.1047 * * \\
(0.0515)\end{array}$ & $\begin{array}{c}0.0650 * * * \\
(0.0109)\end{array}$ & $\begin{array}{c}0.0655 * * * \\
(0.0190)\end{array}$ \\
\hline Expansion $\mathrm{x}$ Post & & $\begin{array}{c}2.2570 * * * \\
(0.2967)\end{array}$ & & $\begin{array}{c}3.1557 * * * \\
(0.3167)\end{array}$ & & $\begin{array}{l}-0.3992 * \\
(0.2120)\end{array}$ & & $\begin{array}{l}-0.1702 \\
(0.1761)\end{array}$ \\
\hline Expansion $x$ Post $x\left(E^{*}+M^{*}\right)$ & & $\begin{array}{c}0.1673 * * * \\
(0.0466)\end{array}$ & & $\begin{array}{c}0.2140 * * * \\
(0.0244)\end{array}$ & & $\begin{array}{l}-0.0478 \\
(0.0527)\end{array}$ & & $\begin{array}{l}-0.0062 \\
(0.0244)\end{array}$ \\
\hline Observations & $9,493,231$ & $9,493,231$ & $9,493,231$ & $9,493,231$ & $9,493,231$ & $9,493,231$ & $9,493,231$ & $9,493,231$ \\
\hline R-squared & 1.0000 & 1.0000 & 0.9993 & 0.9993 & 0.9991 & 0.9991 & 0.9999 & 0.9999 \\
\hline Pre-ACA Dependent Var Mean & 79.88 & 79.88 & 10.53 & 10.53 & 9.31 & 9.31 & 60.75 & 60.75 \\
\hline Non-Expansion States & 77.98 & 77.98 & 9.20 & 9.20 & 9.32 & 9.32 & 59.54 & 59.54 \\
\hline Expansion States & 81.74 & 81.74 & 11.83 & 11.83 & 9.31 & 9.31 & 61.94 & 61.94 \\
\hline
\end{tabular}

Notes: $\left(\mathrm{E}^{*}+\mathrm{M}^{*}\right)$ refers to the share of individuals in a PUMA that are uninsured and within 0-399\% FPL in 2010-13. All shares are standardized to have a mean of 0 . Sample includes civilians ages $26-64$ in the years $2010-2015$. Robust standard errors are in parentheses and are clustered by state $(* * * \mathrm{p}<0.01, * * \mathrm{p}<0.05, *$ p<0.1). Controls include demographic controls (female, black, white, asian, other, hispanic), year FEs, age FEs, PUMA FEs, and PUMA-specific time trends. 


\section{Table A.4: Heterogeneity in Effect of Potential Medicaid/Exchange Enrollment and Medicaid Expansion on Health Insurance Coverage by Observable Characteristics: Pooled Income Groups}

\begin{tabular}{|c|c|c|c|c|c|c|}
\hline VARIABLES & Non-minority & $\begin{array}{c}\text { (2) } \\
\text { Minority }\end{array}$ & $\begin{array}{c}\text { (3) } \\
\text { Childless } \\
\text { Adult } \\
\end{array}$ & $\begin{array}{c}(4) \\
\text { Has Child } \\
\text { Under } 18 \\
\end{array}$ & $\begin{array}{c}(5) \\
\text { HSG or less }\end{array}$ & $\begin{array}{c}\text { (6) } \\
\text { Some College } \\
\text { or More }\end{array}$ \\
\hline Post $x\left(E^{*}+M^{*}\right)$ & $\begin{array}{c}0.0816^{* * * *} \\
(0.0272)\end{array}$ & $\begin{array}{c}0.0956 \\
(0.0615)\end{array}$ & $\begin{array}{c}0.1113 * * \\
(0.0467)\end{array}$ & $\begin{array}{c}0.1561 * * * \\
(0.0391)\end{array}$ & $\begin{array}{c}0.1068 * * * \\
(0.0383)\end{array}$ & $\begin{array}{c}0.1259 * * * \\
(0.0443)\end{array}$ \\
\hline Expansion x Post & $\begin{array}{c}2.0825 * * * \\
(0.3129)\end{array}$ & $\begin{array}{c}2.1197 * * * \\
(0.6153)\end{array}$ & $\begin{array}{c}2.5898 * * * \\
(0.3279)\end{array}$ & $\begin{array}{c}1.5787 * * * \\
(0.4129)\end{array}$ & $\begin{array}{c}3.3311 * * * \\
(0.6044)\end{array}$ & $\begin{array}{c}1.4175^{* * *} \\
(0.2235)\end{array}$ \\
\hline Exp x Post $x\left(E^{*}+M^{*}\right)$ & $\begin{array}{c}0.1997 * * * \\
(0.0429)\end{array}$ & $\begin{array}{l}0.1482 * \\
(0.0744)\end{array}$ & $\begin{array}{c}0.2008 * * * \\
(0.0538)\end{array}$ & $\begin{array}{c}0.0937 * * \\
(0.0453)\end{array}$ & $\begin{array}{c}0.1603 * * * \\
(0.0555)\end{array}$ & $\begin{array}{c}0.1370 * * * \\
(0.0483)\end{array}$ \\
\hline Observations & $6,537,661$ & $2,955,570$ & $6,266,853$ & $3,226,378$ & $3,602,122$ & $5,891,109$ \\
\hline R-squared & 1.0000 & 1.0000 & 1.0000 & 1.0000 & 1.0000 & 1.0000 \\
\hline Pre-ACA DV Mean & 85.56 & 69.39 & 78.07 & 83.19 & 68.73 & 87.03 \\
\hline Non-Exp States & 83.85 & 65.85 & 76.43 & 80.82 & 66.79 & 85.69 \\
\hline Expansion States & 87.35 & 72.39 & 79.68 & 85.50 & 70.80 & 88.26 \\
\hline VARIABLES & $\begin{array}{c}(7) \\
\text { Male } \\
\end{array}$ & $\begin{array}{c}(8) \\
\text { Female } \\
\end{array}$ & $\begin{array}{l}(9) \\
\text { Young } \\
(26-44)\end{array}$ & $\begin{array}{c}(10) \\
\text { Near Elderly } \\
(45-64)\end{array}$ & $\begin{array}{c}(11) \\
\text { Married }\end{array}$ & $\begin{array}{c}\text { (12) } \\
\text { Not Married }\end{array}$ \\
\hline Post $\mathrm{x}\left(\mathrm{E}^{*}+\mathrm{M}^{*}\right)$ & $\begin{array}{c}0.1322 * * * \\
(0.0346)\end{array}$ & $\begin{array}{c}0.1198 * * \\
(0.0489)\end{array}$ & $\begin{array}{c}0.1036 * * * \\
(0.0374)\end{array}$ & $\begin{array}{c}0.1463 * * * \\
(0.0456)\end{array}$ & $\begin{array}{c}0.1648 * * * \\
(0.0356)\end{array}$ & $\begin{array}{c}0.0525 \\
(0.0509)\end{array}$ \\
\hline Expansion x Post & $\begin{array}{c}2.5490 * * * \\
(0.3216)\end{array}$ & $\begin{array}{c}1.9753 * * * \\
(0.3480)\end{array}$ & $\begin{array}{c}2.4257 * * * \\
(0.3848)\end{array}$ & $\begin{array}{c}2.0985 * * * \\
(0.2729)\end{array}$ & $\begin{array}{c}1.6938 * * * \\
(0.2810)\end{array}$ & $\begin{array}{c}2.7965 * * * \\
(0.5360)\end{array}$ \\
\hline Exp x Post $x\left(E^{*}+M^{*}\right)$ & $\begin{array}{c}0.1662 * * * \\
(0.0383)\end{array}$ & $\begin{array}{c}0.1687 * * * \\
(0.0584)\end{array}$ & $\begin{array}{c}0.1608 * * * \\
(0.0484)\end{array}$ & $\begin{array}{c}0.1721 * * * \\
(0.0508)\end{array}$ & $\begin{array}{c}0.1224 * * * \\
(0.0388)\end{array}$ & $\begin{array}{c}0.2113 * * * \\
(0.0661)\end{array}$ \\
\hline Observations & $4,629,672$ & $4,863,559$ & $4,167,626$ & $5,325,605$ & $5,875,157$ & $3,618,074$ \\
\hline R-squared & 1.0000 & 1.0000 & 1.0000 & 1.0000 & 1.0000 & 1.0000 \\
\hline Pre-ACA DV Mean & 77.53 & 82.16 & 75.25 & 84.26 & 86.02 & 71.17 \\
\hline Non-Exp States & 75.75 & 80.13 & 72.79 & 82.82 & 84.75 & 68.16 \\
\hline Expansion States & 79.25 & 84.16 & 77.61 & 85.68 & 87.29 & 74.02 \\
\hline
\end{tabular}

Notes: Dependent variable is health insurance coverage and each column corresponds to a separate subsample. "Nonminority" indicates white non-Hispanic. "Has Child Under 18" refers to individuals with at least one child living in the same household who is under 18. "HSG or less" indicates that a high-school degree (including GED) or less is the highest educational attainment. "Male" refers to gender. "Young" are ages 26-44. "Married" refers to marital status. $\left(\mathrm{E}^{*}+\mathrm{M}^{*}\right)$ refers to the share of individuals in a PUMA that are uninsured and 0-399\% FPL in 2010-13. All shares are standardized to have a mean of 0 . Robust standard errors are in parentheses and are clustered by state $(* * * \mathrm{p}<0.01$, ** $\mathrm{p}<0.05, * \mathrm{p}<0.1$ ). Controls include demographic controls (female, black, white, asian, other, hispanic), year FEs, age FEs, PUMA FEs, and PUMA-specific time trends. 


\section{Table A.5: Effect of Potential Medicaid/Exchange Enrollment and Medicaid Expansion on Not in the Labor Force by Observable Characteristics: Pooled Income Groups}

\begin{tabular}{|c|c|c|c|c|c|c|}
\hline VARIABLES & $\begin{array}{c}(1) \\
\text { Non-minority }\end{array}$ & $\begin{array}{c}\text { (2) } \\
\text { Minority }\end{array}$ & $\begin{array}{c}\text { (3) } \\
\text { Childless } \\
\text { Adult } \\
\end{array}$ & $\begin{array}{c}(4) \\
\text { Has Child } \\
\text { Under } 18 \\
\end{array}$ & $\begin{array}{c}(5) \\
\text { HSG or less }\end{array}$ & $\begin{array}{c}\text { (6) } \\
\text { Some College } \\
\text { or More }\end{array}$ \\
\hline Post $x\left(E^{*}+M^{*}\right)$ & $\begin{array}{l}-0.0013 \\
(0.0133)\end{array}$ & $\begin{array}{c}0.0169 \\
(0.0130)\end{array}$ & $\begin{array}{l}-0.0080 \\
(0.0169)\end{array}$ & $\begin{array}{c}0.0253 * * \\
(0.0125)\end{array}$ & $\begin{array}{c}0.0176 \\
(0.0228)\end{array}$ & $\begin{array}{l}-0.0015 \\
(0.0115)\end{array}$ \\
\hline Expansion x Post & $\begin{array}{c}0.0939 \\
(0.2005)\end{array}$ & $\begin{array}{c}0.1900 \\
(0.2314)\end{array}$ & $\begin{array}{c}0.2357 \\
(0.1788)\end{array}$ & $\begin{array}{l}-0.0853 \\
(0.1743)\end{array}$ & $\begin{array}{c}0.2742 \\
(0.2456)\end{array}$ & $\begin{array}{c}0.0791 \\
(0.1607)\end{array}$ \\
\hline Exp x Post $x\left(E^{*}+M^{*}\right)$ & $\begin{array}{l}-0.0047 \\
(0.0242)\end{array}$ & $\begin{array}{l}-0.0105 \\
(0.0215)\end{array}$ & $\begin{array}{c}-0.0000 \\
(0.0205)\end{array}$ & $\begin{array}{c}-0.0093 \\
(0.0189)\end{array}$ & $\begin{array}{c}-0.0044 \\
(0.0278)\end{array}$ & $\begin{array}{l}-0.0179 \\
(0.0152)\end{array}$ \\
\hline Observations & $6,537,661$ & $2,955,570$ & $6,266,853$ & $3,226,378$ & $3,602,122$ & $5,891,109$ \\
\hline R-squared & 0.9996 & 0.9998 & 0.9997 & 0.9996 & 0.9998 & 0.9996 \\
\hline Pre-ACA DV Mean & 21.58 & 24.38 & 25.39 & 17.38 & 30.60 & 17.41 \\
\hline Non-Exp States & 22.34 & 25.39 & 26.61 & 17.32 & 31.34 & 17.82 \\
\hline Expansion States & 20.78 & 23.52 & 24.21 & 17.43 & 29.82 & 17.03 \\
\hline VARIABLES & $\begin{array}{l}\text { (7) } \\
\text { Male }\end{array}$ & $\begin{array}{c}(8) \\
\text { Female }\end{array}$ & $\begin{array}{l}(9) \\
\text { Young } \\
(26-44)\end{array}$ & $\begin{array}{c}(10) \\
\text { Near Elderly } \\
(45-64)\end{array}$ & $\begin{array}{c}(11) \\
\text { Married }\end{array}$ & $\begin{array}{c}\text { (12) } \\
\text { Not Married }\end{array}$ \\
\hline Post $x\left(E^{*}+M^{*}\right)$ & $\begin{array}{c}0.0103 \\
(0.0150)\end{array}$ & $\begin{array}{l}-0.0012 \\
(0.0149)\end{array}$ & $\begin{array}{c}0.0116 \\
(0.0143)\end{array}$ & $\begin{array}{l}-0.0002 \\
(0.0145)\end{array}$ & $\begin{array}{c}0.0131 \\
(0.0120)\end{array}$ & $\begin{array}{l}-0.0040 \\
(0.0230)\end{array}$ \\
\hline Expansion x Post & $\begin{array}{l}-0.0472 \\
(0.2038)\end{array}$ & $\begin{array}{l}0.3126^{*} \\
(0.1818)\end{array}$ & $\begin{array}{c}0.0724 \\
(0.1784)\end{array}$ & $\begin{array}{c}0.1766 \\
(0.1768)\end{array}$ & $\begin{array}{c}0.0667 \\
(0.1502)\end{array}$ & $\begin{array}{c}0.1943 \\
(0.2152)\end{array}$ \\
\hline Exp x Post $x\left(E^{*}+M^{*}\right)$ & $\begin{array}{l}-0.0168 \\
(0.0177)\end{array}$ & $\begin{array}{c}0.0067 \\
(0.0210)\end{array}$ & $\begin{array}{l}-0.0118 \\
(0.0198)\end{array}$ & $\begin{array}{c}0.0021 \\
(0.0199)\end{array}$ & $\begin{array}{l}-0.0173 \\
(0.0171)\end{array}$ & $\begin{array}{c}0.0109 \\
(0.0292)\end{array}$ \\
\hline Observations & $4,629,672$ & $4,863,559$ & $4,167,626$ & $5,325,605$ & $5,875,157$ & $3,618,074$ \\
\hline R-squared & 0.9996 & 0.9998 & 0.9997 & 0.9997 & 0.9996 & 0.9998 \\
\hline Pre-ACA DV Mean & 17.14 & 27.82 & 17.74 & 27.11 & 21.23 & 24.45 \\
\hline Non-Exp States & 17.94 & 28.53 & 18.12 & 28.19 & 21.77 & 25.60 \\
\hline Expansion States & 16.35 & 27.12 & 17.37 & 26.05 & 20.70 & 23.35 \\
\hline
\end{tabular}

Notes: Dependent variable is not in the labor force and each column corresponds to a separate subsample. "Nonminority" indicates white non-Hispanic. "Has Child Under 18" refers to individuals with at least one child living in the same household who is under 18. "HSG or less" indicates that a high-school degree (including GED) or less is the highest educational attainment. "Male" refers to gender. "Young" are ages 26-44. "Married" refers to marital status. $\left(\mathrm{E}^{*}+\mathrm{M}^{*}\right)$ refers to the share of individuals in a PUMA that are uninsured and 0-399\% FPL in 2010-13. All shares are standardized to have a mean of 0 . Robust standard errors are in parentheses and are clustered by state $(* * * \mathrm{p}<0.01$, ** $\mathrm{p}<0.05, * \mathrm{p}<0.1$ ). Controls include demographic controls (female, black, white, asian, other, hispanic), year FEs, age FEs, PUMA FEs, and PUMA-specific time trends. 